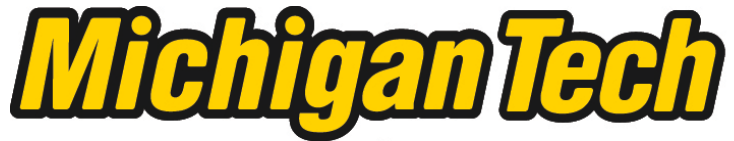 \\ Michigan Technological University Create the Future Digital Commons @ Michigan Tech
}

2013

\section{BIOCHEMICAL AND CELLULAR MECHANISMS OF RETINA AND RETINAL PIGMENT EPITHELIUM APOPTOSIS}

Srinivasa Rao Sripathi

Michigan Technological University

Follow this and additional works at: https://digitalcommons.mtu.edu/etds

Part of the Biochemistry Commons

Copyright 2013 Srinivasa Rao Sripathi

\section{Recommended Citation}

Sripathi, Srinivasa Rao, "BIOCHEMICAL AND CELLULAR MECHANISMS OF RETINA AND RETINAL PIGMENT EPITHELIUM APOPTOSIS", Dissertation, Michigan Technological University, 2013.

https://doi.org/10.37099/mtu.dc.etds/581

Follow this and additional works at: https://digitalcommons.mtu.edu/etds

Part of the Biochemistry Commons 


\title{
BIOCHEMICAL AND CELLULAR MECHANISMS OF RETINA AND RETINAL PIGMENT EPITHELIUM APOPTOSIS
}

\author{
By \\ Srinivasa R. Sripathi \\ A DISSERTATION \\ Submitted in partial fulfillment of the requirements for the degree of \\ DOCTOR OF PHILOSOPHY \\ In Biological Sciences
}

MICHIGAN TECHNOLOGICAL UNIVERSITY

2013

Copyright (C) Srinivasa R. Sripathi 2013 
This dissertation has been approved in partial fulfillment of the requirements for the Degree of DOCTOR OF PHILOSOPHY in Biological Sciences.

Department of Biological Sciences

Dissertation Co-Advisor: Ramakrishna Wusirika

Dissertation Co-Advisor: Wan Jin Jahng

Committee Member: $\quad$ Rupali Datta

Committee Member: Jeremy Goldman

Department Chair: Chandrashekhar P. Joshi 


\section{Table of Contents}

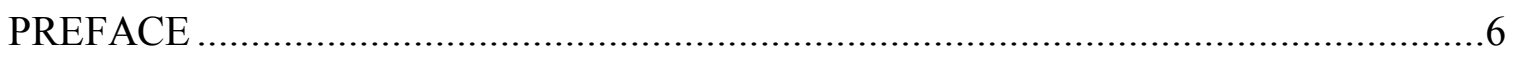

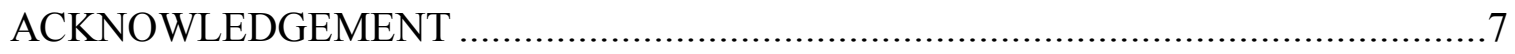

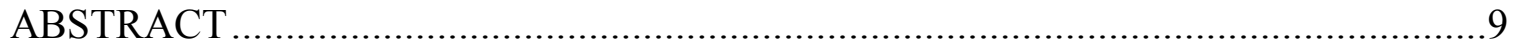

CHAPTER 1: INTRODUCTION AND BACKGROUND .........................................10

1.1. Role of oxidative stress in the retina and RPE during the progression of retinal degenerative diseases .............................................................................. 10

1.2 Multifunctional role of prohibitin (PHB) in the retina and retinal pigment epithelium (RPE) under oxidative stress .................................................. 11

1.3 Nitric oxide (NO) regulated cytoskeleton reorganization and apoptosis in the RPE

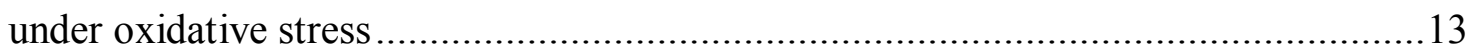

CHAPTER 2: MITOCHONDRIAL-NUCLEAR COMMUNICATION BY PROHIBITIN SHUTTLING UNDER OXIDATIVE STRESS..................................15

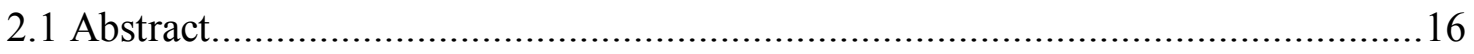

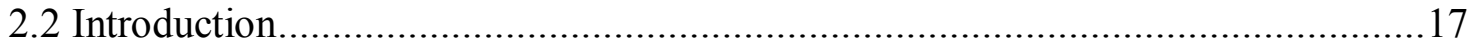

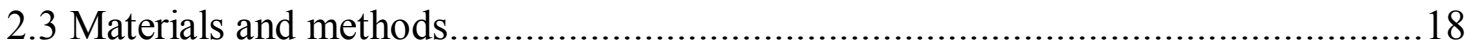

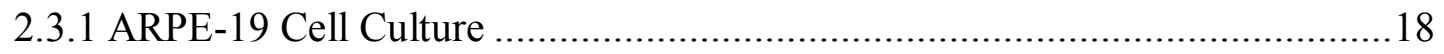

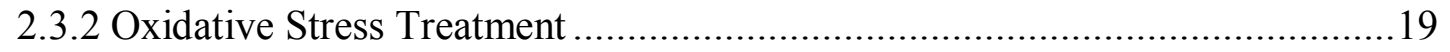

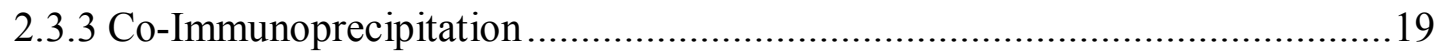

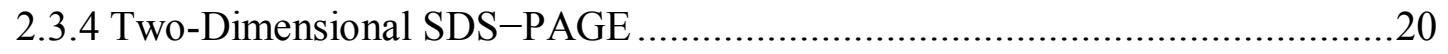

2.3.5 In-Gel Digestion and Mass Spectrometry ............................................21

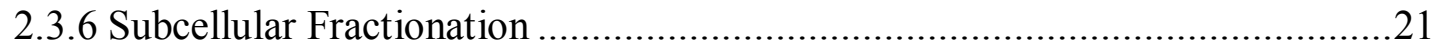

2.3.7 SDS-PAGE and Western Blot Analysis................................................21

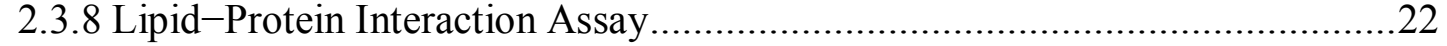

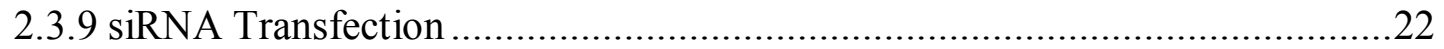

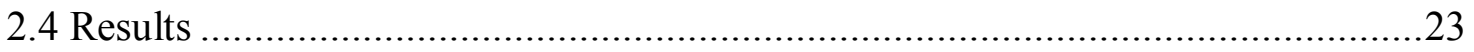

2.4.1 Mitochondrial-Nuclear Trafficking of Prohibitin ....................................23

2.4.2 Subcellular Localization of Prohibitin in the Retina and RPE Cells ...............27

2.4.3 Prohibitin Binds Cardiolipin under Oxidative Stress ...................................32 
2.4.4 Anti-Apoptotic Prohibitin Function in Mitochondria ..................................34

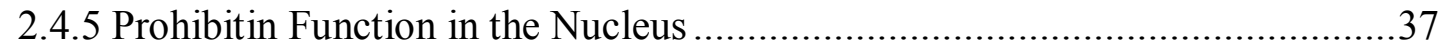

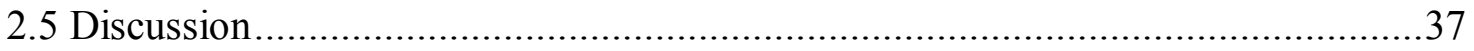

CHAPTER 3: NITRIC OXIDE LEADS TO CYTOSKELETAL REORGANIZATION IN THE RETINAL PIGMENT EPITHELIUM UNDER OXIDATIVE STRESS ..........42

3.1 Abstract................................................................................................ 43

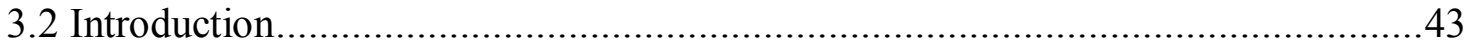

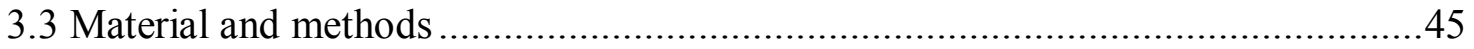

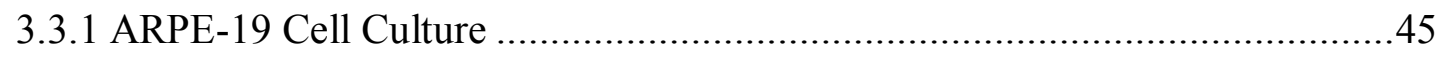

3.3.2 Light, oxidative stress, reoxygenation, and LPS treatment.........................45

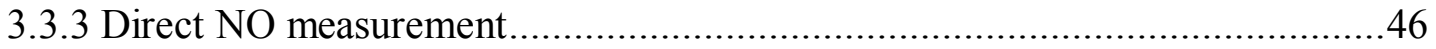

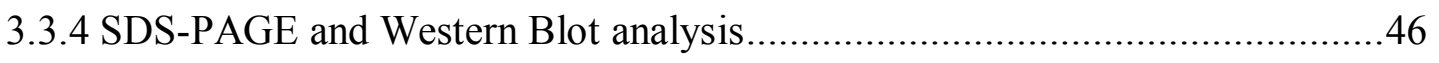

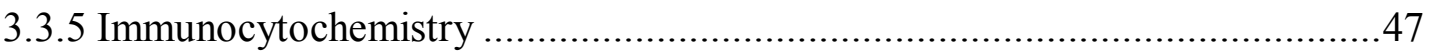

3.3.6 Scanning Electron Microscopy (SEM) ....................................................48

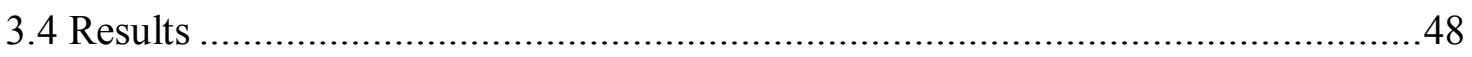

3.4.1 NO Production in the RPE under Oxidative Stress ..................................48

3.4.2 Treatment with LPS, tert-butyl hydroperoxide (t-BuOOH) and light upregulates inducible nitric oxide synthase (iNOS) in the RPE ..........................53

3.4.3 Expression and localization of iNOS under oxidative stress ........................54

3.4.4 Oxidative stress induced protein nitration shown by 3-nitrotyrosine in the RPE

3.4.5 NO Induced Vimentin Dephosphorylation and PP2Ac Phosphorylation in the

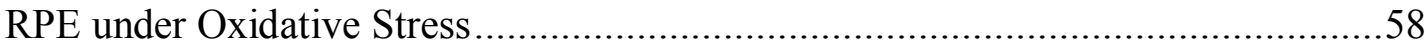

3.4.6 NO Induced anti-Apoptotic Signaling in the RPE under Oxidative Stress.......61

3.4.7 Light induced vimentin filament disorganization in the RPE ......................61

3.4.8 Apoptosis Mediated Morphological Changes of RPE under Oxidative Stress.62

3.5 Discussion.

CHAPTER 4: PROHIBITIN DEPLETION LEADS TO MITOCHONDRIAL DYSFUNCTION IN RETINAL PIGMENT EPITHELIUM OF AGE-RELATED MACULAR DEGENERATION. .68

4.1. Abstract. .69 


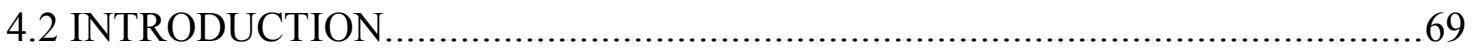

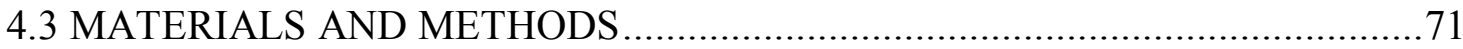

4.3.1 ARPE-19 and HRP Cell Culture ………………..................................

4.3.2 Oxidative Stress Treatment ......................................................................

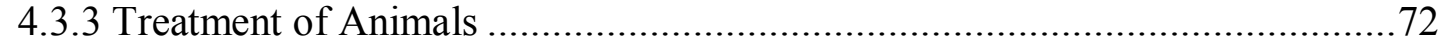

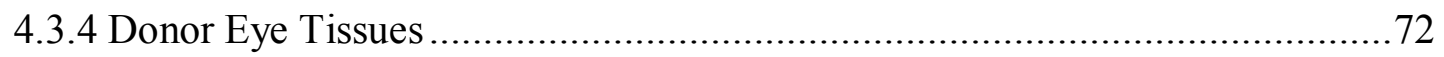

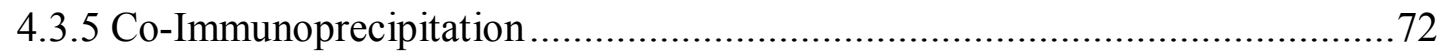

4.3.6 In-Gel Digestion and MALDI TOF Mass Spectrometry .................................73

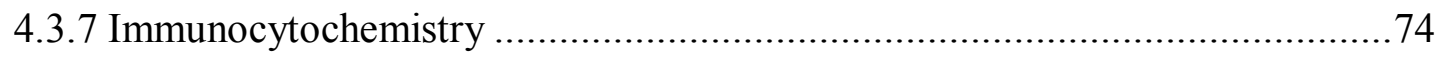

4.3.8 SDS-PAGE and Western Blot Analysis.....................................................75

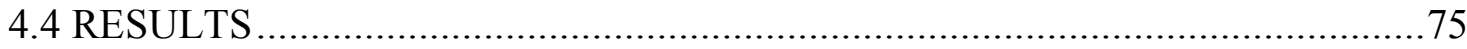

4.4.1 Prohibitin Expression Downregulated in the Retina of the Diabetic Model.....75 4.4.2 Prohibitin Expression Increased in the Retina but Decreased in the RPE of

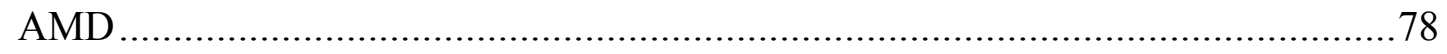

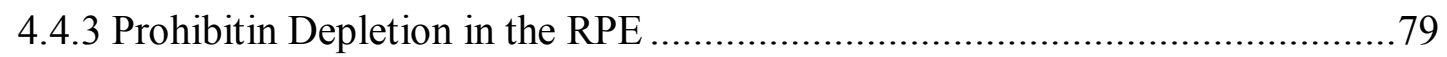

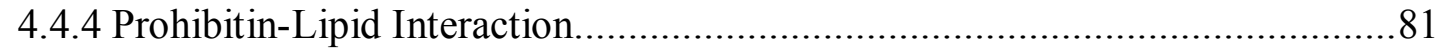

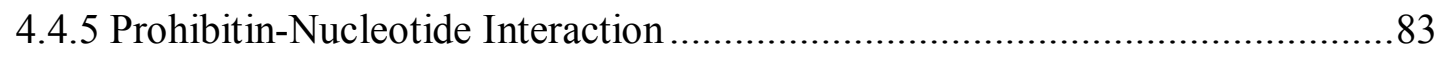

4.4.6 Lipid Binding Pocket in Prohibitin...............................................................91

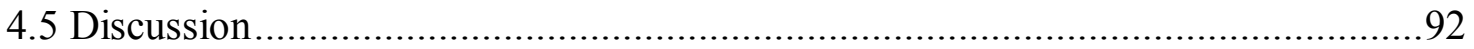

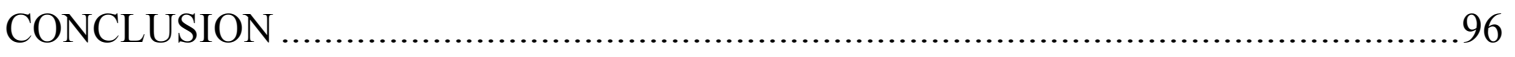

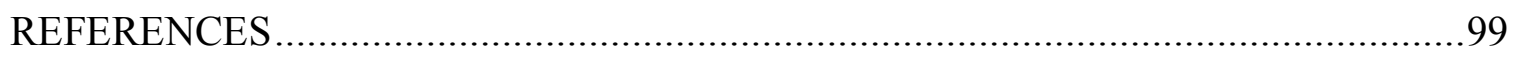

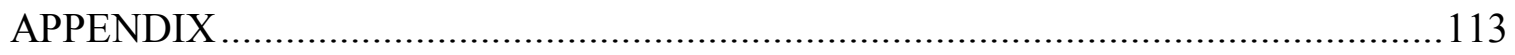




\section{PREFACE}

The material used in chapter 2 of this dissertation was reproduced in its entirety with kind permission from ACS publications. This article was previously published in "Biochemistry 2011, 50 (39), pp 8342-8351." Entire data was produced in Dr. Wan Jin Jahng's laboratory in Department of Biological Sciences, Michigan Technological University. Dr. Jahng was the corresponding author. He conducted data analysis and revised the manuscript.

The material used in chapter 3 of this dissertation was reproduced in its entirety with kind permission from Scientific Research Publishing Inc. "Adavances in Bioscience and Biotechnology 2012, 3(8), pp 1167-1178."Entire data was produced in Dr. Wan Jin Jahng, Dr. Ramakrishna Wusirika and Dr. Megan C. Frost laboratory in Department of Biological Sciences and Department of Biomedical Engineering Michigan Technological University. Dr. Jahng and Dr. Frost were the corresponding authors. Dr. Jahng conducted data analysis and revised the manuscript.

The data for the material used in chapter 4 of this dissertation was produced in Dr. Wan

Jin Jahng and Dr. Ramakrishna Wusirika laboratory in the Department of Biological Sciences, Michigan Technological University. Dr. Jahng is the corresponding author. Dr. Jahng conducted data analysis and revised the manuscript.

\section{Role of other authors}

Figures 2.2 to 2.6 from chapter 2, figures 3.1 and 3.6 from chapter 3 and figures 4.8 , 4.10 and 4.11 are generated by Weilue He from chapter 4 . Table 4.1 from chapter 4 was analyzed and prepared by Ji-Yeon Um. 


\section{ACKNOWLEDGEMENT}

I would like to express my deepest gratitude to Dr. Wan Jin Jahng for accepting me to pursue my research career in his laboratory with his excellent guidance, caring and support towards my doctoral studies. It would not be possible to perform my experiments in the lab and publish the research in scientific journals without his timely advices, contribution and financial support.

I would like to express my utmost gratitude to Dr. Ramakrishna Wusirika for accepting me to work in his laboratory with his excellent guidance, constant encouragement and caring. I am very much grateful for his support and patience which helped me to overcome many crisis situations and finish this dissertation in time.

I am sincerely grateful to my committee members Dr. Rupali Datta and Dr. Jeremy Goldman for their excellent guidance and support to finish my doctoral studies. I really appreciate their valuable time, suggestions and directions on my proposal, projects and dissertation. I am also very much thankful to them for providing instrumentation facility in their laboratories.

I am very much grateful to my research collaborators Dr. Megan C. Frost (Dept. Of Biomedical Engineering, MTU), Dr. Manuela Bartoli (Georgia Health Sciences University), Dr. Paul Bernstein (University Of Utah), Dr. Choong-Min Kang (Wayne State University) and Dr. Erik Lilleskov (Dept. of Forestry and northern research station, MTU) for providing the precious diseased human eye samples for performing my proteomic analysis, sharing equipment and providing financial support to finish my projects.

I would like to thank Dr. Michael Gibson (Ex Chair), Dr. Chandrasekhar Joshi, Dr. Nancy Auer (graduate program director), Dr. Susan Bagley, Dr. Thomas Werner, Dr. Mi Hye Song, Dr. Aparna Deshpande, Dr. Xiaoqing Tang, Dr. Michael Gretz, Dr. Thomas P. Snyder, Dr. Casey Huckins, Dr. John Durocher and all other faculty members from biological sciences.

I would like to express my gratitude to the staff members of Department of Biological Sciences: Jeff Lewin, Patricia Asselin and Emily Betterly and Department of Chemistry: Andrew Galernaue for their indispensable assistance. 
I am sincerely thankful to my lab mates and graduate students Weilue He, Beth M. Elledge and undergraduates Cameron Atkinson, Trevor Moser, Ji-Yeon Um, Stevie Dehnbostle, Jackie Pribyle, Alex Kiem and others for their excellent technical assistance in the lab.

I would like to specially thank my teaching advisers Dr. Wan Jin Jahng and Stacy Cotey for their excellent guidance and great help in effective teaching to achieve outstanding teaching assistant award from department.

I am very much thankful to my friends, graduate students and postdoctoral fellows for their great help during my graduate studies. This list includes, but not limited to Kiran Koya (Wayne state university), Folami Lamoke (Georgia health Sciences University), Ryan Terry (University of Utah), Shankar Jai Kishan (University of Texas), Surendar Dhadi, Ramana Reddy, Rafi Shaik, Kefeng Li, Claire Doskey, Stephanie Groves, Aparupa Sengupta, Komal Kumar, Emily Geiger, Giri Vegesna, Rajani Vegesna, Hansika Vegesana, Srinivas R. Mandalapu, Jithendar Rao Gujja, Nazmiye, Jagadeesh Janjanam, Vimala Janjanam, and Navya Janjanam.

I would like to extend my gratitude to the graduate school dean, Dr. Jacqueline E. Huntoon, Dr. Debra D. Charlesworth, and Nancy Byers Sprague for providing special fellowship to continue my graduate studies and excellent suggestions to finish my dissertation and degree.

I would like to thank department of Biological Sciences and Biotech Research Center (BRC) and Graduate School Government (GSG) for providing graduate teaching assistantship and travel grants to present my research at the ARVO conference.

Finally, I am forever indebted to my parents, family and relatives for their support to pursue my graduate studies at MTU. 


\begin{abstract}
Oxidative stress, intense light exposure and oxygen imbalances such as hypoxic or hyperoxic conditions perturb mitochondria, nuclear function and further lead to cellular damage of retina and retinal pigment epithelial (RPE) cells. Our major aim is to understand the various biochemical and proteomic events that occur during the progression of retina and RPE cell death. The comprehensive objectives of this dissertation are to understand the functional aspects of protein expression, posttranslational modifications, protein or lipid binding changes, phenotypic, morphological alterations and their regulation during the retina and RPE apoptosis under oxidative stress. The entire study is divided into four chapters Chapter 1 contains introduction and background on apoptotic signaling in retina and RPE cells. In chapter 2, we demonstrated that the oxidative stress biomarker prohibitin shuttles between mitochondria and nucleus as an anti-apoptotic molecule and acts as a transcriptional regulator by altering its lipid binding affinity and by posttranslational modifications during oxidative damage to the retina and RPE. In chapter 3, we demonstrated that oxidative and photo-oxidative stress induced nitric oxide regulates the RPE apoptosis by altering serine/threonine protein phosphatase 2A (PP2A) catalytic subunit, vimentin phosphorylation and $\mathrm{Bcl} x \mathrm{xL}$ expression regulation in the RPE cells in vitro. In chapter 4, we further analyzed the differential expression of prohibitin in the retina and RPE during oxidative stress, diabetic retinopathy (DR) and age-related macular degeneration (AMD) condition. Our analysis of postmortem retinas reveals that prohibitin is significantly increased in aged and AMD retina, and decreased in retinas of human diabetic retinopathy and RPE of AMD. Our study demonstrates that prohibitin levels determine the apoptotic signaling in the retina and RPE during retinal degenerative disease progression.
\end{abstract}




\section{CHAPTER 1: INTRODUCTION AND BACKGROUND}

Eye is a complex organ of the human body which contains different parts with various functions indispensable for clear vision. The front portion of the eye with transparent dome shaped structure which covers the iris and pupil is called cornea. Cornea helps in protecting the inner parts of the eye and focuses the light that enters the eye. Lens is another transparent oval shaped body compacted with crystalline, which directs the movement of light towards the retina to initiate the visual transduction. The vitreous humor is clear and colorless substance within the anterior chamber that fills the space between lens and retina. Retina is the neural portion of the eye which comprises of different classes of neurons such as photoreceptors (rods and cones), bipolar cells, ganglion cells, horizontal cells and amacrine cells. Retina is connected to the central nervous system. Retinal pigment epithelium (RPE) is the single layer of cells located underneath the neurosensory retina firmly attaching to the choroid.

\subsection{Role of oxidative stress in the retina and RPE during the progression of retinal degenerative diseases}

Retinal pigment epithelium (RPE) is highly pigmented, hexagonally packed cuboidal monolayered epithelium located on the Bruch's membrane between the neural retina and the choriocapillaries. RPE performs various functions such as phagocytosis of photoreceptor outer segments, transportation of nutrients, protection against reactive oxygen species, synthesis of vitamin-A metabolites (retinoid recycling) and maintaining the retina blood barrier which are highly indispensable for sustaining vision (Zangwill et al., 2000). High metabolic activities and visual signal transduction process in the retina, especially in macula contributes high oxygen tension in RPE (Alder and Cringle, 1985). Although the retina and RPE have powerful oxygen regulating mechanism, formation of reactive oxygen species (ROS) are predictable during pathophysiological conditions of Age-related macular degeneration (AMD), retinitis pigmentosa (RP), diabetic retinopathy (DR) and retinopathy of prematurity (ROP). Intense light exposure has been linked to the ocular damage which may cause the development of AMD, possibly due to the oxidative damage to the RPE layer (Taylor et al., 1992). Frequency of retinal irradiation, presence 
of chromophores/photo sensitizers, oxidation of poly unsaturated fatty acids (PUFA) such as Docohexanoic acids (DHA) in RPE provide an ideal environment for the generation of ROS (Beatty et al., 2000). Lack of protective mechanism against the oxidative damage may initiate the choroidal neovascularization in mouse model (Dong et al., 2009). Although the accumulation of photo-toxic ROS, lipo-protein complexes (drusen) suggests a correlation between oxidative stress and AMD, the mechanism of RPE apoptosis under oxidative stress is elusive. We speculated that identification of oxidative stress induced biomarkers in the retina and RPE provides novel insights towards signaling mechanism of retinal degeneration at the molecular level. Since oxidative stress contributes the progressive cell death of retina and RPE, our previous research team performed the proteomic analysis from bovine and human RPE cells under oxidative stress environment (Arnouk et al., 2011a). They found that aging related mitochondrial protein prohibitin is down-regulated in the bovine RPE cells along with the differential expression of several other proteins such as apoptotic related, DNA repair, respiratory chain related proteins (COX). Our later studies focused on the multifunctional protein prohibitin in the retina and RPE under elevated oxidative stress. Our proteomic approaches revealed that prohibitin is down regulated in the RPE, where as it was upregulated in the retina from aged and diabetic rat model. Our further proteomic studies confirm the tissue specific and sub cellular localization (mitochondria and nucleus) of prohibitin in the retina (ganglion cell, outer and inner nuclear layer) and RPE. (Lee et al., 2010a). Subsequently, we are interested in the functional role of prohibitin and its regulation in the RPE under oxidative. Our proteomic analysis provides the evidence that prohibitin communicates between the mitochondria and nucleus, acts as an anti-apoptotic molecule and transcription regulator in the retina and RPE under oxidative stress (Sripathi et al., 2011a).

\subsection{Multifunctional role of prohibitin (PHB) in the retina and retinal pigment epithelium (RPE) under oxidative stress}

Prohibitin is a highly conserved mitochondrial membrane protein with the molecular mass of ${ }^{n} 30-32 \mathrm{kDa}$, located on chromosome 17 at q21. The amino acid sequence of 
prohibitin in rat and mouse are identical and differ from the human prohibitin sequence by single amino acid (Mcclung et al., 1995b). The prohibitin complex (PHB1, PHB2) have been identified in mitochondria and plasma membrane as they both bind together to form a heterodimer and anchor to inner mitochondrial membrane through $\mathrm{N}$ terminalhydrophobic regions present in PHB1 and PHB2 (Artal-Sanz and Tavernarakis, 2010). Prohibitin acts as a potential tumor suppressor with anti-proliferative activity by regulating the cell cycle progression and apoptosis (Nuell et al., 1991). PHB1 co localizes in the nucleus with $\mathrm{E} 2 \mathrm{~F} 1$, retinoblastoma protein $\mathrm{pRb} 2$ and $\mathrm{p} 53$ to modulate transcriptional activity and recruit HDAC1 towards the repression of histone deacetylation (Wang et al., 2002a). Differential expression, regulation of both mitochondrial and nuclear genes may alter the sub cellular translocalization and function of a protein. Nuclear genes enable the mitochondrial- nuclear shuttling as seen in case of breast cancer cell lines (Delsite et al., 2002).

Irrespective of various cancers, neurodegenerative diseases, functional aspects of prohibitin in the eye are not well studied yet. The multifunctional protein prohibitin is significantly down regulated in bovine and human RPE cells under oxidative stress (Arnouk et al., 2011a). Our proteomic studies reveal that prohibitin is involved in the oxidative stress induced cell signaling and is identified as an oxidative stress biomarker in the retina and RPE. Prohibitin expression is controlled by oxidative, light induced stress and shows the differential expression levels in aged and diabetic retina (Lee et al., 2010a). We found that prohibitin translocalizes between mitochondria and nucleus by binding with the membrane lipid cardiolipin, tumor suppressor protein p53 and by the differential phosphorylation. Prohibitin knockdown approach using small interfering RNA (siRNA) demonstrate the elevated apoptotic signaling in the RPE under oxidative stress and prohibitin is considered as an anti-apoptotic protein in the RPE (Sripathi et al., 2011b). We also observed that the prohibitin expression was down regulated in the diabetic retinopathy of rat, mouse and human RPE. On the other hand, prohibitin expression was significantly upregulated in the aged retinas from rat, mouse and human. Interestingly, our western blotting analysis showed that prohibitin levels increased in 
both central (macula) and peripheral retinal regions, whereas the levels in the central (macula) and peripheral regions of RPE were significantly decreased from the agerelated macular degeneration (AMD) donor eyes compared to the age matched controls. To investigate the various functional properties of prohibitin and its relevant signaling pathways, we aimed to understand the prohibitin's potential binding partners and its interacting network using different proteomic approaches such as coimmunoprecipitation and MALDI-TOF mass spectrometry.

\subsection{Nitric oxide (NO) regulated cytoskeleton reorganization and apoptosis in the RPE under oxidative stress}

Nitric oxide is a soluble atmospheric gas synthesized in different cell types and freely diffusible across the cell membrane. Nitric oxide synthases (NOS) generates the nitric oxide by the oxidation of guanidino nitrogen of its substrate L-arginine. The reaction occurs in the presence of oxygen and NADPH with the formation of citrulline and NADP as byproducts. Three different isoforms of NOS have been identified from different genes with different localization, catalytic action, regulation and inhibition (Marletta et al., 1988; Nathan, 1992). Nitric oxide is synthesized by three different isoforms of nitric oxide syntheses (NOS) such as NOS-I (nNOS), NOS-II (iNOS) and NOS-III (eNOS). nNOS is the first and predominating isoform mainly localized in the neuronal tissue of central and peripheral nervous system, amacrine cells, bipolar cells and photoreceptor (rod and cone) cells (Koch et al., 1994; Perez et al., 1995; Yamamoto et al., 1993). Inducible nitric oxide synthase (iNOS) is a calcium dependent inducible isoform generated by the immunological or inflammatory stimuli and the expression is observed in the retinal Müller glial and retinal pigment epithelial cells after stimulation with cytokines (IFN $\gamma$ ) and endotoxins (LPS) (Goureau et al., 1994). Recently, iNOS expression was also identified in the retinal pericytes and capillary endothelial cells (Chakravarthy et al., 1995). The calcium dependent eNOS isoform expresses in the vascular endothelial cells and generates lower levels of nitric oxide. Endothelial nitric oxide synthase (eNOS) expression was identified in endothelial cells of the blood vessels located on the vitreous surface, between the nerve fiber layer (NFL), axons of 
retinal ganglion cell layer (GCL), choroid and vascular endothelium of anterior segment (Osborne et al., 1993). Various studies confirmed that nitric oxide acts as a neuro modulator of synaptic transmission due to the modifications of electrical coupling in the retinal horizontal cells (Miyachi et al., 1990). Nitric oxide generated from endothelial and neuronal cells plays a major role in the regulation of cerebral blood flow (Estrada and DeFelipe, 1998), synaptic transmission (Holscher, 1997). Rat RPE cells generates higher levels of nitric oxide via inducible nitric oxide synthase (iNOS) in response to endotoxin lipopolysaccharide (LPS), cytokines interferon- $\gamma$ (IFN- $\gamma$ ), tumor necrosis factor- $\alpha(\mathrm{TNF}-\alpha)$ and competitively inhibited with the treatment of nitric oxide synthase inhibitor NG-Monomethyl-L-Arginine (L-NMMA) and cycloheximide (Liversidge et al., 1994). Our studies reveal that RPE generates nitric oxide in concentration and time dependent manner under light, oxidative stress and reoxygenation conditions. However, the physiological levels of nitric oxide produced in the cells need to be detected to understand role of NO during RPE apoptosis under pathological conditions. 


\section{CHAPTER 2: MITOCHONDRIAL-NUCLEAR COMMUNICATION BY PROHIBITIN SHUTTLING UNDER OXIDATIVE STRESS ${ }^{1}$}

Srinivas R. Sripathi, Weilue He, Cameron L. Atkinson, Joseph J. Smith, Zhicong Liu, Beth M. Elledge, and Wan Jin Jahng ${ }^{1}$

${ }^{1}$ The material included in this chapter was previously published in the journal Biochemistry, 2011, 50 (39), pp 8342-8351DOI: 10.1021/bi2008933

Publication Date (Web): August 31, 2011Copyright (C) 2011 American Chemical Society http://pubs.acs.org/doi/abs/10.1021/bi2008933

This study was supported by the Century II Equipment fund and the Research Excellence Fund of Michigan Technological University. 


\subsection{Abstract}

Mitochondrial-nuclear communication is critical for maintaining mitochondrial activity under stress conditions. Adaptation of the mitochondrial-nuclear network to changes in the intracellular oxidation and reduction milieu is critical for the survival of retinal and retinal pigment epithelial (RPE) cells, in relation to their high oxygen demand and rapid metabolism. However, the generation and transmission of the mitochondrial signal to the nucleus remain elusive. Previously, our in vivo study revealed that prohibitin is up regulated in the retina, but down regulated in RPE cells in the aging and diabetic model. In this study, the functional role of prohibitin in the retina and RPE cells was examined using biochemical methods, including a lipid binding assay, two-dimensional gel electrophoresis, immunocytochemistry, Western blotting, and a knockdown approach. Protein depletion by siRNA characterized prohibitin as an anti-apoptotic molecule in mitochondria, while the lipid binding assay demonstrated sub cellular communication between mitochondria and the nucleus under oxidative stress. The changes in the expression and localization of mitochondrial prohibitin triggered by reactive oxygen species are crucial for mitochondrial integrity. We propose that prohibitin shuttles between mitochondria and the nucleus as an anti-apoptotic molecule and a transcriptional regulator in a stress environment in the retina and RPE cells. 


\subsection{Introduction}

Mitochondrial-nuclear reciprocal signaling is the central question that needs to be answered to understand the maintenance mechanism of appropriate mitochondrial activities and functions in neurodegeneration. Disruptions of the mitochondrial-nuclear network lead to accelerated aging and age-related diseases. Considering the significant consequences of mitochondrial dysfunction in neurodegeneration and aging, it is crucial to understand the molecular mechanisms of mitochondrial-nuclear communication by protein shuttling (Cannino et al., 2007; Ryan and Hoogenraad, 2007). Cellular proteome changes, including expression, localization, and modifications, to adapt an oxidative environment are critical for the survival of retinal and retinal pigment epithelial (RPE) cells, because of their high oxygen demand and upregulated metabolism, especially under constant phototransduction. Oxidative stressors, including reactive oxygen species (ROS) and a hypoxic environment, are serious risk factors in retinal degeneration, including agerelated macular degeneration (AMD) and diabetic retinopathy (DR). Understanding the molecular mechanisms that mediate oxidative stress-induced proteome changes and protein translocalization between mitochondria and nuclei may provide insight into pathogenesis of retinal degeneration. Previously, our proteomic study demonstrated that prohibitin is involved in oxidative stress signaling in the retina and RPE cells (Arnouk et al., 2011b; Lee et al., 2010a). An in vivo study revealed that the aging process upregulated prohibitin in the retina and decreased its level in RPE cells. Prohibitin was first reported as an anti-proliferative protein or a tumor suppressor that binds to p53, E2F, and Rb (McClung et al., 1989; Nijtmans et al., 2000a). It forms a high-molecular mass complex with its isoform, prohibitin 2, in mitochondria (Steglich et al., 1999). Localization of prohibitin has been controversial, possibly because of cell type and extracellular stress, in being identified as mitochondrial, nuclear, or cell surface (RiveraMilla et al., 2006; Wang et al., 2002b). Prohibitin is ubiquitous in organisms ranging from bacteria to plants to humans, but its function is not clearly understood at the molecular level in each sub cellular organelle (McClung et al., 1995a). Prohibitin is proposed to have roles as a cell cycle inhibitor, transcriptional regulator, inflammatory modulator, plasma membrane receptor, and mitochondrial chaperone (Kolonin et al., 
2004a; Mishra et al., 2005; Nijtmans et al., 2000a; Patel et al., 2010; Sharma and Qadri, 2004a; Theiss et al., 2007b; Wang et al., 1999a; Wang et al., 1999b). Prohibitin plays a role in apoptosis and aging by stabilizing newly synthesized respiratory enzymes; however, its presence and function in the eye have never been elucidated (Bourges et al., 2004; Nijtmans et al., 2002). In this study, we examined the antiapoptotic function and the altered lipid interactions of prohibitin under oxidative stress. Translocalization of prohibitin was observed between mitochondria and the nucleus as apoptotic signaling. The changes in the expression and location of mitochondrial prohibitin triggered by redox imbalance mediated by ROS suggest a critical role of prohibitin translocalization in the maintenance of mitochondrial integrity. Here, we demonstrate that prohibitin is a new dynamic regulator of mitochondrial and nuclear functions under stress in the retina and RPE cells. Knockdown of prohibitin upregulated pro-apoptotic factors, including BAK and caspases, and decreased the levels of anti-apoptotic molecules such as BCL-xL. The significance of our study resides in our characterization of prohibitin as a mitochondrionnucleus shuttle to respond to $\mathrm{ROS}$ as an anti-apoptotic protein and also as a transcriptional regulator by binding to p53 in the nucleus.

\subsection{Materials and methods}

\subsubsection{ARPE-19 Cell Culture}

ARPE-19 cells were transferred to tissue culture flasks (Nunc, Roskilde, Denmark) containing Dulbecco's modified Eagle's medium (DMEM) supplemented with 10\% fetal bovine serum (FBS) and 1\% penicillin/ streptomycin and the flasks placed in a 5\% $\mathrm{CO} 2$ incubator at $37{ }^{\circ} \mathrm{C}$. After proliferation, cells were retrypsinized with a $0.1 \%$ trypsinEDTA solution (Sigma, St. Louis, MO) for $5 \mathrm{~min}$ at $37^{\circ} \mathrm{C}$. After centrifugation $(125 \mathrm{~g}$ for $7 \mathrm{~min}$ ), cells were plated in 24- or 6-well plates (Nunc) at a density of $2 \times 104$ or $8 \times 104$ cells/well, respectively, and allowed to grow to confluence for 2-4 days. Eight- to twelve-passage cells were used for experiments (Davis et al., 1995; Dunn et al., 1996). 


\subsubsection{Oxidative Stress Treatment}

ARPE-19 cells were incubated with fresh medium for $12 \mathrm{~h}$ before being treated. Hydrogen peroxide (Mallinckrodt Inc.) was diluted (50, 100, 200, and $250 \mu \mathrm{M})$ in FBSfree medium. Cells were washed with PBS three times before being treated. Cells were treated with $\mathrm{H}_{2} \mathrm{O}_{2}$ for $1,2,4,6,8,12$, and $24 \mathrm{~h}$ at $37^{\circ} \mathrm{C}$ in a $5 \% \mathrm{CO} 2$ incubator. Medium was removed immediately after the treatment, and cells were washed with PBS and harvested. Cells were lysed by RIPA buffer [0.5 M Tris- $\mathrm{HCl}(\mathrm{pH} 7.4), 1.5 \mathrm{M} \mathrm{NaCl}, 2.5 \%$ deoxycholic acid, 10\% NP-40, and $10 \mathrm{mM}$ EDTA (Millipore)] containing protease inhibitor cocktail (Thermo Scientific) for sodium dodecyl sulfate-polyacrylamide gel electrophoresis (SDS-PAGE) and Western blot analysis or immunocytochemistry. Immunocytochemistry. ARPE-19 cells were incubated with the final concentration of 100 nM MitoTracker Orange CMTMRos (Molecular Probes, Carlsbad, CA) in FBS-free culture medium for $30 \mathrm{~min}$ at $37^{\circ} \mathrm{C}$. After being washed in PBS, cells were fixed with $10 \%$ formaldehyde in PBS for $25 \mathrm{~min}$ at room temperature, and the membrane was permeabilized with $0.2 \%$ Triton X-100 (Sigma) in PBS for 20 min. Cells were blocked with complete medium containing 10\% FBS and 0.05\% Tween 20 (Sigma) for $1 \mathrm{~h}$. Cells

were incubated with the anti-prohibitin antibody (1:500; Genemed Synthesis Inc., San Antonio, TX) overnight at $4{ }^{\circ} \mathrm{C}$. After being washed with PBS three times, cells were incubated with Alexa Fluor 488- conjugated anti-rabbit IgG (1:700; Molecular Probes) for $1 \mathrm{~h}$ at $25^{\circ} \mathrm{C}$. Finally, cells were mounted with VECTASHIELD Mounting Medium with DAPI (4, 6-diamidino-2- phenylindole) to counterstain the nucleus. Images were acquired using a Zeiss AxioVert 200 M Apo Tome fluorescent microscope with 63× magnification.

\subsubsection{Co-Immunoprecipitation}

ARPE-19 cells were homogenized in lysis buffer [25 mM Tris, $120 \mathrm{mM} \mathrm{NaCl}, 0.3 \%$ Triton X-100, 15\% glycerol, 2 mM PMSF, $10 \mathrm{mM}$ EDTA, 0.2\% sodium orthovanadate, and protease inhibitor cocktail]. Cells were lysed by repeated freeze-thaw cycles and sonication $(3 \times 5 \mathrm{~min})$, followed by centrifugation at $13000 \mathrm{~g}$ for $30 \mathrm{~min}$. Proteins in supernatant were purified by using control agarose resin, cross-linked by $4 \%$ bead 
agarose, to minimize nonspecific binding. The purified anti-prohibitin antibody was immobilized with amino-linked protein A beads in the column with coupling buffer [0.5 $\mathrm{mM}$ sodium phosphate and $7.5 \mathrm{mM} \mathrm{NaCl}(\mathrm{pH}$ 7.2)] and incubated with $3 \mu \mathrm{L}$ of $5 \mathrm{M}$ sodium cyanoborohydride on a shaker at $25{ }^{\circ} \mathrm{C}$ for $2 \mathrm{~h}$. Columns were washed with a washing buffer $[0.025 \mathrm{M}$ Tris, $0.15 \mathrm{M} \mathrm{NaCl}, 0.001 \mathrm{M}$ EDTA, $1 \% \mathrm{NP}-40$, and 5\% glycerol (pH 7.4)]. Protein samples were incubated in the protein A-antibody column with gentle mixing overnight at $4{ }^{\circ} \mathrm{C}$. Columns were washed three times to remove nonspecific binding proteins. Samples were equilibrated with Laemmli sample buffer containing $100 \mathrm{mM}$ DTT. Eluted proteins were separated by SDS-PAGE and visualized by Western blot analysis using primary antibodies against prohibitin and p53. Protein bands on the gel were visualized by silver staining (Bio-Rad, Hercules, CA).

\subsubsection{Two-Dimensional SDS-PAGE}

Protein samples were purified with the ReadyPrep 2-D Cleanup Kit (Bio-Rad) and quantified using the BCA protein assay kit (Pierce, Rockford, IL). One hundred fifty micrograms of protein was incubated in $200 \mu \mathrm{L}$ of rehydration buffer ( $8 \mathrm{M}$ urea, $2 \mathrm{M}$ thiourea, 2\% CHAPS, and $50 \mathrm{mM}$ DTT) and supplemented with $0.5 \%$ destreak IPG buffer ( $\mathrm{pH} \mathrm{3-10)}$ (GE Healthcare). Isoelectric focusing was conducted using $11 \mathrm{~cm}$ immobiline dry strips (Bio-Rad) with linear $\mathrm{pH} 3$ to 10 and $\mathrm{pH} 4$ to 7 gradients. Strips were rehydrated for $12 \mathrm{~h}$ at $20{ }^{\circ} \mathrm{C}$. Proteins were separated with the Ettan IPGphor-3 instrument (GE Healthcare) using programmed voltage gradients at $20{ }^{\circ} \mathrm{C}$ for a total of $12 \mathrm{kVh}(1 \mathrm{~h}$ at $500 \mathrm{~V}, 1 \mathrm{~h}$ at $1000 \mathrm{~V}, 2 \mathrm{~h}$ at $6000 \mathrm{~V}$, and $40 \mathrm{~min}$ at $6000 \mathrm{~V})$. The IPG strips were reduced in equilibration buffer I [0.375 M Tris- $\mathrm{HCl}(\mathrm{pH} 8.8), 6 \mathrm{M}$ urea, $20 \%$ glycerol, $2 \%$ SDS, and $50 \mathrm{mM} \mathrm{DTT}$ ] for $20 \mathrm{~min}$ at $25{ }^{\circ} \mathrm{C}$ and alkylated for $20 \mathrm{~min}$ in equilibration buffer II containing $150 \mathrm{mM}$ iodoacetamide. The equilibrated strips were placed on top of polyacrylamide gels ( $8-16 \%$; Bio-Rad) and sealed with $1 \%$ agarose

buffer. Proteins were visualized by Coomassie staining using Imperial Protein Stain (Pierce) and Western blot analysis. 


\subsubsection{In-Gel Digestion and Mass Spectrometry}

Selected protein spots from two-dimensional (2D) electrophoresis were excised from gels. The gel pieces were destained twice with $200 \mu \mathrm{L}$ of $50 \%$ acetonitrile $(\mathrm{MeCN}) / 25$ $\mathrm{mM}$ NH4HCO3 buffer ( $\mathrm{pH} \mathrm{8.0)}$ at room temperature for $20 \mathrm{~min}$, washed once with 200 $\mu \mathrm{L}$ of $100 \% \mathrm{MeCN}$, and vacuum-dried with a Speed Vac concentrator (Savant, Holbrook, $\mathrm{NY}$ ). The gel pieces were rehydrated with $13 \mathrm{ng} / \mu \mathrm{L}$ sequencing grade modified trypsin (Promega, Madison, WI) in $25 \mathrm{mM} \mathrm{NH} 4 \mathrm{HCO} 3$ and incubated at $37{ }^{\circ} \mathrm{C}$ overnight. Peptides were subsequently extracted twice with $50 \mu \mathrm{L}$ of a $50 \% \mathrm{MeCN} / 5 \%$ formic acid mixture for $15 \mathrm{~min}$ at $37^{\circ} \mathrm{C}$. All extracts were combined and dried. The peptide extracts were purified using the C18 ZipTip (Millipore). The peptides were eluted with $5 \mu \mathrm{L}$ of a $75 \% \mathrm{MeCN} / 0.1 \%$ TFA mixture. The samples were analyzed by MALDI-TOF or tandem ESI MS/MS as previously described (Arnouk et al., 2011b; Lee et al., 2010a; Lee et al., 2010b; Lee et al., 2011; Zhang et al., 2010a).

\subsubsection{Subcellular Fractionation}

Bovine retinal tissues were separated and proteins isolated by the Cox and Emili method, which uses different centrifugation in density gradients to generate nuclear, mitochondrial and cytosolic protein components (Cox and Emili, 2006b). Cold PBS-pre rinsed tissue was homogenized in homogenization buffer and centrifuged at $800 \mathrm{~g}$ for 15 min. The pellet was resuspended for further isolation of nuclear proteins. The supernatant was collected and centrifuged at $6000 \mathrm{~g}$ for $15 \mathrm{~min}$. The pellet was saved for mitochondria and supernatant for cytosol-microsome separation. The crude nuclear fraction was suspended in nuclear extraction buffer and separated by ultracentrifugation at $80000 \mathrm{~g}$ for 35 min. To obtain mitochondrial membrane and matrix protein, the pellet was resuspended in membrane extraction hypotonic lysis buffer centrifuged at $9000 \mathrm{~g}$ for 30 min. Cytosolic proteins were obtained by spinning the supernatant for $1 \mathrm{~h}$ at $10,0000 \mathrm{~g}$.

\subsubsection{SDS-PAGE and Western Blot Analysis}

Protein quantification was conducted with the BCA protein assay kit (Pierce). Samples were dissolved in Laemmli sample buffer [62.5 mM Tris- $\mathrm{HCl}(\mathrm{pH} \mathrm{6.8),} \mathrm{25 \%}$ glycerol, $2 \%$ SDS, and $0.01 \%$ bromophenol blue]. Proteins were resolved using 8 to $16 \%$ 
polyacrylamide precast gels (Bio-Rad), followed by electrotransfer onto the methanolactivated PVDF membrane, and blocked in 5\% nonfat milk prepared in TTBS [0.1\% (v/v) Tween 20] for $1 \mathrm{~h}$ at $25^{\circ} \mathrm{C}$. The membranes were incubated with primary antibodies at $4{ }^{\circ} \mathrm{C}$ overnight and subsequently incubated with corresponding horseradish peroxidaseconjugated secondary antibodies for $1 \mathrm{~h}$ at $25^{\circ} \mathrm{C}$. Proteins were visualized by using West Pico Chemiluminescent Substrate (Pierce). Immunoreactive protein bands were acquired using a LAS 4000 mini luminescent image analyzer and quantified using Quantity One (Bio-Rad). Proteins in gels were stained with Imperial Protein stain and scanned using a GS800 imaging densitometer (Bio-Rad).

\subsubsection{Lipid-Protein Interaction Assay}

Lipid strips were purchased from Echelon Biosciences or prepared using a nitrocellulose membrane in the lab. For commercially available lipid strips, membranes with a solvent blank control and 15 different lipids were initially blocked with SuperBlock (Pierce) blocking buffer for $1 \mathrm{~h}$ at room temperature. To prepare our own lipid strips, we spotted different amounts of lipids (100 pmol to $10 \mathrm{nmol}$ ), including cardiolipin, cholesterol, and phosphatidylserine, onto the nitrocellulose membrane. The membrane was air-dried for $1 \mathrm{~h}$ at room temperature. Crude proteins, fractionated samples, or prohibitin partially purified by co-IP $(1 \mu \mathrm{g} / \mathrm{mL})$ from control ARPE-19 cells or cells under oxidative stress $\left(200 \mu \mathrm{M} \mathrm{H}_{2} \mathrm{O}_{2}\right)$ was incubated with a nitrocellulose membrane overnight. The membrane was washed three times with TTBS buffer [Trisbuffered saline with $0.1 \%(\mathrm{v} / \mathrm{v})$ Tween 20], followed by incubation with the prohibitin antibody (1:1000; Genemed Synthesis Inc.) overnight at $4{ }^{\circ} \mathrm{C}$ with gentle agitation. Blots were washed with TTBS buffer and incubated with horseradishperoxidase conjugated anti-rabbit secondary antibody (1:10000; Agrisera, Sweden) for $1 \mathrm{~h}$ at $25^{\circ} \mathrm{C}$. Strips were

developed with Super Signal West Pico Chemiluminescence Substrate (Pierce), and proteins were visualized using a LAS 4000 mini luminescent image analyzer (Fuji).

\subsection{9 siRNA Transfection}

ARPE-19 cells were seeded in 24-well plates at a density of $6 \times 104$ cells/well with 0.1 $\mathrm{mL}$ of DMEM containing 10\% FBS and 1\% penicillin/streptomycin. Cells were 
incubated at $37{ }^{\circ} \mathrm{C}$ with $5 \% \mathrm{CO}$. Cells were treated with $175 \mathrm{ng}$ (final concentration of $23 \mathrm{nM}$ ) of siRNA (AAAGCCAGCTTCCTCGCATCT) against prohibitin (FlexiTube siRNA) and random sequence control siRNA in $100 \mu \mathrm{L}$ of culture medium without serum. Transfection was conducted with HiPerFect transfection reagent (Qiagen, Valencia, CA), and cells were harvested $48 \mathrm{~h}$ post-transfection. Proteins were assayed by Western blot for detection of AIF (EMD Millipore), BCL-xL (sc-634; Santa Cruz Biotechnology), caspase-9 (AB16969; EMD Millipore), BAK (ab32371; Abcam), and actin (sc-47778; Santa Cruz Biotechnology). Protein localization and expression were also analyzed by immunocytochemistry.

\subsection{Results}

\subsubsection{Mitochondrial-Nuclear Trafficking of Prohibitin}

Oxidative stress induced by hydrogen peroxide has been implicated in many ocular diseases. RPE cells maintain a reducing environment within cells to balance the production of reactive oxygen species and detoxification. Recently, we studied early molecular signaling events during oxidative stress in the retina and RPE cells using a comparative proteomics approach to identify altered protein levels (Arnouk et al., 2011b; Chung et al., 2009b; Lee et al., 2010a; Lee et al., 2010c; Lee et al., 2011; Zhang et al., 2010b). In RPE cells, one of the downregulated proteins under oxidative stress was prohibitin. Changes in the prohibitin level in both diabetic and aging eyes suggest that it may have an apoptosis-related function in RPE cells, especially under chronic stress and pathophysiological conditions(Lee et al., 2010a).

First, we examined the cellular localization of prohibitin, which is a controversial question. Translocalization of prohibitin in response to oxidative stress was examined using immunocytochemistry. Subcellular organelles and prohibitin were visualized by DAPI (nuclear DNA, blue, 369 and $460 \mathrm{~nm}$ for absorbance and emission, respectively), MitoTracker Orange (mitochondria, red, 578 and $599 \mathrm{~nm}$ for absorbance and emission, respectively), and Alexa Fluor 488 (prohibitin, green, 495 and $519 \mathrm{~nm}$ for absorbance and emission, respectively), by taking three color fluorescent images every hour. A kinetic assay confirmed that the signaling pathway was involved in the movement of prohibitin 
to the nucleus from mitochondria. Confluent ARPE-19 cells were treated with $200 \mu \mathrm{M}$ $\mathrm{H}_{2} \mathrm{O}_{2}$ for $24 \mathrm{~h} \mathrm{H}_{2} \mathrm{O}_{2}$ treated cells showed nuclear trans-localization of prohibitin, whereas untreated cells showed localization in mitochondria (Figure 1). After $8 \mathrm{~h}$, prohibitin showed an accumulation in the nucleus as compared to the control group. After $24 \mathrm{~h}$, more nuclear prohibitin was observed and much less co localized with mitochondria.

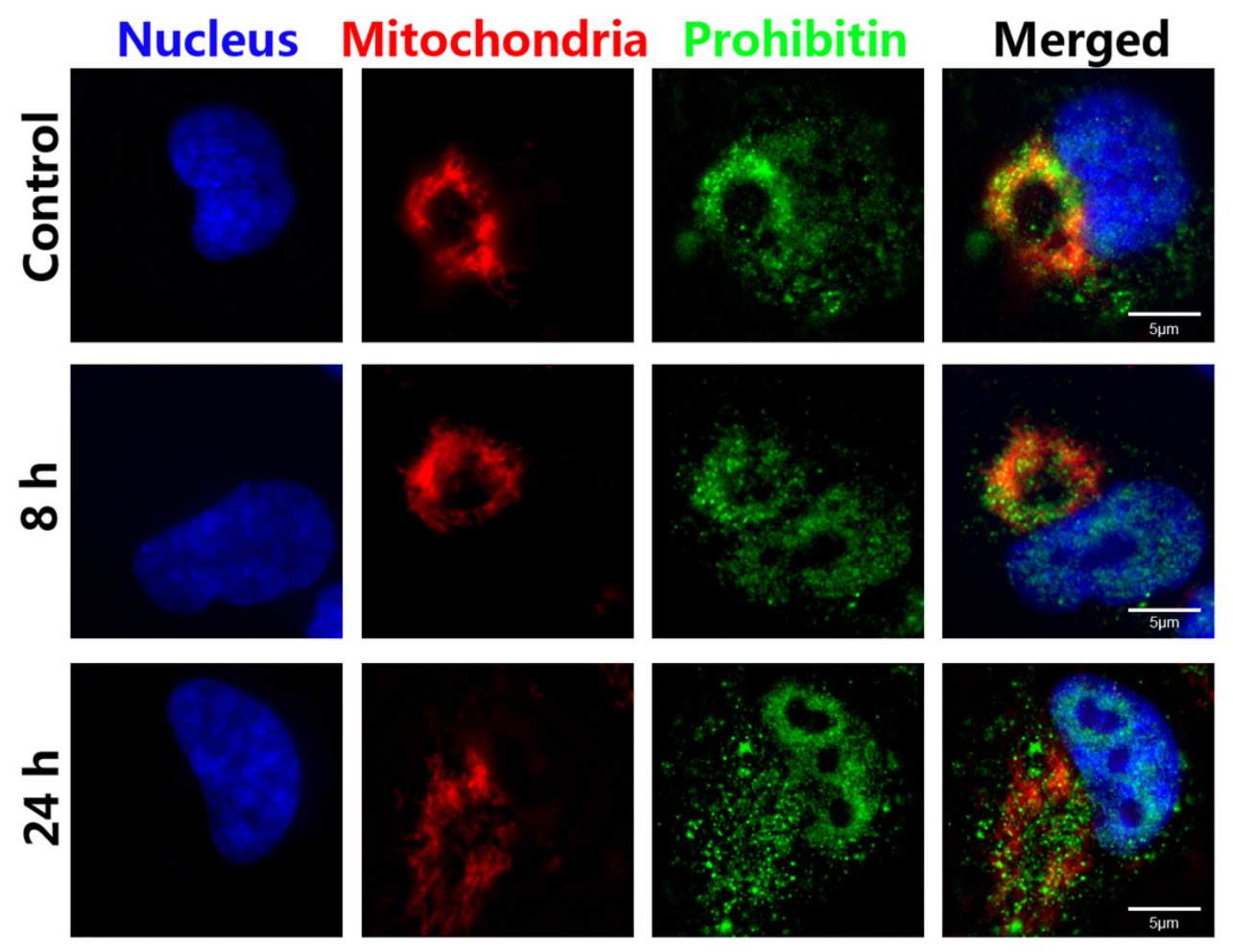

Figure 2.1 Translocalization of prohibitin under oxidative stress. ARPE-19 cells treated with $\mathrm{H}_{2} \mathrm{O}_{2}(200 \mu \mathrm{M}$ for 8 or $24 \mathrm{~h})$ were analyzed by immunocytochemistry. Subcellular organelles and prohibitin were visualized by DAPI (blue, nucleus), the prohibitin-specific primary antibody, the Alexa Fluor 488-conjugated secondary antibody (green, prohibitin), and MitoTracker Orange (red, mitochondria). Prohibitin was translocalized from mitochondria to the nucleus under oxidative stress in a time-dependent manner. The scale bar is $5 \mu \mathrm{m}$.

To examine prohibitin response in apoptosis signaling in detail, we then examined changes in the protein expression level in vitro using ARPE-19 cells. We examined changes in the prohibitin level under $\mathrm{H}_{2} \mathrm{O}_{2}$ in a time- and dose-dependent manner. Protein analysis by SDS-PAGE and Western blotting demonstrated that prohibitin is down 
regulated under oxidative stress $\left(200 \mu \mathrm{M} \mathrm{H}_{2} \mathrm{O}_{2}\right.$ for 1-24 h) (Figure 2.2). Cells treated with $200 \mu \mathrm{M} \mathrm{H}_{2} \mathrm{O}_{2}$ showed a $40 \%$ decrease in their level of prohibitin, but the levels between treated groups after $24 \mathrm{~h}$ revealed no significant difference by $t$ test, indicating that a decreased level of prohibitin caused by oxidative stress is an acute process that occurs within $2 \mathrm{~h}$. Down regulation of prohibitin under stress conditions suggests that the nuclear prohibitin may not be a newly synthesized protein as there was no increase in the level of prohibitin for $24 \mathrm{~h}$; the nuclear prohibitin might derive from mitochondria because prohibitin was not colocalized with mitochondria after extended $\mathrm{H}_{2} \mathrm{O}_{2}$ treatment.

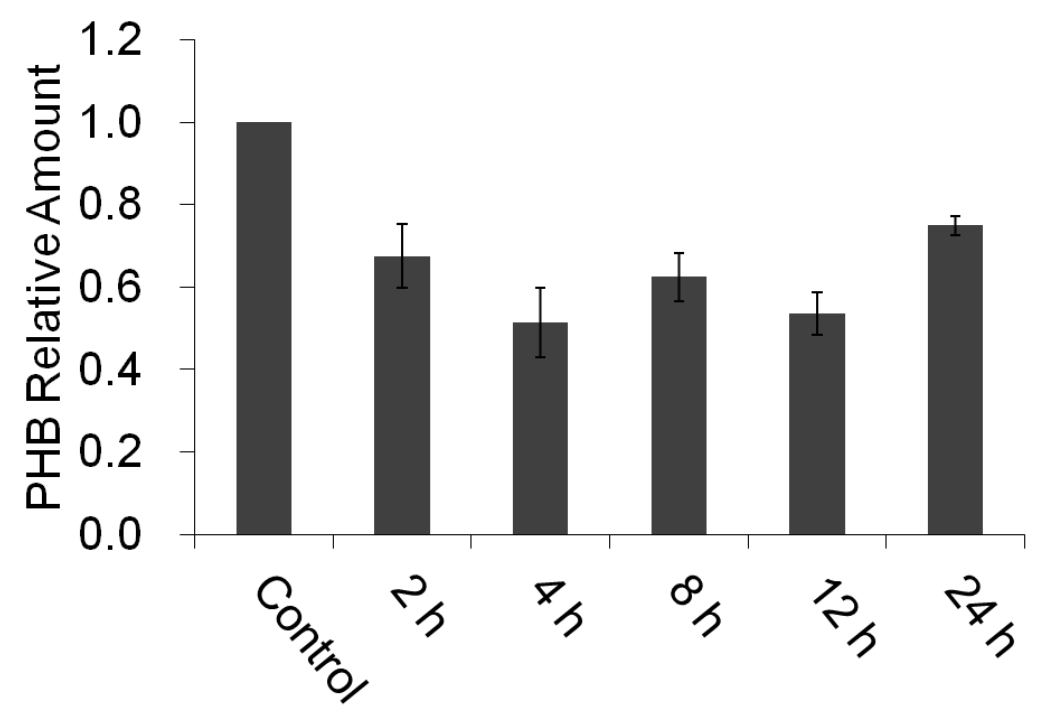

Figure 2.2 Downregulation of prohibitin under oxidative stress. ARPE-19 cells were treated with $\mathrm{H}_{2} \mathrm{O}_{2}$. At specific time points, cells were harvested and proteins separated by SDS-PAGE. Prohibitin was visualized by Western blotting. The level of prohibitin decreased in all treated groups. ANOVA was used to demonstrate the differences among groups. Statistical analysis showed that there is a significant difference among groups $(P$ $<0.01)$. Tukey's Honestly Significant Difference (HSD) test was applied to find the source of the difference. Results showed that control group was significantly different from the treated groups (4 and $12 \mathrm{~h}, P<0.01 ; 2,8$, and $24 \mathrm{~h}, P<0.05$ ). No significant difference was found among treated groups.

To address the issue of the membrane binding property of prohibitin in RPE cells, we investigated the effect of stress on protein solubility. First, we examined the correlation between oxidative stress and soluble prohibitin and found that the ratio of soluble prohibitin to membrane binding prohibitin decreased under oxidative stress. Prohibitin 
exists in both detergent resistant insoluble and soluble fractions and was separated by SDS-PAGE using 8 to $16 \%$ gradient gels and the maximal running time. Membranebinding prohibitin showed slightly higher molecular mass when compared to that of soluble prohibitin. As shown in panels A and B of Figure 3, the level of soluble prohibitin from ARPE-19 cells decreased and the level of detergent-resistant, membrane-binding insoluble prohibitin increased under stress conditions in $4 \mathrm{~h}$. To compare insoluble and soluble forms from subcellular organelles, we separated prohibitins from mitochondria (M), cytosol (CYT), and whole cell lysate (WCL) by SDS-PAGE and visualized them by Western blotting (Figure 3C). Soluble prohibitin from ARPE- 19 cells in the cytosolic fraction $(32 \mathrm{kDa})$ moved faster than membrane-bound mitochondrial and microsomal prohibitin $(34 \mathrm{kDa})$. The insoluble, detergent-resistant, membrane binding prohibitin exhibited a slightly higher-molecular mass band compared to that of cytosolic, soluble prohibitin. Prohibitins in whole cell lysate from both retinal and RPE cells showed two bands as insoluble and soluble forms. It is possible that the membrane-binding and soluble prohibitins may exist in different subcellular organelles, so we next examined the subcellular localization of prohibitin. 


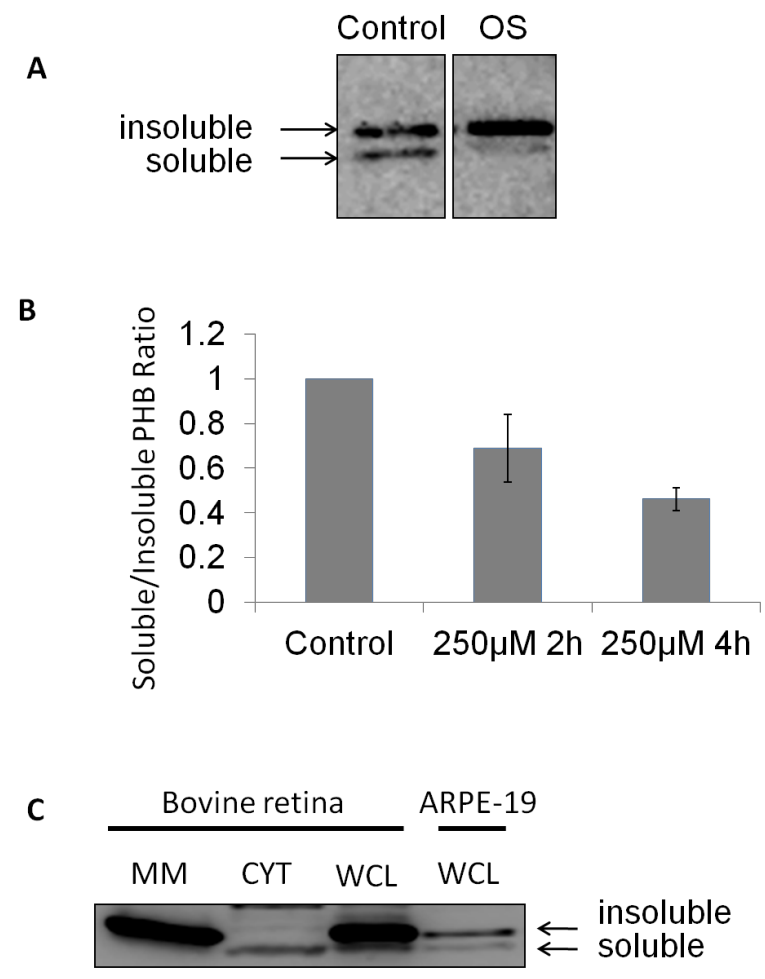

Figure 2.3 Detergent-resistant membrane prohibitin under oxidative stress. (A) Detergent-resistant (insoluble) and soluble prohibitins were separated by SDS-PAGE and visualized by Western blotting. Under oxidative stress (OS, $250 \mu \mathrm{M} \mathrm{H}_{2} \mathrm{O}_{2}, 4 \mathrm{~h}$ ), detergent-resistant prohibitin was upregulated compared to the control. (B) Quantitative analysis of insoluble and soluble prohibitin under oxidative stress. (C) Prohibitins from bovine retinal cells and ARPE-19 cells were compared for the analysis of insoluble and soluble forms. Mitochondrial prohibitin (M) moved slightly slower than the cytosolic form (CYT). Whole cell lysate (WCL) from both bovine retinal cells and ARPE-19 cells shows detergent-resistant insoluble and soluble forms of prohibitin.

\subsubsection{Subcellular Localization of Prohibitin in the Retina and RPE Cells}

Our previous experiments demonstrated that prohibitin may respond differently in the retina and RPE cells under various oxidative stress conditions, including diabetes and aging. To specify the location of prohibitin in the retina, we fractionated bovine retina using serial centrifugation and specific detergents, including polyamines (Cox and Emili, 2006a). Via this method, proteins were separated by nuclear and mitochondrial extraction buffer. Denatured and native gel electrophoresis and Western blotting of the subcellular organelle showed that prohibitin is widely distributed in retina cells but centralized in 
mitochondria (Figure 2. 4). We used cytochome $c$, RNA polymerase II, and transketolase as positive controls to show mitochondrial, nuclear, and cytosolic fractions, respectively. Quantitative analysis showed that $60-80 \%$ of prohibitin in bovine retina was localized in the mitochondrial membrane pellet (Figure 2.4, Mitochondria II) in bovine retina cells, but the cytosol and nucleus (soluble I and membrane II) also contain a substantial amount of prohibitin. Then we explored the prohibitin levels in different subcellular locations in RPE cells. Our fractionation experiments using ARPE-19 cells showed that prohibitin has a membrane-binding and soluble form. In ARPE-19 cells, prohibitin was mainly expressed in mitochondria $(60-80 \%)$ as determined by the Cox fractionation method (Cox and Emili, 2006a).

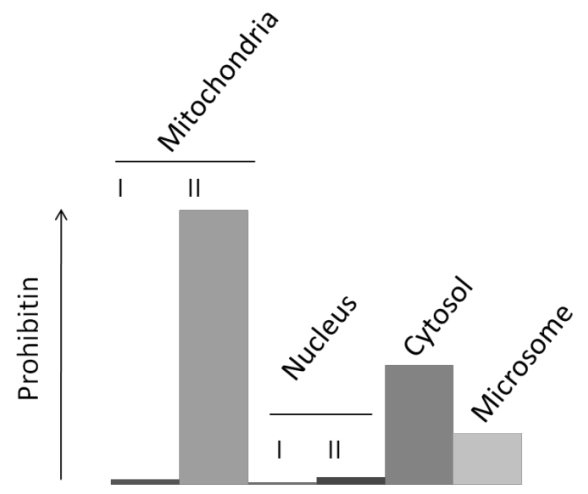

Figure 2.4 Subcellular localization of prohibitin. Subcellular fractions were separated by the Cox and Emili method. Proteins in the retina were fractionated on the basis of serial centrifugations with extraction buffers and separated by SDS-PAGE. The prohibitin concentration was quantitatively analyzed. Prohibitin in bovine retina was localized mostly in mitochondria as a membrane-associated form (II, mitochondrial membrane) rather than a soluble form (I, mitochondrial matrix). Prohibitin was also detected in the nucleus. The relative amounts of prohibitin are presented as matrix (I) and membrane (II) in mitochondria, nucleus (supernatant I and membrane-associated II), cytosol, and microsome.

As prohibitin is widely spread in each subcellular fraction, we asked whether different subcellular prohibitins have the same isoelectric point (pI). We used 2D electrophoresis to isolate prohibitin from the fractionated subcellular proteome. Mitochondrial, nuclear, cytosolic, and microsomal prohibitin were separated and visualized by Coomassie staining and Western blotting (Figure 2.5). In the mitochondrial fraction, prohibitin exhibited a molecular mass of $32 \mathrm{kDa}$ and a $\mathrm{pI}$ of 5.6 as expected. Prohibitin was more acidic in the nucleus, with a pI of 5.3, because of post-translational 
modifications such as phosphorylation. Cytosolic prohibitin showed very basic spots of pI 6-7 and a higher molecular mass as shown in the box, representing potential ubiquitination. As each subcellular prohibitin exhibited different $\mathrm{pI}$ values in 2D electrophoresis, we examined potential post-translational modifications in bovine retinal cells, including phosphorylation, using a different fractionation method (Cox and Emili, 2006a). Mitochondrial and nuclear fractions were further separated by matrix (Mito I and Nucl I) versus membrane (Mito II and Nucl II) proteins. Prohibitin in the mitochondrial matrix (Figure 2. 6, lane 1) and cytosol (Figure 2.6, lane 5) may exist as a putative heterodimer at $75 \mathrm{kDa}$, whereas it showed multiple bands around $32 \mathrm{kDa}$ in the nucleus and cytosol, possibly because of phosphorylation or peripheral membrane interactions. Proteins in each fraction were separated by electrophoresis, and prohibitin was visualized by Western blotting using prohibitin and phosphatidylserine (p-Ser) antibodies. Only the nuclear fraction exhibited phosphorylated prohibitin demonstrated by p-Ser Western blot (Figure 2.6, lanes 9 and 10). Mitochondrial, cytosolic, and microsomal prohibitins did not show phosphorylation. To confirm these data, we performed native gel electrophoresis and produced the same result (Figure 2.6, lanes 9 and 10). Mass spectrometry (MALDITOF-TOF) analysis revealed that S101 and S151 sites are phosphorylated (data not shown). 


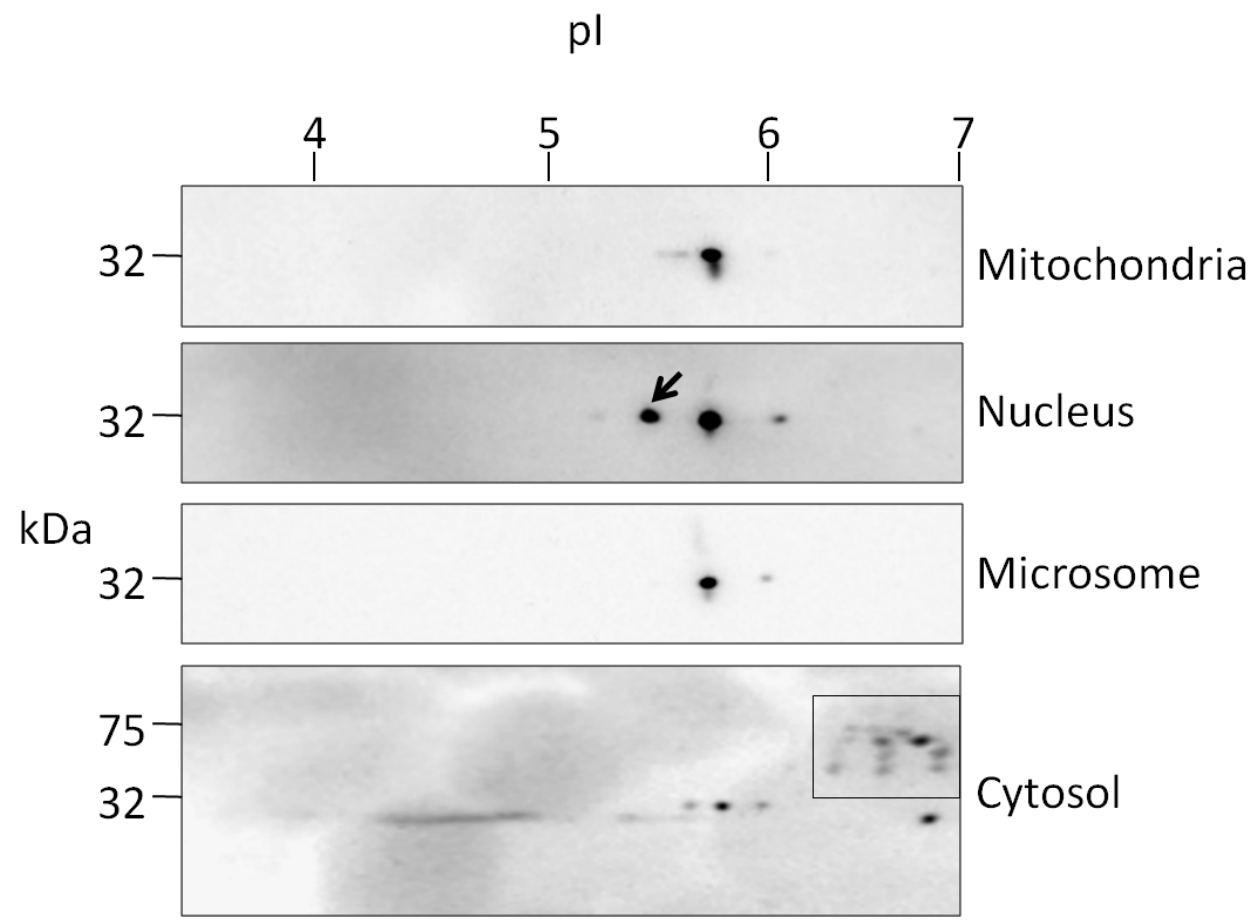

Figure 2.5 2D SDS-PAGE analysis of prohibitin. Each fraction from bovine retinal cells was separated by isoelectric focusing and gel electrophoresis. Prohibitin was visualized by Western blotting. The nuclear fraction showed phosphorylated prohibitin as one acidic spot at pI 5.3 shown by the arrow, whereas many modified prohibitin spots in the box were detected in the cytosolic fraction. 
A Denatured

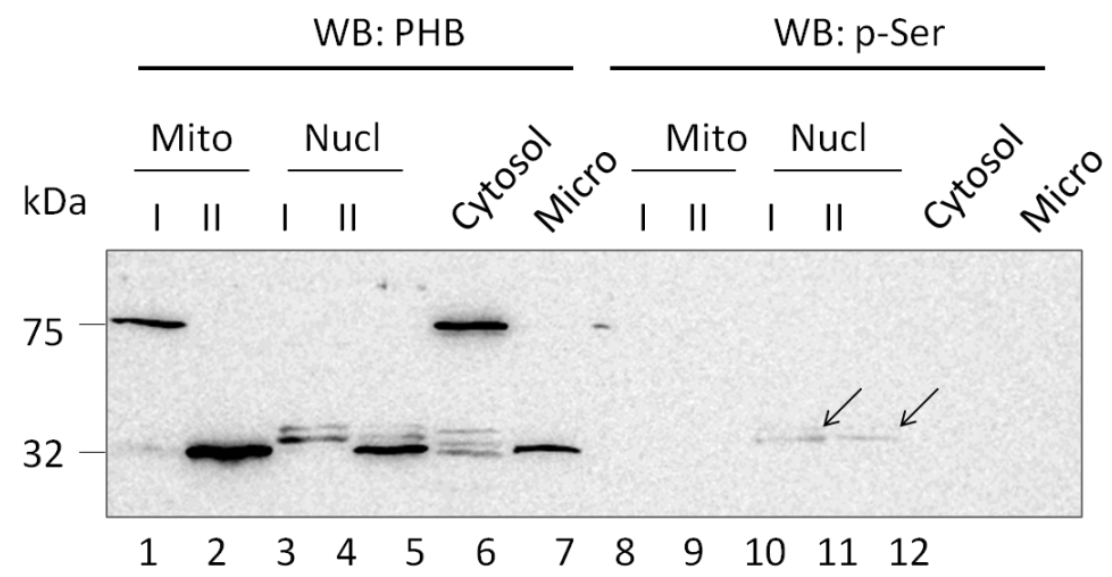

B

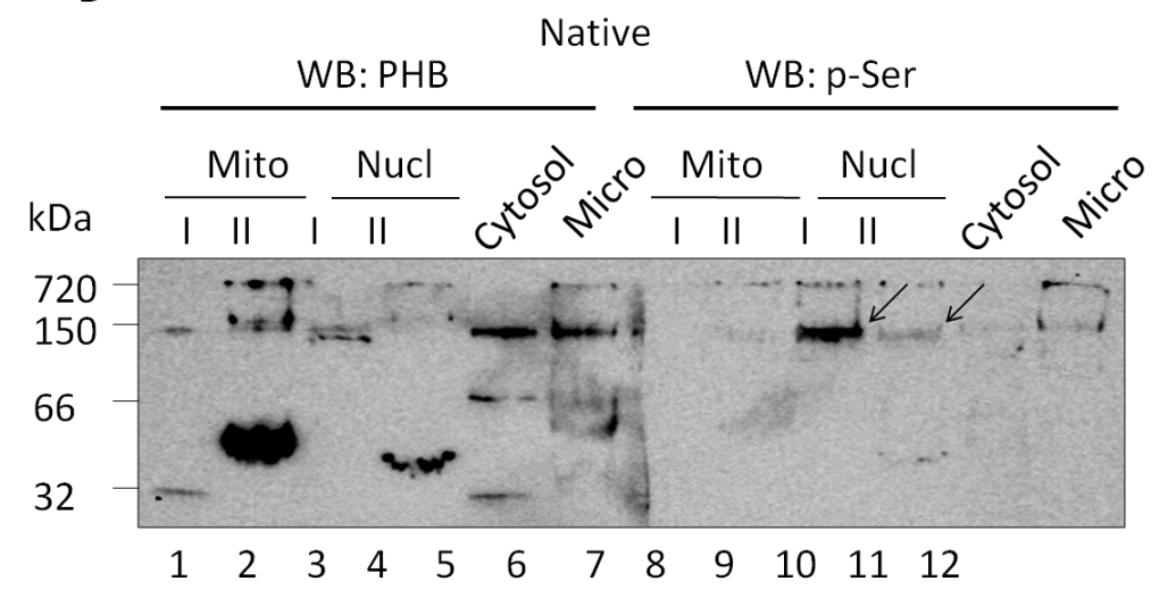

Figure 2.6 Phosphorylation of prohibitin in the nucleus. (A) Each fraction was further separated by SDS-PAGE and phospho-Western blotting. Prohibitin in the mitochondrial matrix (I) and cytosol shows a putative heterodimer at $75 \mathrm{kDa}$ under denaturing conditions, whereas nuclear prohibitin (supernatant I and membrane II) shows multiple bands due to modifications and membrane association. Prohibitin in the nuclear fraction was phosphorylated as shown by using the p-Ser antibody (lanes 9 and 10). (B) Proteins were separated by native gel electrophoresis, and prohibitin was visualized by Western blotting using the anti-prohibitin primary antibody and p-Ser antibody. Prohibitin in the nucleus is phosphorylated as shown in lanes 9 and 10. Prohibitin may exist as a heterodimer or oligomer as shown in lane 2 (mitochondrial membrane, 50, 150, and 750 $\mathrm{kDa}$ ), lane 3 (nuclear supernatant, $150 \mathrm{kDa}$ ), lane 5 (cytosol, 75 and $150 \mathrm{kDa}$ ), and lane 6 (microsome, $150 \mathrm{kDa}$ ). 


\subsubsection{Prohibitin Binds Cardiolipin under Oxidative Stress}

We next asked whether prohibitin localization could be controlled by membrane lipid binding. Considering mitochondrion- specific lipid composition, we speculated that the localization and trafficking of prohibitin might be determined by a mitochondrionspecific lipid such as cardiolipin. Prohibitin in the bovine retina binds with cardiolipin, a major mitochondrial phospholipid (Figure2.7A). The lipid interaction assay demonstrated that mitochondrial prohibitin from bovine retina has a strong affinity at relatively low cardiolipin concentrations (10-15 $\mu \mathrm{g}, 6-10 \mathrm{nmol})$, whereas nuclear prohibitin showed a weaker affinity for cardiolipin (Figure 2.7). However, prohibitins in RPE cells showed different lipid interactions under oxidative stress when we examined prohibitin using ARPE-19 cells. Under normal conditions, prohibitin from ARPE-19 cells demonstrated a strong interaction with phosphatidylinositol 3,4,5-triphosphate (PIP3) but not with cardiolipin (Figure 2.8). The lipid binding affinity changed dramatically under oxidative stress induced by $\mathrm{H}_{2} \mathrm{O}_{2}(200 \mu \mathrm{M})$. Prohibitin under stress showed a strong affinity for cardiolipin as shown in Figure 2.8. This observation led us to conclude that prohibitin has an affinity for negatively charged phospholipids, especially cardiolipin. Lipid analysis by mass spectrometry demonstrated that the cardiolipin concentration decreased $20-70 \%$ under $200 \mu \mathrm{M} \mathrm{H}_{2} \mathrm{O}_{2}$ (data not shown). 


\section{Cardiolipin concentration}

A
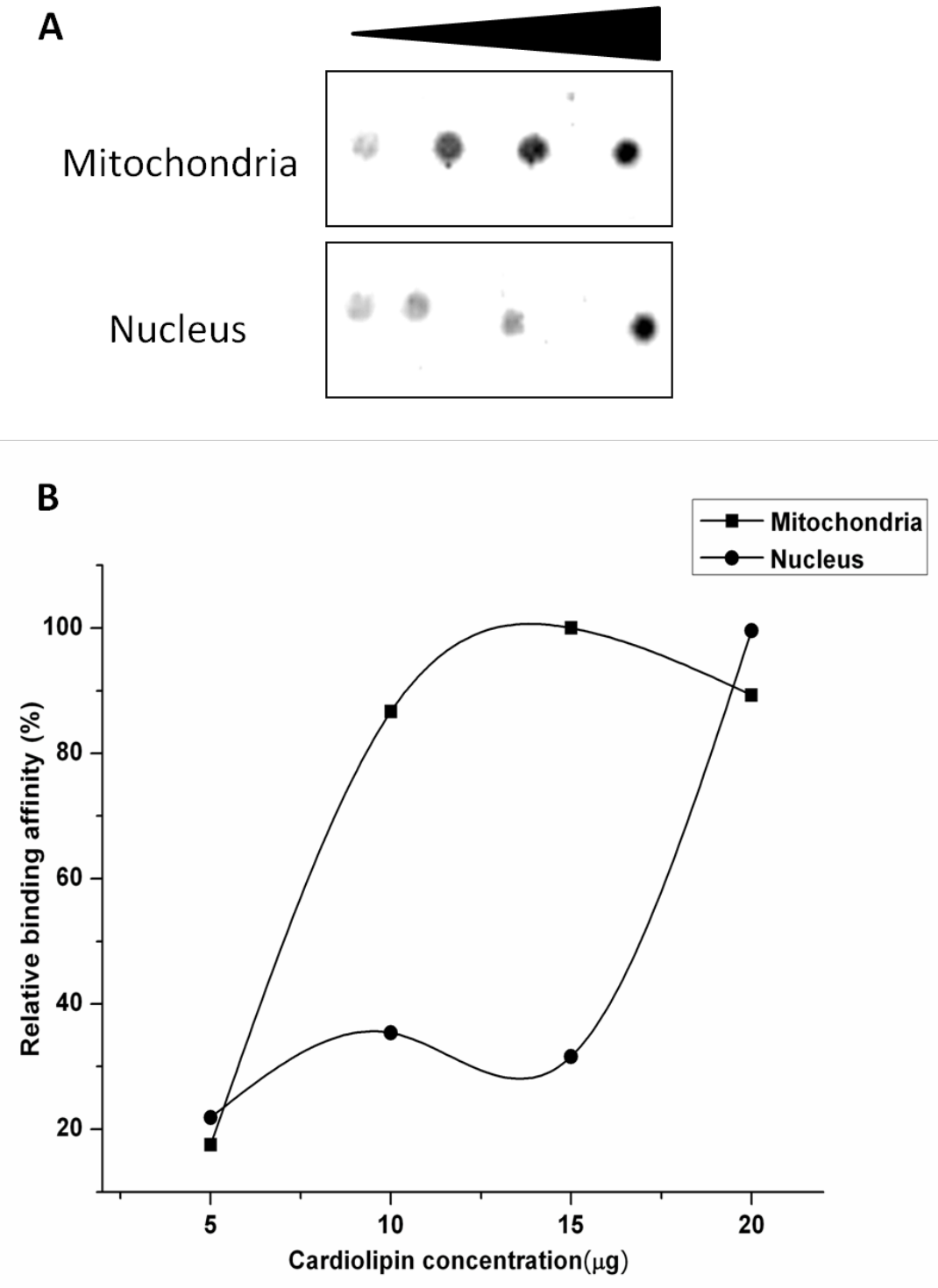

Figure 2.7 Prohibitin-cardiolipin interactions. (A) Prohibitin in the nucleus and mitochondria from bovine retina showed different cardiolipin affinities depending on the cardiolipin concentration. (B) Quantitative analysis of prohibitin-cardiolipin binding. Data for mitochondrial prohibitin ( $\bullet$ ) and nuclear prohibitin $(\bullet)$ are shown. The $Y$-axis represents the relative binding affinity and the $X$ axis the cardiolipin concentration. 


\section{A. Control}

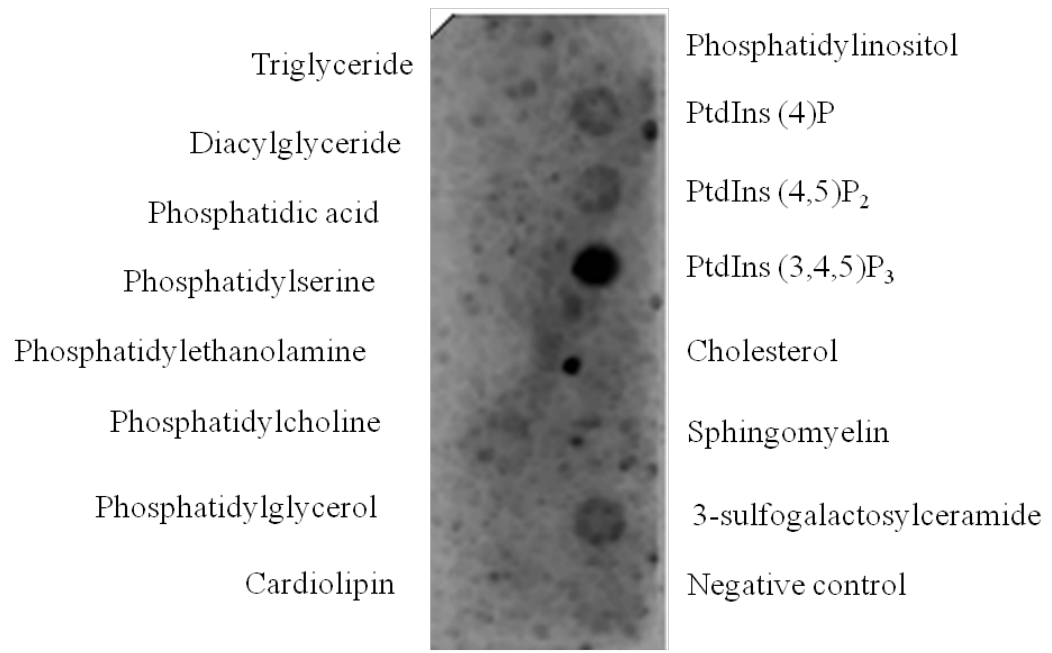

B. Oxidative Stress

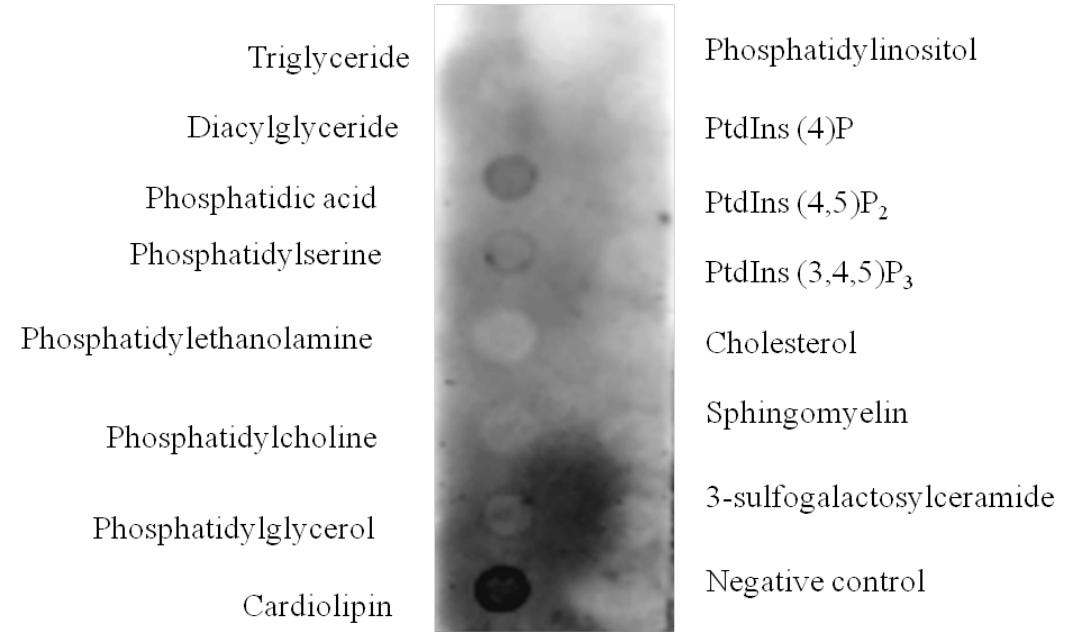

Figure 2.8 Fractionated or IP-purified proteins were incubated with the nitrocellulose membrane coated with various lipids. The membrane was incubated with immunoprecipitated prohibitin, and the lipid- prohibitin interaction was visualized by Western blotting. Prohibitin-lipid binding was changed under oxidative stress $(200 \mu \mathrm{M}$ $\mathrm{H}_{2} \mathrm{O}_{2}$ ). Under normal conditions, prohibitin interacts with phosphatidylinositol phosphates (PIP3), whereas under oxidative stress, prohibitin binds with cardiolipin.

\subsubsection{Anti-Apoptotic Prohibitin Function in Mitochondria}

We performed a loss of function study with prohibitin-specific small interfering RNA (siRNA), resulting in an increase in the level of apoptotic signaling at decreased prohibitin levels (Figure 2.9). We tested two siRNA constructs that inhibit prohibitin 
expression against a control siRNA that has a random sequence. A solvent vehicle was used as a negative control. We chose conditions under which the levels of prohibitin expression were reduced by $80-90 \%$ when compared to the random sequence control. We examined whether anti-apoptotic molecules such as BCL-xL and proapoptotic molecules that include apoptosis inducing factor (AIF), caspases, and BCL-2 homologous antagonist/killer (BAK) are also activated as essential markers in apoptosis (Figure 2.9). The activation of AIF and caspase-9 cleavage, the upstream regulators in apoptosis, showed early apoptotic signaling under prohibitin knockdown conditions. However, the level of anti-apoptotic BCL-xL decreased when prohibitin was downregulated. Further, we investigated whether prohibitin knockdown cleaves poly(ADP ribose) polymerase (PARP) as a pro-apoptotic marker. PARP cleavage is an early marker of caspase activation. Transfection of siRNA of prohibitin into ARPE-19 cells resulted in an increased level of cleavage of PARP, which represents the fact that an apoptotic signal is induced when prohibitin is downregulated (data not shown). Our results demonstrate that knockdown of prohibitin increases the strength of apoptotic signaling. These observations suggest that prohibitin may act as an anti-apoptotic protein in mitochondria by forming a functional complex with apoptotic proteins. The prohibitin concentration is inversely correlated with the initiation of apoptosis. Then we examined whether a decreased level of prohibitin disrupts the filamentous reticular network of mitochondria and results in fragmented mitochondria. Immunocytochemical analysis showed that prohibitin knockdown led to accumulation of fragmented mitochondria as shown in Figure 2.9B. Fragmented mitochondria imply that the fusion of mitochondrial membranes is impaired when the prohibitin concentration is decreased. 

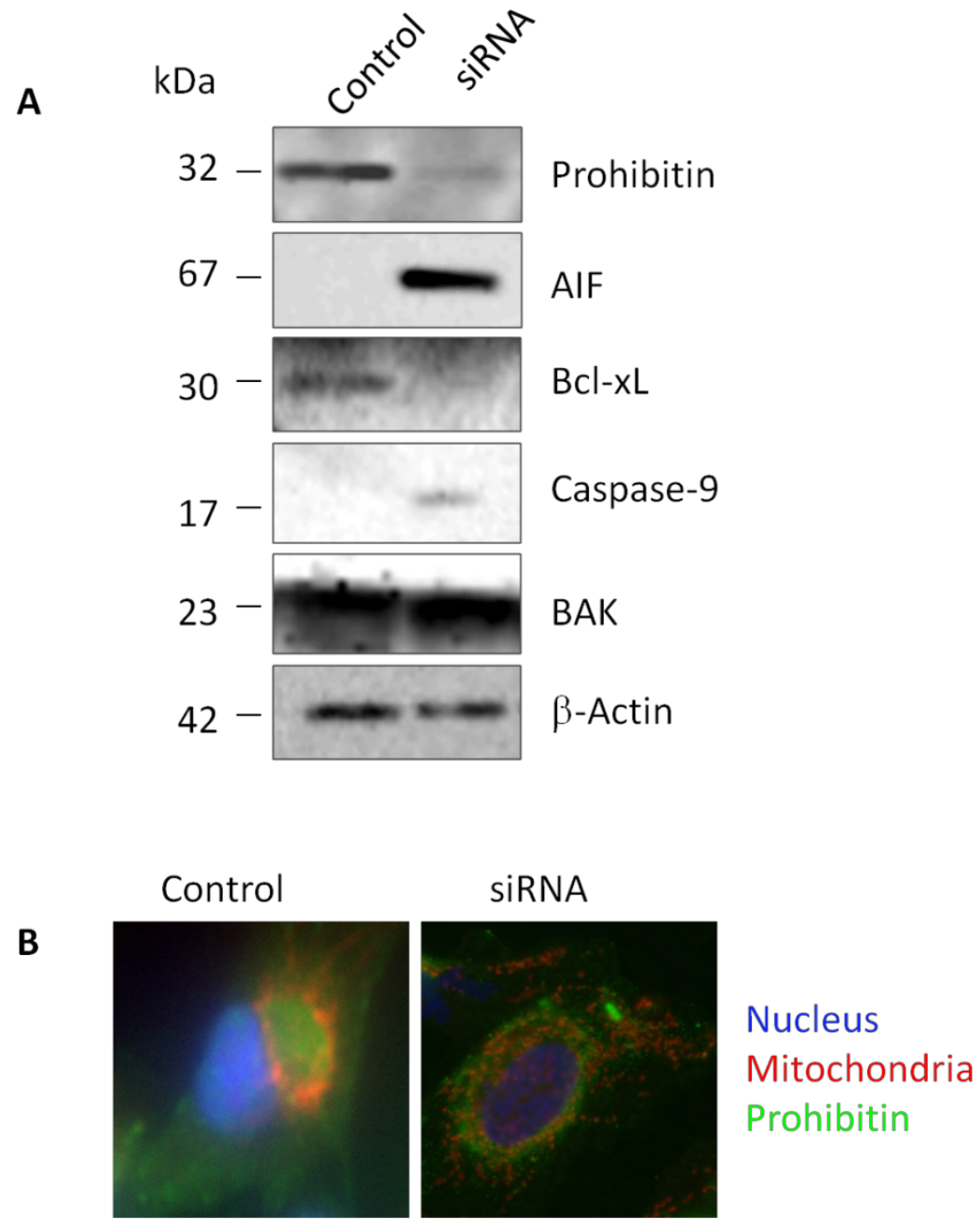

Figure 2.9 Anti-apoptotic prohibitin shown by knockdown analysis. (A) ARPE-19 cells were transfected by siRNA and random sequence. The level of anti-apoptotic BCL-xL increased when prohibitin was downregulated. Pro-apoptotic proteins, including AIF, caspase-9, and BAK, were upregulated under prohibitin knockdown conditions. (B) ARPE-19 cells under siRNA or random sequence were analyzed by immunocytochemistry. Prohibitin, mitochondria, and the nucleus were visualized by Alexa Fluor 488 (green), MitoTracker Orange (red), and DAPI (blue), respectively. When prohibitin was downregulated by siRNA, the mitochondrial structure was disrupted, and mitochondrial prohibitin was moved to the nuclear membrane. 


\subsubsection{Prohibitin Function in the Nucleus}

To address a putative functional role of prohibitin in the nucleus, protein- protein interaction was examined. Immunoprecipitation of prohibitin demonstrated that prohibitin is involved in direct regulation of transcription through p53 binding. The prohibitin-protein binding assay using the anti-prohibitin primary antibody, followed by SDS-PAGE, and mass spectrometry demonstrated that prohibitin has interactions with transcription factors that include tumor suppressor p53. A Western blot of immunoprecipitated fractions confirmed prohibitin-p53 interaction as shown in Figure 2.10. To test oxidized cardiolipin-dependent translocalization, we examined a known cardiolipin antioxidant etoposide. Etoposide is an antitumor drug that acts as a topoisomerase II inhibitor and is used to block cardiolipin oxidation and prohibitin translocalization. Treatment for $1 \mathrm{~h}$ induced translocalization of prohibitin from the nucleus to the cytosol.

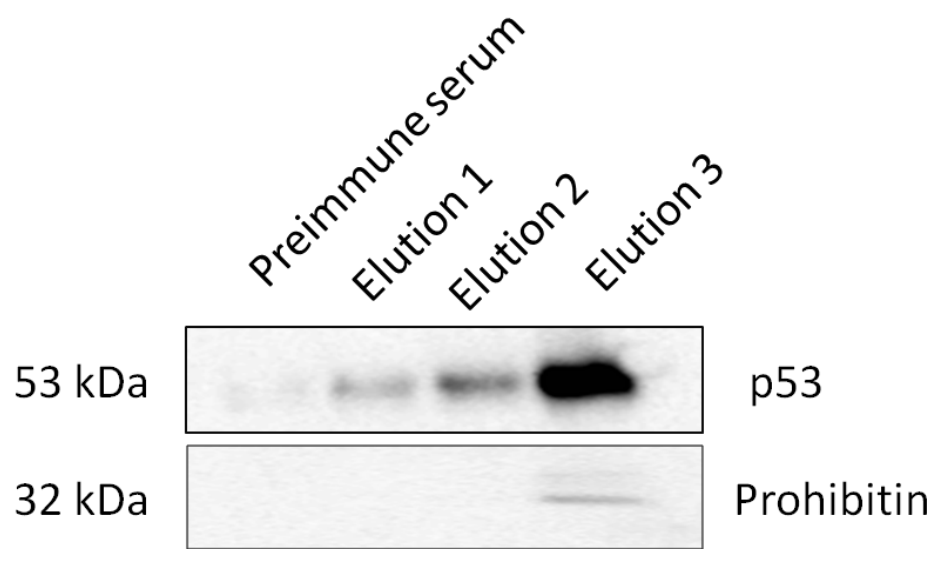

Figure 2.10 Binding of prohibitin to $\mathrm{p} 53$. Immunoprecipitation using the prohibitin antibody demonstrated the interaction between prohibitin and $\mathrm{p} 53$. The purified antiprohibitin antibody was immobilized with amino-linked protein A and washed. Protein samples were incubated in the protein $\mathrm{A}$-antibody column with gentle mixing overnight at $4{ }^{\circ} \mathrm{C}$. Columns were washed three times to remove nonspecific binding proteins. Eluted fractions were separated by SDS-PAGE and visualized by western blotting using primary antibodies against prohibitin and $\mathrm{p} 53$.

\subsection{Discussion}

In this study, we demonstrate that prohibitin is translocalized from mitochondria to the nucleus as a mitochondrial response to oxidative stress in vitro. Previously, we 
investigated oxidative stress-induced proteome changes in RPE cells using the differential gel electrophoresis (DIGE) technique to identify early biomarkers of eye diseases (Lee et al., 2010a; Ryan and Hoogenraad, 2007). We were seeking a novel protein that shuttles between mitochondria and the nucleus as the initiation step in retinal pathogenesis. We found that prohibitin changes its subcellular location under stress conditions. In this study, dynamic translocalization of prohibitin was examined by subcellular fractionation, immunocytochemistry, a lipid binding assay, and a knockdown approach. This study challenges a question of mitochondrial-nuclear (MT-NU) communication by protein translocalization through the lipid interaction change mechanism. Knockdown and immunoprecipitation studies suggest that trafficking prohibitin may have a dual function as an anti-apoptotic molecule that maintains mitochondrial structure and as a transcriptional activator that interacts with p53 in the nucleus. We tested the hypothesis that a lipid binding property of prohibitin may determine mitochondrial localization. As prohibitins are expected to be dynamically translocated within retinal and RPE cells, there is an essential need for a time-dependent assay of cellular prohibitin movement. Under oxidative stress, the level of cardiolipin decreased and the level of cardiolipin-prohibitin interactions increased. At relatively low cardiolipin concentrations $(<6-10 \mathrm{nmol})$, mitochondrial prohibitin competes with nuclear prohibitin for cardiolipin binding. We examined whether levels of prohibitin in mitochondria and the nucleus are altered by oxidative stress. We found that the level of prohibitin initially decreased by mild oxidative stress with $\mathrm{H}_{2} \mathrm{O}_{2}$ treatment especially at the $\mathrm{IC}_{50}$ concentration (Chung et al., 2009b; Lee et al., 2010a). Translocalization of prohibitin under stress conditions led us to investigate post-transcriptional regulation. A proteomics approach using SDS-PAGE and phosphor-Western blotting demonstrated that soluble nuclear prohibitin is phosphorylated. Gel electrophoresis under denatured or native conditions showed that prohibitin may exist as a heterodimer, soluble, membraneassociated, and post-translationally modified form in different subcellular organelles. Upregulation of pro-apoptotic molecules and down regulation of anti-apoptotic proteins under prohibitin depletion by siRNA suggest an anti-apoptotic response of prohibitin depending on the prohibitin levels. To maintain mitochondrial integrity, nuclear and 
mitochondrial genes should communicate with each other, especially under stress conditions that include hypoxia, abnormal temperature, nutrient deficiency, and aging. Our results suggest that prohibitin may fulfill dual roles as a phospholipid scaffold switch and an MT-NU shuttle under stress conditions in the retina and RPE cells. Coordinated prohibitin-lipid interactions, including cardiolipin and PIP3, support the phospholipid scaffold switch mechanism hypothesis (Osman et al., 2009; van Gestel et al., 2010). Cardiolipin, a negatively charged diphosphatidylglycerol-derived phospholipid, is mainly localized in mitochondria and plays a significant role in maintaining mitochondrial membrane function and structure. The level of cardiolipin decreases with aging and is involved in the upregulation of mitochondrially derived reactive oxygen species. Considering cardiolipin's role in mitochondria, it is reasonable to speculate that cardiolipin composition may affect targeted trafficking of mitochondrial proteins, especially under oxidative stress. The age-related decrease in the level of cardiolipin is correlated with increased cholesterol: phospholipid ratio (Shigenaga et al., 1994a). Cholesterol depletion using $\beta$-cyclodextrin and simvastatin upregulated prohibitin expression, and cholesterol treatment decreased the level of prohibitin in ARPE-19 cells (data not shown). Post-translational modifications that include hydrophobic palmitoylation and negatively charged phosphorylation may affect membrane binding and translocalization in subcellular organelles (Ande and Mishra, 2010; Lee et al., 2010b; Morrow et al., 2002; Xue et al., 2004). Consistent with our results, recent studies using proapoptotic peptide targeting prohibitin demonstrated that prohibitin might be connected to upregulation of lipid turnover and an increased metabolic rate (Kolonin et al., 2004a). Changes in cellular metabolism are a central hallmark in the aging process in the retina and RPE cells. When apoptosis was induced by prohibitin-peptide binding, it was shown that the levels of lipid metabolism, energy expenditure, oxygen consumption, and heat generation increased. Using Caenorhabditis elegans as a model system, it was reported that prohibitin depletion affected ATP levels, lipid content, and mitochondrial proliferation in an age-specific manner (Artal-Sanz and Tavernarakis, 2009b). Our results support the hypothesis that prohibitin may have a similar role in modulating mitochondrial structure by binding cardiolipin to maintain mitochondrial integrity under 
stress conditions. This study also demonstrated that prohibitin expression levels may determine the mitochondrial morphology and distribution as shown by the knockdown approach. Recent studies examined the versatile functions of prohibitin as a drug resistance mediator, plasma membrane receptor, obesity regulator, and cancer target (Artal-Sanz and Tavernarakis, 2009b; Gregory-Bass et al., 2008; Ko et al., 2010; Nuell et al., 1991; Patel et al., 2010; Terashima et al., 1994; Zubovych et al., 2006). A metabolic switch mechanism of prohibitin was shown by pyruvate carboxylase inhibition and PIP3 binding (Ande and Mishra, 2009). Prohibitin may modulate glucose and fatty acid oxidation by balancing between oxidative phosphorylation and anaerobic glycolysis under rapid proliferation, which are associated with malignant transformation (Mishra et al., 2006). Down regulation of prohibitin may activate a retrograde communication that induces mitochondrial proliferation and an increased level of reactive oxygen species (ROS) (Artal-Sanz and Tavernarakis, 2009a; Artal-Sanz et al., 2003; Coates et al., 1997; Fusaro et al., 2003b; Ikonen et al., 1995; Rajalingam et al., 2005; Sanchez-Quiles et al., 2010; Shigenaga et al., 1994b). A functional role for prohibitin in the nucleus was suggested as a transcriptional regulator by observation of its interactions with p53, E2F, and $\mathrm{Rb}$ (Fusaro et al., 2003a). In cancer cells, prohibitin is localized in the nuclear matrix (Shi et al., 2009). Cholesterol-induced downregulation of prohibitin was shown as a regulator of cell cycle transit in the nucleus (Dong et al., 2010; Sanchez-Quiles et al., 2010). Our previous study suggested that NF- $\kappa \mathrm{B}$ was translocated into the nucleus under oxidative stress, and protein translocalization may act as a cell survival mechanism under stress conditions (Lee et al., 2010a). Nuclear tumor suppressor p53 also translocalized into mitochondria under apoptotic conditions. The coordinated translocalization of prohibitin may determine cell viability and the apoptotic cell population in the retina and RPE cells. Prohibitin under oxidative stress and altered lipid environments may regulate the cell survival or death pathway by changing protein-lipid interactions. In the beginning of retinal degeneration, prohibitin may act as anti-apoptotic molecules as the default function in mitochondria, whereas it may become a transcriptional regulator under prolonged or repeated stress conditions. This dual function of prohibitin might be the essential mechanism for controlling apoptotic signaling as a cell fate determinant from 
uncontrolled proliferation as suggested by the conserved gene evolution in an oxidative environment (Di et al., 2010).

\section{Acknowledgements}

We thank Drs. Ramakrishna Wusirika, Mi Hye Song, Jeremy Goldman, Mike Gibson, and Manuela Bartoli for insightful discussions and sharing equipment. We thank Jackie Pribyl, Aram Kim, and Sulagna Gupta for their excellent technical assistance. Matthew Durocher is acknowledged for his suggestions and critical reading. 


\section{CHAPTER 3: NITRIC OXIDE LEADS TO CYTOSKELETAL \\ REORGANIZATION IN THE RETINAL PIGMENT EPITHELIUM UNDER OXIDATIVE STRESS ${ }^{2}$}

Srinivas R. Sripathi, Weilue He, Ji-Yeon Um, Trevor Moser, Stevie Dehnbostel, Kimberly Kindt, Jeremy Goldman, Megan C. Frost and Wan Jin Jahng

\footnotetext{
${ }^{2}$ The material included in this chapter was previously published in the journal Advances in Bioscience and Biotechnology, 2012, 3(8), pp 1167-1178. DOI: 10.4236/abb.2012.38143. Publication Date (Web): December 27, 2012. Copyright (C) 2012 Scientific Research Publishing Inc http://www.scirp.org/journal/PaperInformation.aspx?PaperID $=25832$ This study was supported by the Century II Equipment fund and the Research Excellence Fund of Michigan Technological University.
} 


\subsection{Abstract}

Light is a risk factor for various eye diseases, including age-related macular degeneration (AMD) and retinitis pigmentosa (RP). We aim to understand how cytoskeletal proteins in the retinal pigment epithelium (RPE) respond to oxidative stress and how these responses affect apoptotic signaling. Previously, proteomic analysis revealed that the expression levels of vimentin and serine/threonine protein phosphatase 2A (PP2A) are significantly increased when mice are exposed under continuous light for 7 days compared to a condition of $12 \mathrm{~h}$ light/dark cycling exposure using retina degeneration 1 (rd1) model. When melatonin is administered to animals while they are exposed to continuous light, the levels of vimentin and PP2A return to a normal level. Vimentin is a substrate of PP2A that directly binds vimentin and dephosphorylates it. The current study shows that upregulation of PP2Ac (catalytic subunit) phosphorylation negatively correlates with vimentin phosphorylation under stress condition. Stabilization of vimentin appears to be achieved by decreased PP2Ac phosphorylation by nitric oxide induction. We tested our hypothesis that site-specific modifications of PP2Ac may drive cytoskeletal reorganization by vimentin dephosphorylation through nitric oxide signaling. We speculate that nitric oxide determines protein nitration under stress conditions. Our results demonstrate that $\mathrm{PP} 2 \mathrm{~A}$ and vimentin are modulated by nitric oxide as a key element involved in cytoskeletal signaling. The current study suggests that external stress enhances nitric oxide to regulate PP2Ac and vimentin phosphorylation, thereby stabilizing or destabilizing vimentin. Phosphorylation may result in depolymerization of vimentin, leading to nonfilamentous particle formation. We propose that a stabilized vimentin might act as an anti-apoptotic molecule when cells are under oxidative stress.

\subsection{Introduction}

Intense light kills retinal and RPE cells through irreversible apoptotic reactions (Adrian et al., 1977; Grimm et al., 2002; Grimm et al., 2000; Noell et al., 1966; Young, 1988). Paradoxically light may protect the retina and RPE by controlling expression of antiapoptotic and anti-oxidative molecules, including erythropoietin, thioredoxin (THR), and heme oxygenase-1 (HO-1) (Grimm et al., 2002). Excess light may trigger circadian- 
dependent pathologic signals and oxidative stress by changing expression of proteases or proteins in the visual cycle that include caspases, rhodopsin, cellular retinaldehyde binding protein (CRALBP), and RPE65 (Chung et al., 2009b; Lee et al., 2010c; Zhang et al., 2010b). The mechanism of oxidative stress-induced apoptosis still remains elusive, but our previous proteomics approach implies that the protein expression profile, including BCL-xL, prohibitin, and vimentin, might be involved in the initiation of apoptosis as a positive or negative signal (Arnouk et al., 2011b; Chung et al., 2009b; Zhang et al., 2010b). Our studies suggest that the balance between anti- and pro-apoptotic proteins as well as the balance between oxidative stress and anti-oxidative shield may determine the cell fate based on external light/dark cycle environment. Apoptotic cell death induced by intense or constant light in the retina and RPE may lead to major diseases that cause blindness, including AMD and RP (Grimm et al., 2002; Grimm et al., 2000). Retinal and RPE cells have chromophores, including rhodopsin, peropsin, and retinal G protein receptor (RGR) that contain 11-cis-retinoid that can be isomerized by photons. Rhodopsin is a mediator of intense light-induced apoptosis and the activation of the transcription factor AP-1 complex (c-Fos/Jun) acts as a central downstream pathway for light-induced apoptosis. However, the mechanism by which light causes morphological alterations that initiate the death signal is elusive. Lack of such knowledge is an important issue, because without it, acquiring the ability to modulate cellular protection is highly unlikely. Thus there is an urgent need for the understanding of the molecular and biochemical mechanisms involved in light-induced cytoskeletal changes. Our previous studies suggest that post-translational nitration or phosphorylation may regulate cytoskeletal reorganization and protein trafficking under oxidative stress (Arnouk et al., 2011b; Chung et al., 2009b; Lee et al., 2010c; Sripathi et al., 2011c; Zhang et al., 2010b). Nitric oxide (NO) is a highly reactive free-radical gas that is involved in the expression of erythropoietin receptors (EPOR) in neurons from mouse brains (Chen et al., 2010; Genc et al., 2001). Recent studies suggest that NO plays a specific role in the protective pathway; however, it is nearly impossible to establish optimal levels of NO efficacy using current techniques. Clearly defining how much $\mathrm{NO}$ is needed and for what duration it is produced to induce up-regulation of protein phosphorylation is critical 
because excess levels of $\mathrm{NO}$ is toxic and will lead to tissue damage and cell death (Karnovsky, 1985; Sortino, 2010; Sugimoto et al., 2000). In the current study, NO produced by cells was detected continuously in situ using a chemiluminescence reaction between NO and ozone. We aimed to establish therapeutic levels of NO that induces upregulation of protecting molecules. The objective of our study is to answer the question whether NO prevents retinal degeneration by inducing or inhibiting phosphorylation signaling of target proteins. To attain the objective of this aim, we tested the working hypothesis that NO may have a dual role as a physiological neuroprotectant and a pathological cytotoxic compound depending on concentration and location. The levels of NO produced by RPE cells were directly measured under different levels of light or oxidative stimulation. We have quantitatively established what level and duration of NO accounts for its protective properties and at what level NO becomes pathological in RPE cell death. Our results suggest that NO is generated in RPE cells under various oxidative stress conditions in a time-dependent manner. Appropriate levels of NO control phosphorylation of vimentin and PP2A in the RPE that may lead to regulate stressdependent apoptotic pathways.

\subsection{Material and methods}

\subsubsection{ARPE-19 Cell Culture}

Human retinal pigment epithelial cells (ARPE-19) were obtained from American Type Culture Collection (Manassas, VA). Cells were cultured in $25 \mathrm{~cm}^{2}$ flask (Corning, St. Louis, MO) or $56.7 \mathrm{~cm}^{2}$ dishes (Nunc, Naperville, IL) containing Dulbecco's modified Eagle's medium (DMEM) supplemented with 10\% fetal bovine serum (Sigma, St. Louis, $\mathrm{MO}$ ) and $1 \%$ penicillin/ streptomycin (Hyclone, Logan, UT). Cells were maintained in humidified $5 \% \mathrm{CO}_{2}$ incubator at $37^{\circ} \mathrm{C}$.

\subsubsection{Light, oxidative stress, reoxygenation, and LPS treatment}

Confluent ARPE-19 cells were exposed to bright fluorescent light (7000 lux), tert-butyl hydroperoxide $(200 \mu \mathrm{M})$, reoxygenation ( 2 hrs hypoxic condition by $\mathrm{N}_{2}$ then $21 \% \mathrm{O}_{2}$ ) and LPS $(5-10 \mu \mathrm{g} / \mathrm{mL})$ in serum free medium for different time intervals in $\mathrm{CO}_{2}$ incubator. 
Cells grown in $25 \mathrm{~cm}^{2}$ flasks were used to measure NO release in situ. Cells were harvested to extract total proteins using ice cold 1X RIPA lysis buffer [0.5 M Tris- $\mathrm{HCl}$ (pH 7.4), $1.5 \mathrm{M} \mathrm{NaCl}, 2.5 \%$ deoxycholic acid, $10 \% \mathrm{NP}-40$, and $10 \mathrm{mM}$ EDTA(Millipore, Darmstadt, Germany)] containing protease inhibitor cocktail (Pierce, Rockford, IL). Cell lysates were centrifuged at $10,000 \mathrm{x}$ g for $30 \mathrm{~min}$ at $4{ }^{\circ} \mathrm{C}$ to pellet cell debris. Proteins were separated on sodium dodecyl sulfate-polyacrylamide gel electrophoresis (SDS-PAGE), followed by Western blotting analysis.

\subsubsection{Direct NO measurement}

NO release from ARPE-19 cells was measured via chemiluminescence detection with Sievers 280i Nitric Oxide Analyzer (GE Instruments, Boulder, CO) using $200 \mathrm{~mL} / \mathrm{min}$ ambient air with added 5\% $\mathrm{CO}_{2}$ sweep gas. $\mathrm{NO}$ analyzer was equilibrated with $5 \% \mathrm{CO}_{2}$ incubator for 30 minutes before the experiment. Prior to $\mathrm{NO}$ analysis, the instrument was calibrated three times using NO (45 PPM) and air by passing through a Sievers NO zero filters, followed by zero calibration. Confluent cells grown in T25 flask under oxidative environment (light; exposed to 7000 lux of fluorescent light, oxidative stress; treated with $200 \mu \mathrm{M}$ of $t$-butyl hydroperoxide, reoxygenation; $21 \% \mathrm{O}_{2}$ added at $2 \mathrm{hrs,} \mathrm{LPS}$; treated with $5 \mu \mathrm{g} / \mathrm{mL}$ of LPS) were directly connected to Nitric Oxide Analyzer using custom made adaptor. The amount of released NO is measured in PPB (parts per billion) and is converted to mole per surface area by a calibration factor $\left(\mathrm{nmole} \cdot \mathrm{cm}^{-2} \cdot \mathrm{min}^{-1}\right)$ then represented by graphs using MATLAB software. To determine intracellular NO formation using a fluorescent molecule, cells were incubated in media containing 4,5diaminofluorescein-2-diacetate (DAF-2DA, $5 \mu \mathrm{M}$, Sigma) for $15 \mathrm{~min}$ after stress treatment (12,000 lux light, $24 \mathrm{hrs)}$. After washing three times with PBS, cells were fixed with $2 \%$ glutaraldehyde for 3 min. Images were acquired using Zeiss Axiovert 200M Apo Tome fluorescent microscope with $63 \mathrm{X}$ magnifications.

\subsubsection{SDS-PAGE and Western Blot analysis}

Proteins were quantified using BCA protein assay kit (Pierce) based on the manufacturer's protocol by plotting BSA standard curve. Samples were dissolved in 4X 
Laemmli sample buffer (240 mM Tris pH 6.8, 8\% SDS, 40\% glycerol, $0.4 \%$ bromophenol blue, $10 \% \beta$ - mercaptoethanol), heated at $90^{\circ} \mathrm{C}$ for $10 \mathrm{~min}$. Proteins were resolved using $10 \%$ or $8-16 \%$ gradient polyacrylamide precast gels (Bio-Rad), followed by electrotransfer on to the methanol activated PVDF membrane (Bio-Rad) via semidry transfer by applying $20 \mathrm{~V}$ for $30 \mathrm{~min}$. Non-specific proteins were blocked for $1 \mathrm{hr}$ at $4^{\circ} \mathrm{C}$ with 5\% nonfat dry milk (Bio-Rad) prepared in TBS with $0.1 \%(\mathrm{v} / \mathrm{v})$ Tween-20. Membranes were probed with primary antibodies (Santa Cruz Biotechnology Inc, CA), including iNOS (sc-651; 1:100), Nitrotyrosine (sc-32731; 1:25), p-vimentin (sc-16673; 1:500), p-PP2Ac (sc-12615; 1:500), Bcl-xL (sc-634; 1:500) and $\beta$-actin (sc-47778; 1:1000) at $4{ }^{\circ} \mathrm{C}$ for overnight and subsequently incubated with corresponding horse radishperoxidase conjugated secondary antibodies for $2 \mathrm{~h}$ at room temperature. Membranes were developed with West Pico Chemiluminescent Substrate (Pierce) for 2 min and immunoreactive protein bands were visualized using a LAS $4000 \mathrm{mini}$ luminescent image analyzer (GE, Piscataway, NJ). Bands were quantified based on pixel size/intensity/area using Quantity One software (Bio-Rad) and graphs were plotted based on relative intensity of bands using GraphPad Prism software.

\subsubsection{Immunocytochemistry}

ARPE-19 cells were seeded on sterile glass cover slips placed in 6 well plate (Nunc, 10 $\mathrm{cm}^{2}$ per well) with serum containing DMEM/F12 media supplemented with $1 \%$ penicillin-streptomycin (Hyclone) $5 \% \mathrm{CO}_{2}$ incubator at $37{ }^{\circ} \mathrm{C}$. Cells were treated with $200 \mu \mathrm{M}$ of tert-butyl hydroperoxide for 36 or $48 \mathrm{~h}$ to induce oxidative stress. Cells were fixed with $10 \%$ formaldehyde in PBS for $30 \mathrm{~min}$ at RT. After fixation, cells were incubated in $0.2 \%$ Triton X-100 (Sigma) for 25 min to permeabilize cell membrane and blocked with complete media containing 10\% FBS and 0.05\% Tween-20 (Sigma) for $1 \mathrm{hr}$ and probed with anti-iNOS, anti-vimentin antibody (1:100; Santa Cruz) for overnight at $4{ }^{\circ} \mathrm{C}$. Subsequently, cells were stained with Alexa Fluor 488- conjugated anti-rabbit IgG (1:700, Molecular Probes) for $2 \mathrm{hrs}$ at RT. Finally, immunostained samples were mounted

using Vectashield (Vector Laboratories, Burlingame, CA) mounting medium containing DAPI (4, 6-diamidino-2-phenylindole) to counterstain the nucleus. Images were captured 
using fluorescent microscope (Zeiss AxioVert 200 M Apo Tome) with 20X magnification.

\subsubsection{Scanning Electron Microscopy (SEM)}

ARPE-19 cells were cultured on coverslips in 6 well plate (Nunc, $10 \mathrm{~cm}^{2}$ per well). Cells were treated with $100 \mu \mathrm{M}$ of $\mathrm{H}_{2} \mathrm{O}_{2}$ in serum free media for $2 \mathrm{hrs}$ to induce oxidative stress. Sample preparation protocol was followed as previously reported(Karnovsky, 1985). After brief wash with PBS, cells were immersed immediately into fixative solution containing $3 \%$ paraformaldehyde and $0.1 \%$ glutaraldehyde in phosphate buffer $(\mathrm{pH} 7.1)$ at RT for $1 \mathrm{hr}$. Samples were removed from the fixing solution and washed three times with PBS and then post fixed in $1 \%$ osmium tetroxide in $0.2 \mathrm{M}$ phosphate buffer. After three additional brief washings in distilled $\mathrm{H}_{2} \mathrm{O}$, cells were dehydrate in a graded EtOH$\mathrm{H}_{2} \mathrm{O}$ series and then critical-point-dried in a $\mathrm{CO}_{2}$ chamber. Cells were coated with a 10 $\mathrm{nm}$ layer of platinum-palladium alloy in a vacuum evaporator to examine in the scanning electron microscope (JEOL JSM-6400) at 4000X magnification.

\subsection{Results}

\subsubsection{NO Production in the RPE under Oxidative Stress}

To address the issue of the protective and pathological roles of NO in neurodegeneration, we directly measured NO produced by RPE cells exposed to different stresses. First we asked how much NO is generated and what duration it is produced under various environmental stimuli. We aimed to establish therapeutic or cytotoxic levels of $\mathrm{NO}$ that induce up-or down-regulation of phosphorylation signaling of vimentin and PP2A. NO produced by RPE cells were determined in situ after exposure to each of following: dark, light, oxidative stress, reoxygenation, and lipopolysaccharide (LPS) as shown in Figure 3.1A. Cells exposed to dark conditions did not show any detectable increase of NO levels. Cells treated with light (7000 lux) showed an increase in NO concentration after $19 \mathrm{hrs}$ of exposure. Cells treated with $200 \mu \mathrm{M}$ tert-butyl hydroperoxide (t-BuOOH, oxidative stress) showed an increase in NO concentration at 16, 18, and $20 \mathrm{hrs.} \mathrm{Based}$ on the observation of the increased levels of NO, oxidative stress and light play a positive regulatory role in the production of NO by ARPE-19 cells. NO generation positively 
correlates with our Western blotting analysis of iNOS under light and oxidative stress. Cells treated with reoxygenation after hypoxic conditions (nitrogen stream for 2 hours) before being exposed back to normoxia $\left(21 \% \mathrm{O}_{2}\right)$ showed the greatest elevation in NO production, immediately after reoxygenation at $2 \mathrm{hrs}$ and remained active for $20 \mathrm{hrs}$. This data suggests that $\mathrm{O}_{2}$ is the limiting factor for NO synthesis in RPE cells. 
A
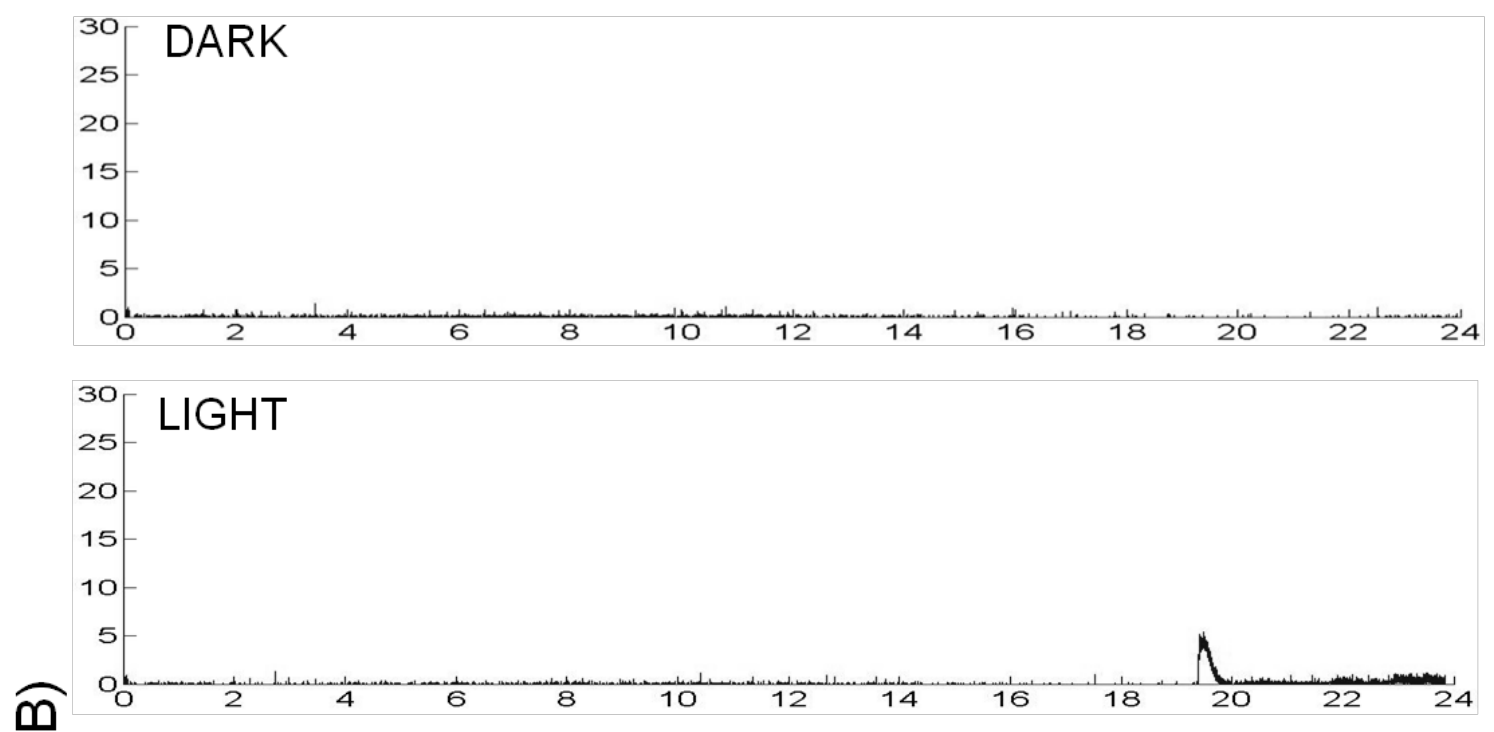

$\stackrel{0}{\mathbb{n}}_{25}^{30}$ - OXIDATIVE STRESS

(1) 20

ปั 15

$\frac{1}{d} 10$

$\stackrel{\square}{\alpha}$

Z
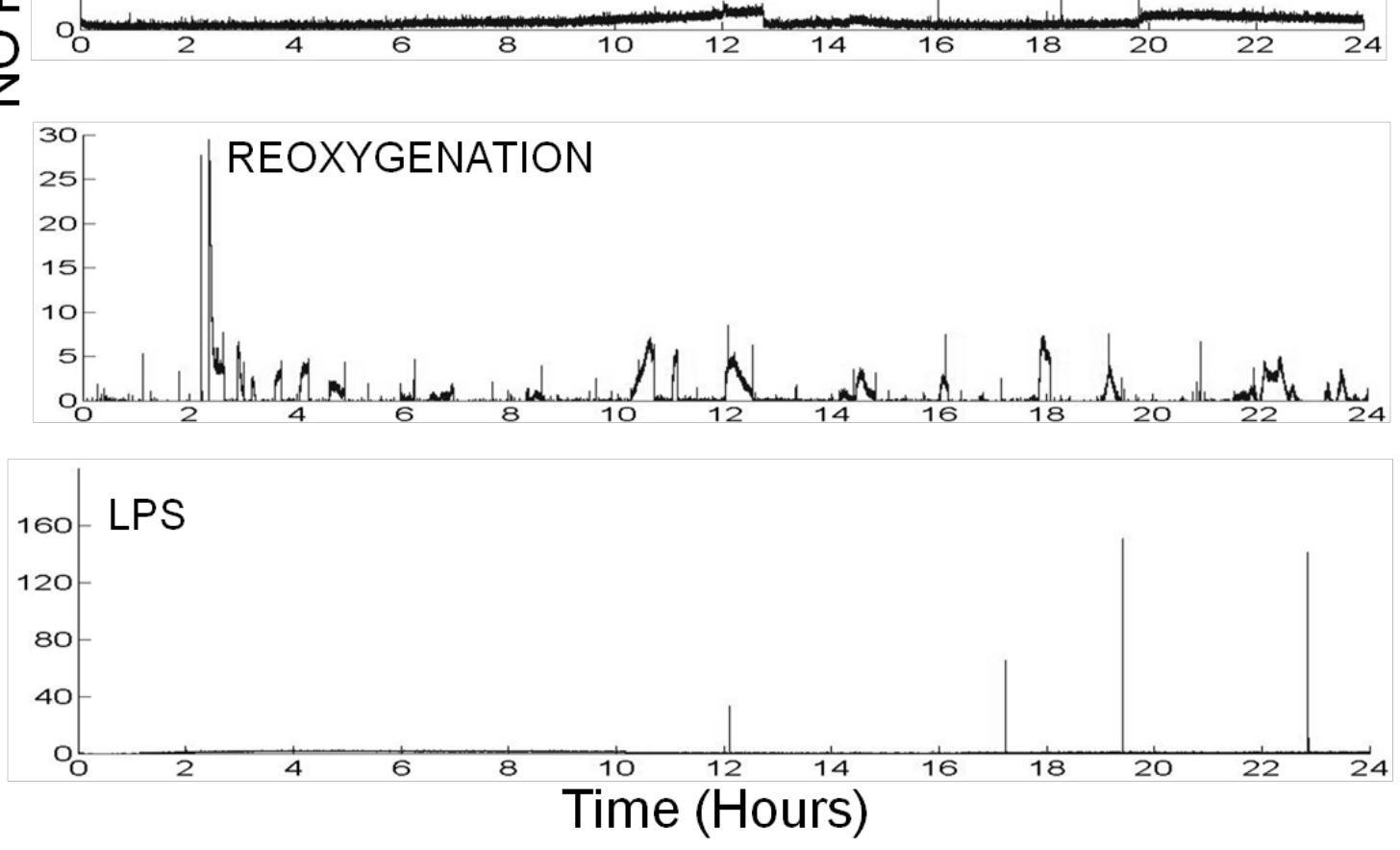
B

\begin{tabular}{|c|c|c|}
\hline Conditions & $\begin{array}{c}\text { NO released } \\
(\mathrm{PPB})\end{array}$ & $\begin{array}{c}\text { NO surface flux } \\
\left(\mathrm{nmole} /\left(\mathrm{min}^{*} \mathrm{~cm}^{\wedge} 2\right)\right.\end{array}$ \\
\hline Dark & 350 & 0.9 \\
\hline Light & 5884 & 14.8 \\
\hline Oxidative stress & 6761 & 17.0 \\
\hline Reoxygenation & 46223 & 116 \\
\hline LPS & 64236 & 162 \\
\hline
\end{tabular}

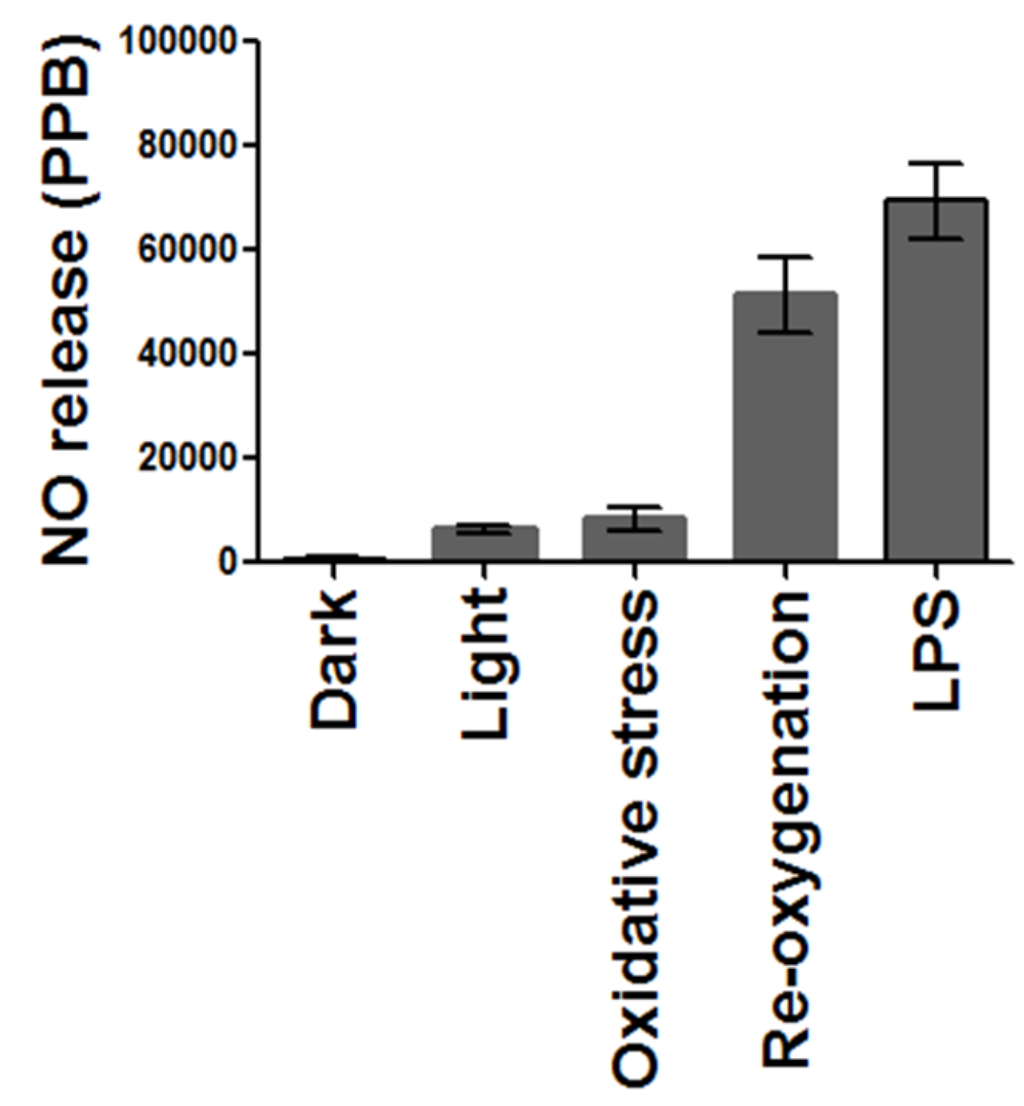



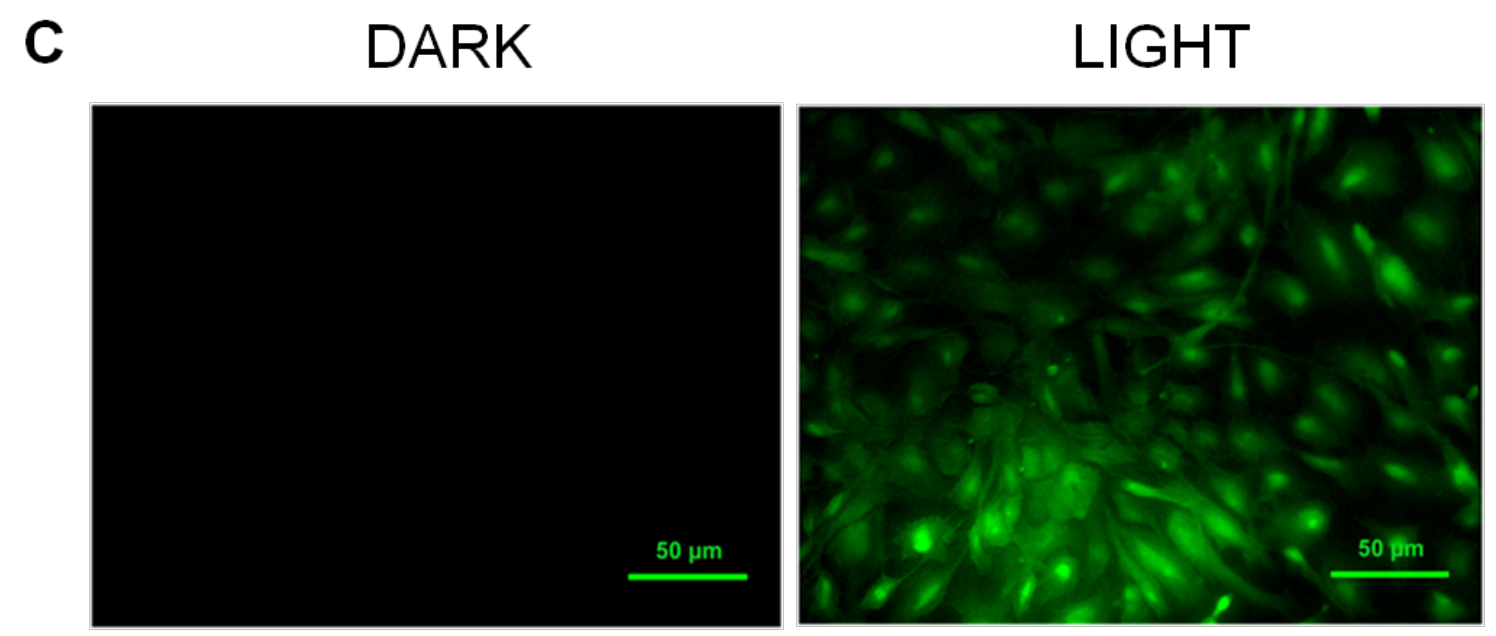

Figure 3.1 A. Dark, light, oxidative stress, reoxygenation, and LPS induced NO production in vitro. Confluent ARPE-19 cells cultured in T-25 flasks were incubated under intense light (7000 lux), oxidative stress $(200 \mu \mathrm{M} t \mathrm{BuOOH})$, reoxygenation (hypoxia by $\mathrm{N}_{2}$ flow for $2 \mathrm{hrs}$ then $\left.21 \% \mathrm{O}_{2}\right)$ and lipopolysaccharide $(5 \mu \mathrm{g} / \mathrm{mL})$ in humidified $5 \% \mathrm{CO}_{2}$ chamber. Released $\mathrm{NO}$ from cells was detected each second for total $24 \mathrm{hrs}$ using Nitric Oxide Analyzer 280i. NO released from cells reacts with ozone to produce $\mathrm{NO}_{2}$ and a photon as a chemiluminescence signal which is proportional to NO concentration. $\mathrm{X}$-axis represents time (hrs) and $\mathrm{Y}$-axis represents concentration in parts per billion (PPB). B. Quantitative analysis of NO released (PPB) and NO surface flux $\left(\mathrm{nmole} /\left(\mathrm{min}^{*} \mathrm{~cm}^{\wedge} 2\right)\right)$ under intense light, oxidative stress, reoxygenation, and lipopolysaccharide condition. C. Light induced NO detection by 4, 5-diaminofluorescein diacetate (DAF-2DA). ARPE-19 cells were treated with the dark or intense light $(12,000$ lux) conditions. Cells were incubated with $5 \mu \mathrm{M} 4,5$ diaminofluorescein diacetate (DAF2DA) (excitation at 470 to $490 \mathrm{~nm}$ and emission at $515 \mathrm{~nm}$, green) for 15 min followed by fixation with $2 \%$ glutaraldehyde to detect $\mathrm{NO}$ levels under light induced stress.

As a positive control for NO production, cells were treated with LPS $(5 \mu \mathrm{g} / \mathrm{mL})$, which also stimulated secretion of NO. NO secretion occurred at 12, 17, 19.5, and 23 hours. This was the most significant increase in NO secretion for any of the conditions tested. A quantitative analysis of NO release is shown in Table 1.1. Light induced intracellular NO in the RPE was detected using 4, 5-diaminofluorescein 2- diacetate (DAF-2DA) as shown in Figure 3.1B. Detection of intracellular NO in living cells using DAF-2DA is a recently developed method in combination with aldehyde fixation. Our fluorescent analysis illustrated that RPE cells exposed to intense light (12,000 lux) generated higher levels of intracellular NO compared to dark control. The control in the 
dark did not show any detectable fluorescence, provides the direct evidence that RPE cells under intense light generate NO.

\subsubsection{Treatment with LPS, tert-butyl hydroperoxide (t-BuOOH) and light upregulates inducible nitric oxide synthase (iNOS) in the RPE}

Since NO generation is controlled by iNOS, expression changes of iNOS in response to external stimuli were analyzed by Western blotting. As shown in Figure 3.2A, LPS, oxidative stress, and light treatment significantly upregulated iNOS expression in RPE cells in concentration or time-dependent manner. Levels of iNOS expression are also consistent with NO production in RPE cells. iNOS is responsible for the conversion of L-arginine to NO and citrulline in the cell. ARPE-19 cells were treated with light $(7,000$ lux) for 12 and 18 hours, as well as a control that had no light exposure (Figure 3.2B). Light exposed cells had higher levels of iNOS expression compared to time 0 controls, with $18 \mathrm{hrs}$ having a higher concentration than $12 \mathrm{hrs}$ and the control showed no visible band of iNOS. Another group of ARPE-19 cells were treated with oxidative stress in the form of $200 \mu \mathrm{M}$ t-BuOOH, or LPS at either 5 or $10 \mu \mathrm{g} / \mathrm{mL}$. A control sample showed no iNOS at $130 \mathrm{kDa}$, while the samples treated with oxidative stress and LPS showed iNOS, suggesting an upregulation of iNOS due to these conditions. LPS exposure caused the most significant increase in iNOS upregulation. 
A
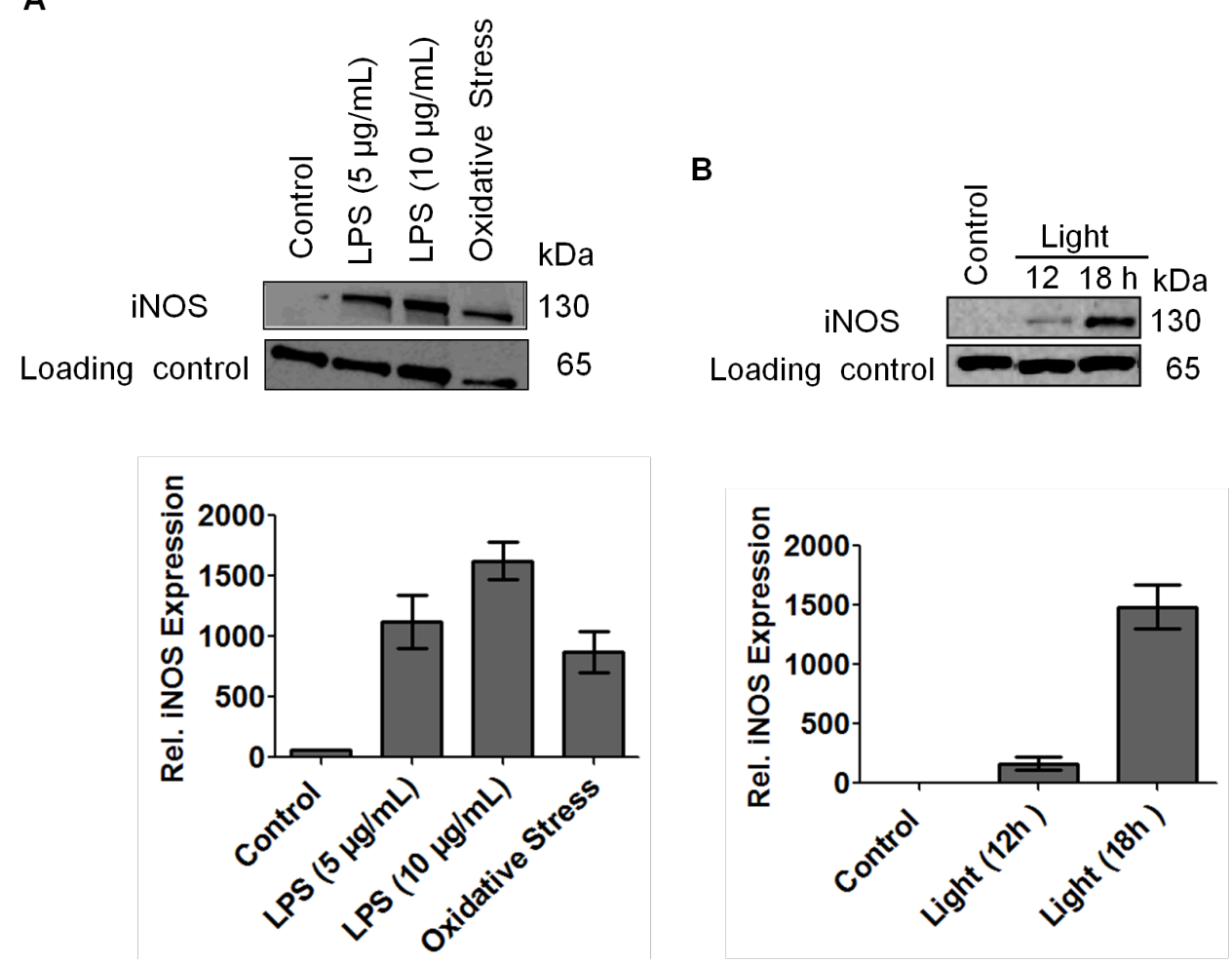

Figure 3.2 Expression of inducible nitric oxide synthase (iNOS) under LPS, oxidative stress and light treatment. ARPE-19 cells were treated with LPS ( 5 or $10 \mu \mathrm{g} / \mathrm{mL}$ for 24 hrs), tert-butyl hydroperoxide (200 $\mu \mathrm{M}$ for $24 \mathrm{hrs}$ ), and intense light (1000 lux for 24 hrs). Cells were harvested, lysed and proteins were separated by SDS-PAGE. Expression of iNOS $(130 \mathrm{kDa})$ was visualized by western blotting using rabbit polyclonal anti-iNOS antibody. A low molecular weight non-specific band at $65 \mathrm{kDa}$ was used as a loading control. A. Oxidative stress induced expression of iNOS in RPE cells. B. Light induced iNOS expression in RPE cells. Bands were quantified based on pixel size/intensity/area using Quantity One software (Bio-Rad). Graphs were plotted based on relative iNOS expression using GraphPad Prism software.

\subsubsection{Expression and localization of iNOS under oxidative stress}

We tested our hypothesis whether oxidative stress controls iNOS expression in RPE cells by using immunocytochemical analysis. Our fluorescent images show that iNOS expression increased under oxidative stress $(200 \mu \mathrm{M}, t$-BuOOH$)$ compared to untreated control as shown in figure 3.3A. A negative control without anti-iNOS primary antibody confirmed that our immunocytochemical images are iNOS-specific (Figure 3.3B). Nucleus staining with DAPI revealed cytoplasmic localization of iNOS. 


\subsubsection{Oxidative stress induced protein nitration shown by 3 -nitrotyrosine in the RPE}

Formation of 3-nitrotyrosine is a post-translational modification caused by NO derived peroxynitirite during pathophysiological conditions, which in turn alters protein structure and function. Our Western blotting analysis showed that relative protein nitration increased in $30,35,37 \mathrm{kDa}$ proteins and other proteins $(55,32,20,18,10 \mathrm{kDa})$ under oxidative stress (Figure $3.4 \mathrm{~A}$ ). Reduction (3-nitro tyrosine to 3-amino tyrosine) with disodium dithionite $\left(\mathrm{Na}_{2} \mathrm{~S}_{2} \mathrm{O}_{4}\right)$ confirmed the increased protein nitration in LPS, light and oxidative stress treated samples (Figure $3.4 \mathrm{C}$ ). 


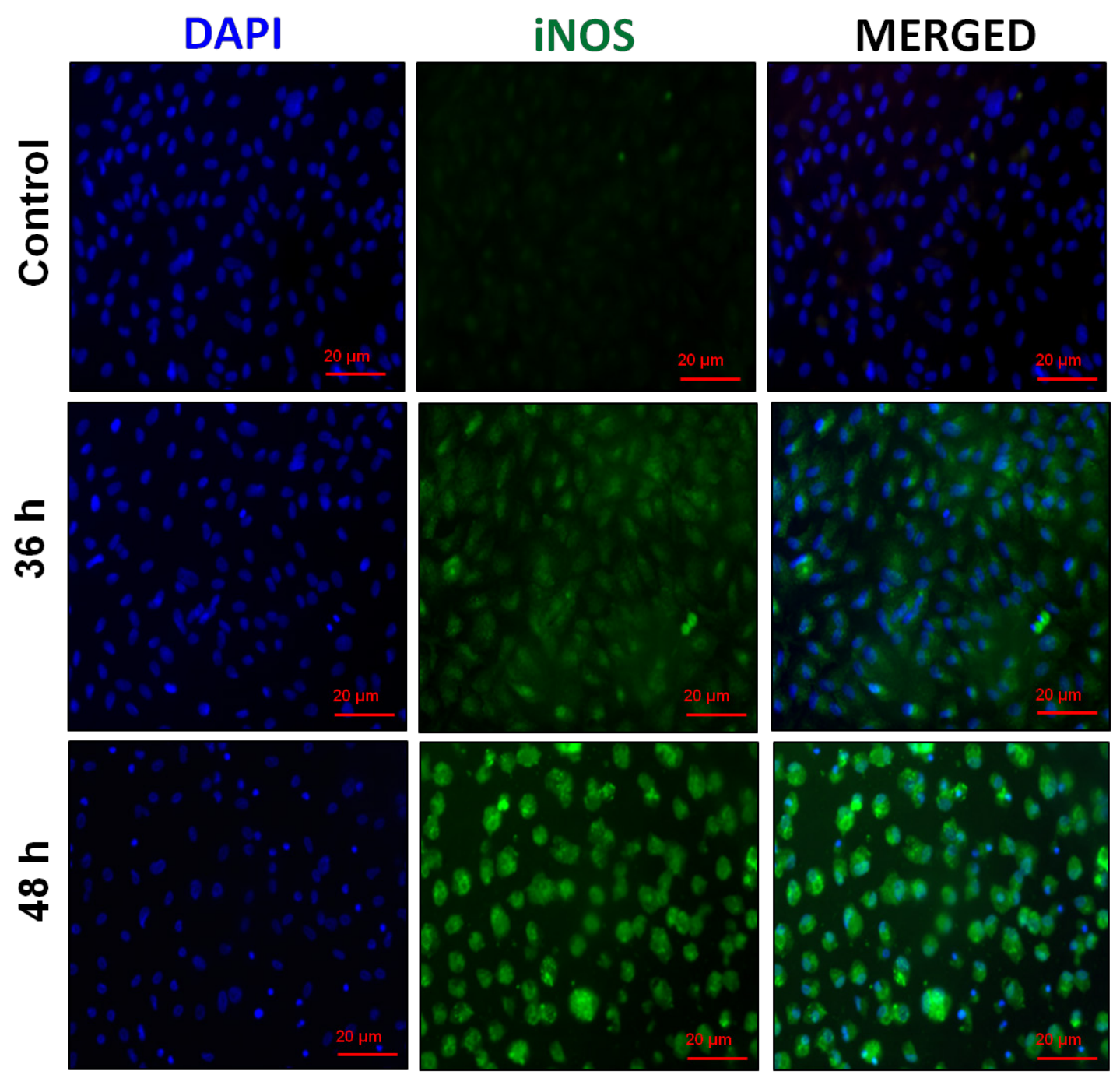

Figure 3.3A Increased expression of inducible nitric oxide synthase (iNOS) under oxidative stress. ARPE-19 cells treated with tert-butyl hydroperoxide (200 $\mu \mathrm{M}$ for 36 or $48 \mathrm{hrs}$.) were analyzed by immunocytochemistry. Expression of iNOS is visualized by the iNOS specific primary antibody, the Alexa Fluor 488-conjugated secondary antibody (green, iNOS) and DAPI (blue, nucleus) staining. Expression of iNOS was observed under oxidative stress condition in a time-dependent manner. Scale bars represent $20 \mu \mathrm{m}$. 

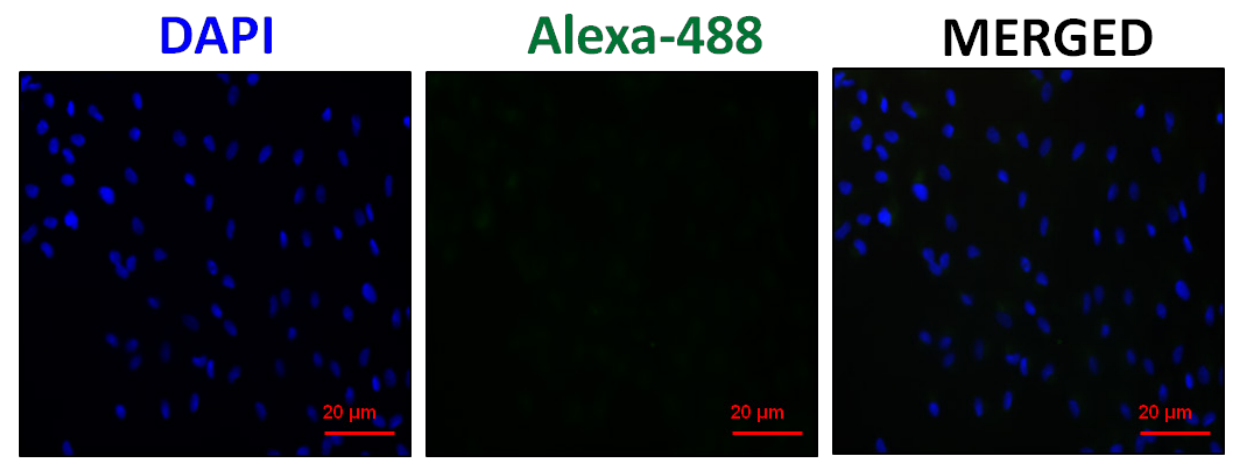

Figure 3.3B Negative control of iNOS immunocytochemistry. iNOS expression in RPE cells was confirmed by immunocytochemistry with Alexa-488 secondary antibody and without anti-iNOS antibody as a negative control. Absence of green fluorescence demonstrates that there are no non-specific binding proteins with Alexa-488 secondary antibody. DAPI (blue) represents counter staining for the nucleus. Scale bars represent 20 $\mu \mathrm{m}$.

A

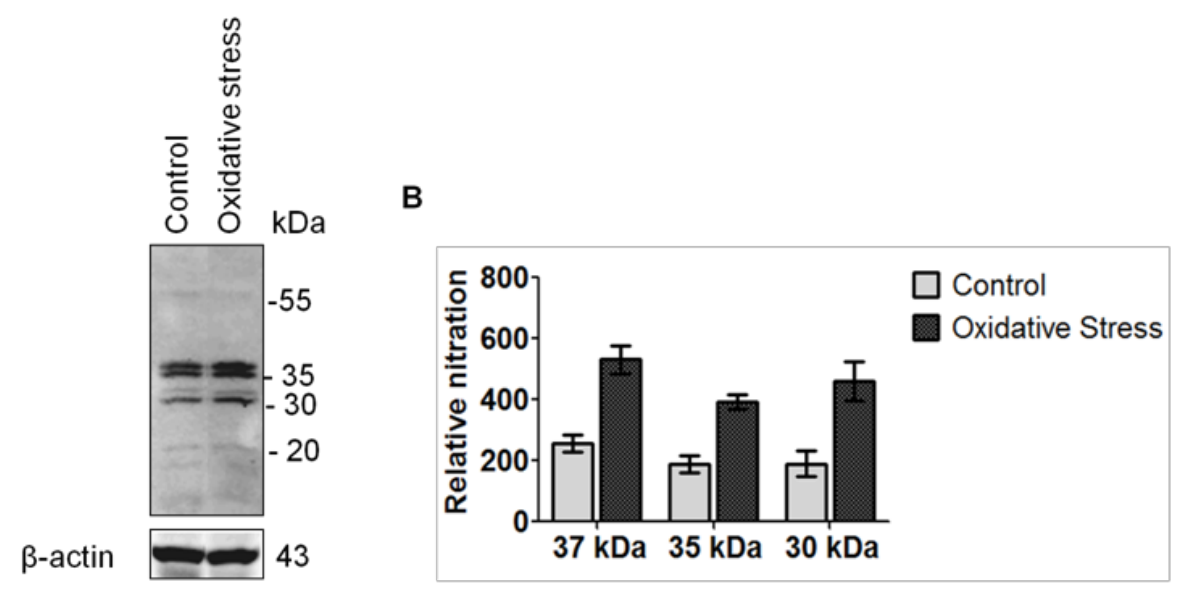

Figure 3.4 A Increased protein nitration in RPE under oxidative stress. ARPE-19 cells were treated with tert-butyl hydroperoxide ( $200 \mu \mathrm{M}$ for $36 \mathrm{~h})$. Cells were harvested, lysed and proteins were separated by SDS-PAGE. A. Proteins with 3-nitrotyrosine were visualized by Western blotting using anti-3-nitro tyrosine antibody (1:50 dilution). Expression levels of nitrated proteins increased 2-3 folds under oxidative stress compared to untreated control. Protein loading was controlled by probing with anti- $\beta$ actin antibody. B. Bands represent the expression of nitrated proteins quantified by pixel intensity and area using Quantity One software (Bio-Rad). Quantitative analysis shows 23 fold increased expression of nitrated proteins under oxidative stress compared to the untreated control. Graphs were plotted using GraphPad Prism software. 


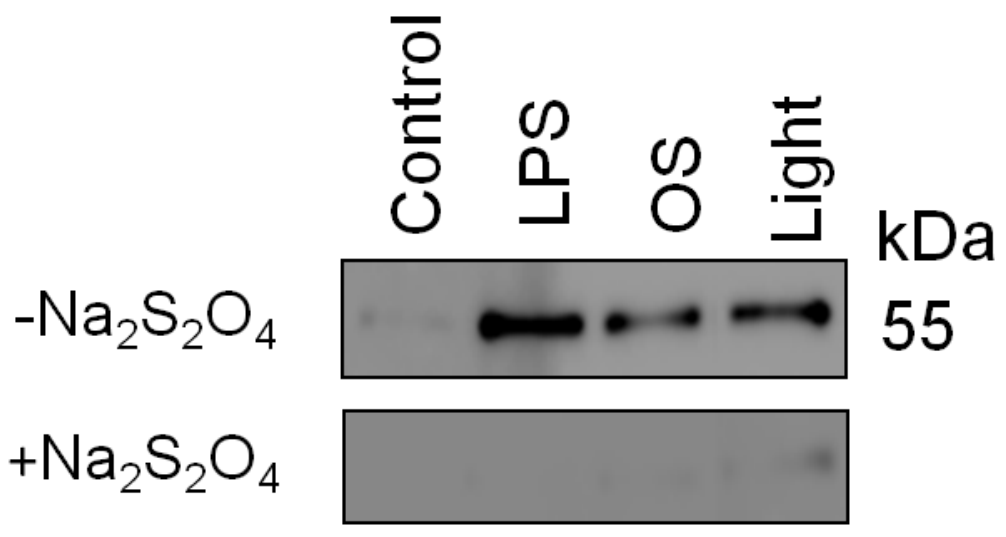

Figure 3.4 C. Western blot analysis before and after reduction of nitrotyrosine to aminotyrosine. Nitration reduction $\left(\mathrm{NO}_{2}\right.$ to $\left.\mathrm{NH}_{2}\right)$ was performed to confirm protein nitration, using disodium dithionite $\left(\mathrm{Na}_{2} \mathrm{~S}_{2} \mathrm{O}_{4}\right)$ to reduce 3-nitrotyrosine to 3aminotyrosine. Reduced tyrosine (3-aminotyrosine) showed no band on Western blotting using3-nitrotyrosine antibody compared to control (3-nitrotyrosine). ARPE-19 cell lysate from LPS, oxidative stress, and light treatment were separated by SDS-PAGE, and proteins were visualized by Western blotting. PVDF membrane was chemically reduced by $10 \mathrm{mM}$ sodium dithionite $\left(+\mathrm{Na}_{2} \mathrm{~S}_{2} \mathrm{O}_{4}\right)$ in $50 \mathrm{mM}$ pyridine acetate buffer $(\mathrm{pH}$ 5.0) for $1 \mathrm{hr}$ before probing by anti-nitrotyrosine antibody. Another PVDF membrane was directly probed with anti-nitrotyrosine antibody without reduction $\left(-\mathrm{Na}_{2} \mathrm{~S}_{2} \mathrm{O}_{4}\right)$.

\subsubsection{NO Induced Vimentin Dephosphorylation and PP2Ac Phosphorylation in the}

\section{RPE under Oxidative Stress}

Oxidative stress disrupts RPE cell junction and barrier integrity which may cause the pathogenesis of RPE related diseases through the degeneration of the blood-retinal barrier (Bailey et al., 2004). Increased site-specific phosphorylation of vimentin induces disassembly of vimentin intermediate filaments in vitro. Both cAMP dependent protein kinase and protein kinase $\mathrm{C}$ dependent phosphorylation of Ser-38 residue, which is located close to arginine substrate, were reported (Ando et al., 1989). To determine NOdependent cytoskeletal change that is regulated by PP2A phosphorylation signaling, we examined the interconnection of NO-vimentin-PP2A signaling (Figure 3.5). Cells were treated with or without oxidative stress, L-arginine, and a NOS antagonist (N'1-nitro-Larginine methyl ester, L-NAME). Cells treated with oxidative stress showed downregulation of the anti-apoptotic protein $\mathrm{p}-\mathrm{PP} 2 \mathrm{Ac}$ relative to the control group. Bcl-xL is 
also an anti-apoptotic protein and is down-regulated in all samples that are exposed to oxidative stress. Bcl-xL expression increased in cells treated with L-arginine (2 $\mathrm{mM})$ under oxidative stress. However, cells treated with oxidative stress, arginine, and LNAME together at the same time had lowest expression of Bcl-xL. Our data implies that increased levels of NO by L-arginine may have a protective role towards RPE cells under oxidative stress by inducing anti-apoptotic molecules, including Bcl-xL. Vimentin phosphorylation is up-regulated in cells under stress. Cells treated with L-arginine (2 $\mathrm{mM}$ ) down-regulated vimentin phosphorylation whereas L-NAME along with L-arginine up-regulated vimentin phosphorylation under oxidative stress. This is likely a result of increased cytoskeletal restructuring due to changes of intermediate filaments. We then asked whether NO can induce PP2Ac catalytic subunit phosphorylation in the RPE under oxidative stress.

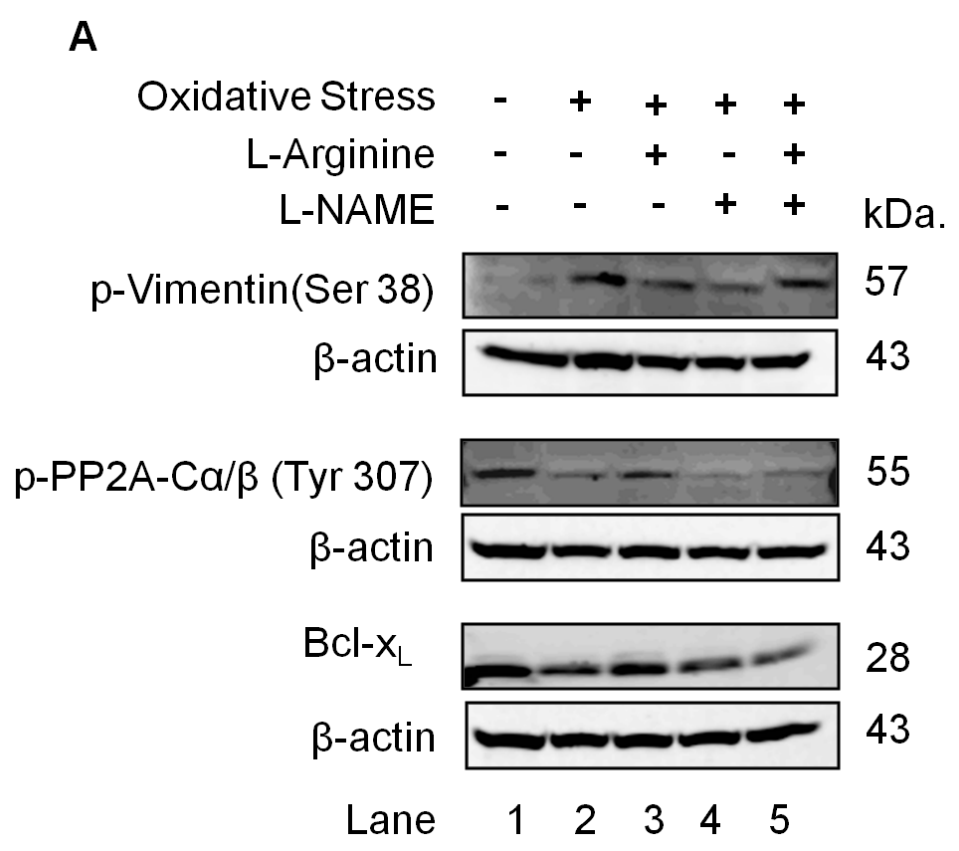

Figure 3.5A. NO dependent concentration changes of p-Vimentin (Ser38), p-PP2Ac (Tyr307) and Bcl-xL under oxidative stress. ARPE-19 cells were incubated with tertButyl hydroperoxide $(200 \mu \mathrm{M})$ or L-Arginine $(2 \mathrm{mM})$ or L-NAME $(2 \mathrm{mM})$ for $24 \mathrm{hrs}$ in serum free media. Cells were harvested, lysed in RIPA lysis to extract proteins. Proteins were separated by SDS-PAGE and probed with anti- p-vimentin (Ser38), anti- p-PP2Ac (Tyr307) and anti- Bcl-xL antibodies to visualize the expression by Western blotting. 


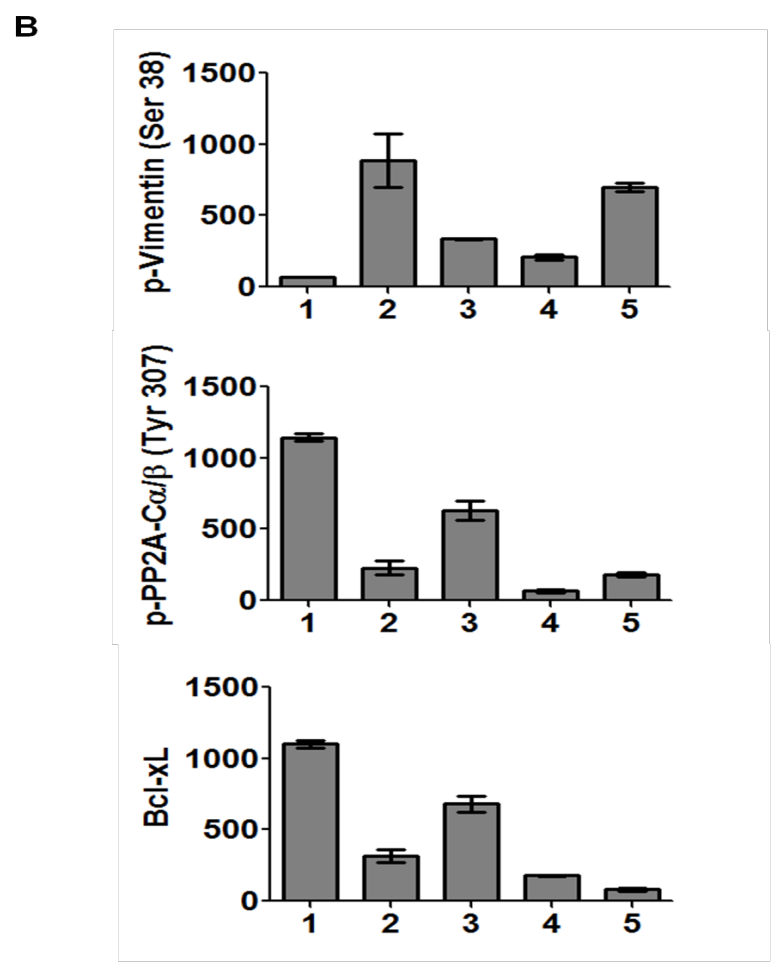

Figure 3.5B Quantitative analysis of Figure 3.5A. $\mathrm{Y}$ axis represents relative phosphorylations in arbitrary unit (a.u.). X axis represents lanes. Lane 1. Control cells without treatments; Lane 2. Cells treated with $200 \mu \mathrm{M}$ tert-butyl hydroperoxide only (oxidative stress); Lane 3. Cells treated with $200 \mu \mathrm{M}$ tert-butyl hydroperoxide and $2 \mathrm{mM}$ L-Arginine; Lane 4. Cells treated with $200 \mu \mathrm{M}$ tert-butyl hydroperoxide and $2 \mathrm{mM} \mathrm{L-}$ NAME; Lane 5. Cells treated with $200 \mu \mathrm{M}$ tert-butyl hydroperoxide, $2 \mathrm{mM}$ L-Arginine and $2 \mathrm{mM} \mathrm{L}$ - NAME.

Stimulation of endothelial cells with LPS and IFN $\gamma$ increases NO-derived peroxynitrite. Up-regulation of peroxynitrite induces PP2Ac tyrosine nitration and nitrated PP2Ac inhibits PP2Ac phosphorylation. Activation of PP2A by nitration in turn causes endothelial barrier dysfunction (Bailey et al., 2004). We tested whether phosphorylation of PP2Ac is down-regulated under oxidative stress in RPE cells. Arginine treatment under oxidative stress shows up-regulated PP2Ac phosphorylation compared to oxidative stress only condition. Arginine treatment with or without L-NAME under oxidative stress clearly demonstrated that PP2Ac phosphorylation is down-regulated compared to nonstress control. 


\subsubsection{NO Induced anti-Apoptotic Signaling in the RPE under Oxidative Stress.}

Anti-apoptotic protein Bcl-xL plays a significant role in RPE cell survival under normal and oxidative stress conditions. Reduced Bcl-xL expression levels confer apoptotic cell death in the RPE (Bailey et al., 2004). Inhibition of Bcl-xL expression alters RPE morphology and diminishes cell survival (Bailey et al., 2004) . We examined whether NO regulates anti-apoptotic signaling via Bcl-xL. While arginine addition increased Bcl-xL, NO reduction by L-NAME down-regulates $\mathrm{Bcl}-\mathrm{x}_{\mathrm{L}}$ compared to oxidative stress only. This result suggests that vimentin phosphorylation may regulate apoptotic cell death signaling in RPE cells. Moreover, increased NO may play a protective role by enhancing anti-apoptotic signaling in the RPE under oxidative stress. Our data shows that Bcl-xL expression levels decreased in the RPE under oxidative stress. RPE cells treated with arginine shows increased expression of Bcl-xL under oxidative stress.

\subsubsection{Light induced vimentin filament disorganization in the RPE}

Interactions between microfilaments, intermediate filaments, and microtubules, stabilize structural, cytoskeletal organization of RPE cells. Vimentin is a major intermediate filament, which is responsible for cell adhesion, migration and signaling (Owaribe et al., 1986). To investigate whether light stress may induce morphological changes through vimentin, we performed immunostaining with fluorescently labeled antibodies as shown in figure 3.6. Control cells in the dark show that vimentin filaments are extended throughout cytoplasm. Nuclear morphology appears as oval shaped and is intact. Intense light induced dramatic morphological changes as rounded vimentin filaments rather than extended form. Nuclear size decreased; major radius reduced to $60-50 \%$ and minor radius

diminished $80-70 \%$ in length under intense light at $20 \mathrm{hrs}$ compared to control. A patchy green color around the nucleus represents vimentin filament disorganization. 
Control

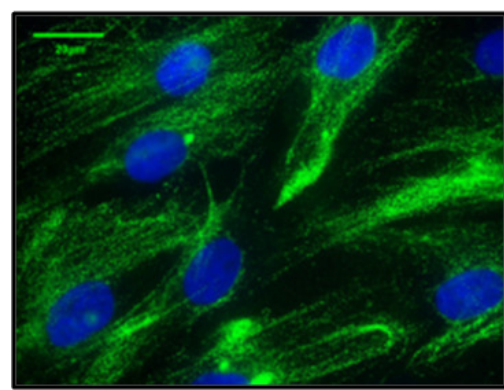

$16 \mathrm{~h}$

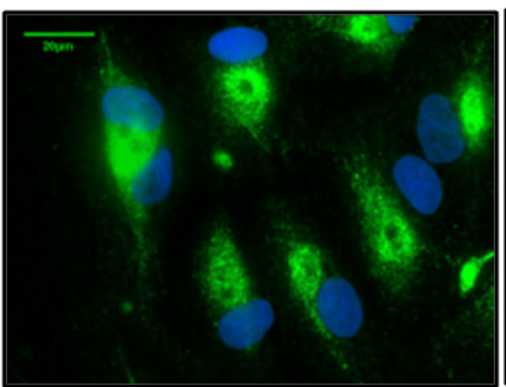

$20 \mathrm{~h}$

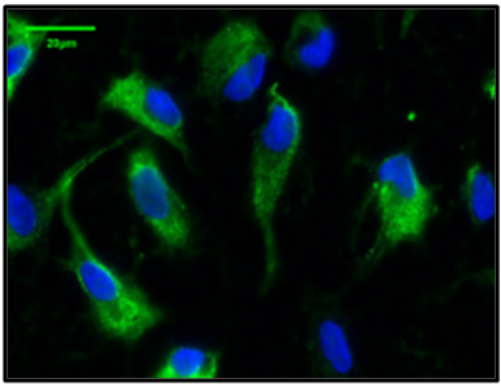

Figure 3.6 Vimentin filament changes in the RPE under light induced stress. ARPE-19 cells were exposed to bright intense light (7000 Lux) for different time points (16 hrs and $20 \mathrm{hrs}$ ). Cells were fixed in methanol at $-20{ }^{\circ} \mathrm{C}$. Vimentin was probed by anti-vimentin and anti-goat Alexa 488 secondary antibody (green, vimentin filaments) and DAPI counterstaining (blue, nucleus). Scale bars represent $20 \mu \mathrm{m}$.

\subsubsection{Apoptosis Mediated Morphological Changes of RPE under Oxidative Stress}

Morphological changes of the RPE are associated with various pathological conditions involved in many posterial ocular diseases. Our scanning electron microscopy analysis of RPE cells under oxidative stress demonstrates that the lateral, basal and apical cell surfaces of RPE are changed during apoptosis. RPE cells were treated with $100 \mu \mathrm{M}$ of $\mathrm{H}_{2} \mathrm{O}_{2}$ for 2 hrs. RPE cells under stress show that apoptotic cell surface changes by forming protrusion (Figure 3.7B), developing bubble-like blebs on their surface (Figure 3.7C), phagocytic alteration like membrane disruption (Figure 3.7D) apical, basal and lateral surface changes, including dense projection of microvilli (Figure 7EF), broken into small, membrane-wrapped fragments (Figure 3.7GH). These results demonstrate that morphological changes of RPE cells under oxidative stress may lead to cell lysis, cytoskeleton collapse, and ultimately cell death. 

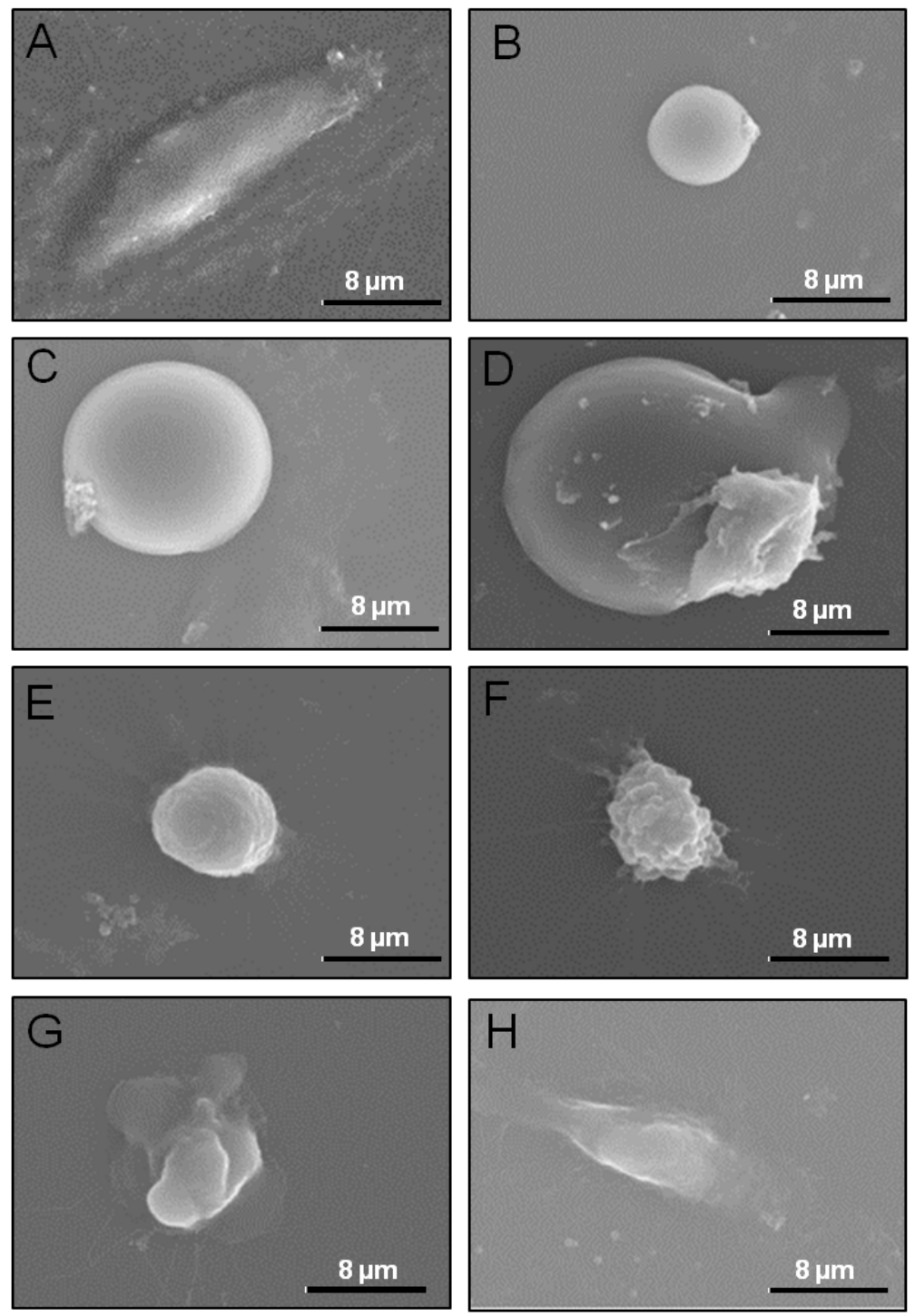

Figure 3.7 Cytoskeletal changes of RPE cells under oxidative stress were identified using scanning electron microscope (SEM). ARPE-19 cells were treated with $\mathrm{H}_{2} \mathrm{O}_{2}(100 \mu \mathrm{M}$ for $2 \mathrm{hrs}$ ). After fixation with 3\% paraformaldehyde and $0.1 \%$ glutaraldehyde in phosphate buffer, morphological changes of ARPE-19 cells were observed using JEOL JSM-6400 SEM at $4000 \mathrm{X}$ magnification. A. Control, B-H. Sequential morphological changes of ARPE-19 cells under oxidative stress. Scale bar represent $8 \mu \mathrm{m}$.

\subsection{Discussion}

Oxidative stress-induced apoptosis is the final cell death pathway in many irreversible ocular diseases (Chang et al., 1993; Porteracailliau et al., 1994). While the end point of apoptosis is well established, the knowledge of early biochemical reactions and 
molecules has been elusive. We have examined early biosignatures and mechanisms of retinal and RPE cell death under oxidative stress (Arnouk et al., 2011b; Chung et al., 2009b; Lee et al., 2010c; Lee et al., 2011; Sripathi et al., 2011c; Zhang et al., 2010b). Our previous studies demonstrated that not only intense light but also constant moderate light and mild oxidative stress may trigger induction of anti-apoptotic Bcl-xL and erythropoietin as well as pro-apoptotic caspases. NO is generated from the oxidation of the guanido nitrogen of its substrate L-arginine with the stoichiometric formation of Lcitrulline by nitric oxide synthase in the presence of oxygen and NADPH. Enzymatic NO formation is involved in physiological processes, including the control of vascular tone, inhibition of platelet aggregation, smooth muscle cell replication, immune response, and wound healing processes (Mann and Motterlini, 2007). NO has been recognized for its paradoxical role as a promoter of cell growth (vascular neogenesis) and cell death apoptosis (Mocellin et al., 2007; Rose and Mascharak, 2008). Exposure to intense light may induce protein nitration via iNOS activation in the retina, which in turn mediates photoreceptor cell death (Palamalai et al., 2006). Elevated tyrosine nitration was observed in the inner segments of photoreceptors and RPE upon intense light exposure due to increase NO production (Miyagi et al., 2002). Inflammatory response and high oxygen demand in the retina are expected to increase NO generation and oxidative damage to Bruch's membrane and could lead to pathophysiological protein nitration (Miyagi et al., 2002). NOS is categorized into three isoforms such as calcium-dependent neuronal (nNOS), endothelial (eNOS) isoforms, and the inducible, calcium independent isoform (iNOS), which are related to neuronal communication, vasolidation and inflammation signaling, respectively (Knowles and Moncada, 1994; Marletta, 1993). Optimum expression levels of NOS isoforms are tightly regulated for normal retinal cell homeostasis and RPE phagocytosis. A high concentration of NO could lead to the accumulation of protein aggregates between photoreceptors and RPE cells, which results in photoreceptor degeneration (Knowles and Moncada, 1994). Light-induced oxygen radicals are mediators of retinal photic injury, based on the observation of the protective effect of free radical scavengers in the light damaged model (Knowles and Moncada, 1994). However, decreased expression of eNOS and nNOS were also observed in 
neuronal and vasoconstrictive changes in AMD choroid. Changes of NOS in AMD suggest that retinal degeneration is directly or indirectly related to local NO concentration in the RPE. NO reacts with superoxide anion $\left(\mathrm{O}_{2}{ }^{-}\right)$to produce peroxynitrite (ONOO-), a potential cytotoxic and tyrosine nitrating molecule under oxidative stress (Knowles and Moncada, 1994). Peroxynitrite modulates tyrosin phosphorylation and dephosphorylation during postsynaptic compartments during cell regulation (Di Stasi et al., 1999). Exogenous NO exposure also resulted in cytoskeletal reorganization through phosphorylation of VASP (vasodilator-stimulated phosphoprotein) in diabetes model (Calzi et al., 2008). The current study suggests that NO may regulate phosphorylation of PP2Ac and vimentin as a physiological regulator of cell respiration to become an agent of cell pathology. In addition, the excessive level of NO or the deficiency of NO may control endothelial dysfunction under oxidative stress. Our results demonstrate that oxidative stress induced disassembly of vimentin intermediate filaments may cause vimentin phosphorylation in the RPE. L-Arginine uptake by RPE cells significantly increases the NO levels in diabetic rat RPE (Calzi et al., 2008). The current study implies dual roles of NO with 1-10 nmole of NO may protect RPE cell by PP2A and vimentin phosphorylation, whereas higher NO (>100 nmole) generation under oxidative stress may induce apoptosis. Our results show that arginine treatment under oxidative stress significantly decreases vimentin phosphorylation compared to no arginine treatment under oxidative stress. Treatment of NOS antagonist, N'1-nitro-L-arginine methyl ester (L-NAME) along with arginine under oxidative stress, shows that vimentin phosphorylation increased compared to arginine only. Addition of both arginine and LNAME under oxidative stress reveals that vimentin phosphorylation has positive and negative correlations with NO under oxidative stress.

Based on our observations in the current study, we postulate that light may induce posttranslational modifications of target proteins, including vimentin and PP2Ac. We speculate that PP2Ac phosphorylation may control its subunit binding that determines its phosphatase activity and substrate specificity under stress conditions. A stabilized vimentin may act as an anti-apoptotic agent when cells are under stress. Our previous 
results demonstrated that $\mathrm{PP} 2 \mathrm{~A}$ and vimentin are modulated by constant light, and are key elements involved in cytoskeletal signaling in rdl mutation model (Zhang et al., 2010b). A positive correlation between the levels of PP2A and vimentin under lightinduced stress suggests that cytoskeletal dynamics are regulated by phosphorylation of vimentin.

PP2A is a heterotrimeric serine/threonine phosphatase, which ubiquitously performs dephosphorylation reactions in cell signaling cascades, including Raf, MEK, and AKT. The regulatory subunit PP2Ab enhances the formation of stable complexes between PP2Aa-c. PP2A positively regulates apoptosis by controlling pro-apoptotic (Bad, Bak, Bax) and anti-apoptotic (Bcl-xL) Bcl-2 family members (Medearis et al., 2011). PP2A dephosphorylates phosducin, a phosphoprotein which modulates the light activated phototransduction cascade in vertebrate retina ( $\mathrm{Wu}$ and Wilson, 2009). Suppression of endogenous PP2Aa by 50\% leads to cell transformation; further suppression results in cell cycle arrest and apoptosis. This suggests that the suppression of PP2A a or c levels induce apoptosis and that a minimal level of PP2A a or $\mathrm{c}$ is required for cell survival (Chen et al., 2005). Under light condition, efficient dephosphorylation of phosducin by PP2A is required to quench high sensitivity so that more intense light can be sensed. PP2Ac tyrosine residue undergoes nitration by peroxynitrite that correlates with decreased tyrosine phosphorylation and increased dephosphorylation activity (Monteiro et al., 2008). Although the potential importance of protein dephosphorylation as a therapeutic target has been appreciated, no detailed approach to date has been made that targets PP2A, especially on retinal degeneration (Kalev and Sablina, 2011; Tanimukai et al., 2009). Abnormalities in PP2A activity and concentration have been linked to neurodegenerative diseases, including Alzheimer's and Parkinson's. However, the mechanism by which PP2A activity is regulated under oxidative stress remains largely elusive. Recent advances in the structural investigation and the light-driven switch mechanism have elucidated PP2A-induced dephosphorylation signaling in the retina (Brown et al., 2002; Cho and Xu, 2007; Xu et al., 2006). Modulating light-induced posttranslational modifications of PP2A and vimentin through NO signaling may assist in 
maintaining the proper filament network in Müller cells, which subsequently supports cell survival and architecture in the retina and RPE.

Our results demonstrate that NO concentration and duration may influence cytoskeletal dynamics and apoptotic pathway via phosphorylation signaling under stress conditions. As progressive loss of neuronal structure precedes cell death, our data elucidates the regulatory mechanism of cytoskeletal organization governed by $\mathrm{NO}$ and PP2A/vimentin phosphorylation. These outcomes are expected to have an important positive impact, because modulation of NO might be assigned as a therapeutic intervention to serve as the pathological target for the balanced phosphorylated cytoskeleton (Thomas et al., 2004; Thomas et al., 2008).

\section{Acknowledgements}

We thank Drs. Ramakrishna Wusirika, Mike Gibson, Haiying Liu, and Mi Hye Song for insightful discussions and sharing equipment. We thank Parrisha Louis, Rissa McDonough, Lu Song, and Alex Keim for their excellent technical assistance. Matthew Durocher is acknowledged for his critical reading and suggestion. 


\section{CHAPTER 4: PROHIBITIN DEPLETION LEADS TO MITOCHONDRIAL} DYSFUNCTION IN RETINAL PIGMENT EPITHELIUM OF AGE-RELATED

\section{MACULAR DEGENERATION ${ }^{3}$}

Srinivas R. Sripathi, O’Donnell Sylvester, Folami Lamoke, Weilue He, Trevor Moser, Ji-Yeon Um, Ramakrishna Wusirika, Paul S. Bernstein, Manuela Bartoli and Wan Jin Jahng

\footnotetext{
${ }^{3}$ This chapter may be submitted to a journal for possible publication in the near future.
} 


\subsection{Abstract}

Oxidative stress contributes towards the disruption of mitochondrial structural integrity, cytoskeletal reorganization and differential expression of pro or anti apoptotic proteins and further leads to progressive cell death of retina and RPE. Our previous study demonstrates that prohibitin levels are upregulated in the retina but downregulated in the RPE of aging and diabetic model. Differential expression of prohibitin and the identification of interacting proteins in the retina and retinal pigment epithelium (RPE) may provide insights into apoptotic signaling mechanism during the progression of retinal degenerative diseases such as age-related macular degeneration (AMD) and diabetic retinopathy (DR). In this study differential expression of prohibitin and its regulation is studied using proteomic strategies including western blotting, immunoprecipitation, two-dimensional electrophoresis and MALDI-TOF mass spectrometry. Our western blotting analysis reveals that prohibitin levels are decreased in the retinas of diabetic retinopathy but the levels are significantly elevated in the aged retinas from mouse, rat models and human donor eyes. Prohibitin levels in the central and peripheral retina are increased but the levels are decreased in the central and peripheral RPE of human AMD eyes. Our mass spectrometry analysis reveals that prohibitin might interact with phospholipid binding receptors, mitochondrial structure determinant proteins and anti-apoptotic regulatory proteins. In the present study we propose that prohibitin levels in the retina and RPE determines the mitochondrial stability, function and apoptotic signaling during the progression of age-related macular degeneration (AMD) and diabetic retinopathy (DR).

\subsection{INTRODUCTION}

Mitochondrial dysfunction that includes oxidative damage and altered energy levels leads to accelerated aging and age-related diseases. Age-related macular degeneration (AMD) involves progressive cell death of post-mitotic retinal pigment epithelial (RPE) cells, which then adversely affects rod and cone survival. AMD is characterized in its early stages by the presence of extracellular deposits, known as drusen, that accumulates between the basal surface of the RPE and Bruch's membrane. Oxidative stress and 
uncontrolled activation of the alternative complement pathways, especially at the membrane surface of RPE cells, are thought to be independently associated with AMD. Emerging evidence suggests that development and progression of AMD involves significant alteration in cell signaling proteins especially apoptosis and immune signaling. However, the identity of the molecules responsible for triggering activation of RPE apoptosis, as well as the downstream molecular interactions that promote AMD pathology, remain elusive. We have been actively seeking early molecular signaling events under oxidative stress in the retina and RPE using a proteomics and metabolomics approach to identify new biomarkers of retinal degeneration (Arnouk et al., 2011b; Chung et al., 2009a; Jahng, 2012; Lee et al., 2010a; Lee et al., 2010b; Lee et al., 2011; Sripathi et al., 2012; Sripathi et al., 2011c; Zhang et al., 2010b). This approach demonstrated that prohibitin is involved in oxidative stress signaling in vitro and in vivo. Prohibitin was originally identified as an anti-proliferative protein (McClung et al., 1995a) that is highly conserved from bacteria to human suggesting essential cellular survival function (Nuell et al., 1991). However, the molecular mechanism of prohibitin on aging and lipid metabolism is not clearly understood. For the last twenty years, prohibitin has been proposed to have a role as a cell cycle inhibitor (Mcclung et al., 1995b), a transcriptional regulator (Fusaro et al., 2003b; Wang et al., 2002a), an inflammatory modulator (Sharma and Qadri, 2004b; Theiss et al., 2007a), a plasma membrane receptor (Kolonin et al., 2004b), a mitochondrial chaperone (Nijtmans et al., 2000b; Sanz et al., 2004) and a lipid binding shuttle (Sripathi et al., 2011b). Prohibitin is involved in apoptosis and aging by stabilizing newly synthesized respiratory enzymes, however, its presence and function in the eye has been elusive. Localization of prohibitin has been controversial, being mitochondrial, nuclear, or cell surface, possibly due to different cell type and lipid membrane environment. Our previous biochemical experiments demonstrated that prohibitin is a lipid binding shuttle primarily expressed in mitochondria, however, it translocalizes to the nucleus under stress condition. The extent of prohibitin localization in mitochondria inversely correlates with levels of oxidative stress. Knockdown approach using siRNA suggests that prohibitin may have the antiapoptotic function through Bcl-2 and mitochondrial DNA binding mechanisms. Our data 
further suggests that specific lipid-binding mechanisms involving altered cardiolipin interactions might be the key element to determine prohibitin shuttling between mitochondria and the nucleus. Mitochondrial dysfunction is associated with AMD and our studies also suggest specific patho-physiological mechanisms involving altered mitochondrial disruption. The current in vivo models and molecular interaction studies, inlcuding lipid, nucleotide and protein with prohibitin, may provide a new insight into the underlying mechanisms involved in the development and progression of AMD and further suggest the relationship between various risk facotors, such as oxidative stress and aging. Such information are critical for the development of more effective therapeutic strategies for the treatment of AMD.

\subsection{MATERIALS AND METHODS}

\subsubsection{ARPE-19 and HRP Cell Culture}

Human retinal progenitor (HRP) cells and human retinal pigment epithelial (ARPE-19) cells were obtained from University of North Texas Health Science Center and ATCC (Manassas, VA) respectively. Cells were cultured in $56.7 \mathrm{~cm}^{2}$ dishes (Nunc, Naperville, IL) containing Dulbecco's modified Eagle's medium (DMEM) supplemented with 10\% fetal bovine serum (FBS) and 1\% penicillin/ streptomycin and the flasks placed in a 5\% $\mathrm{CO}_{2}$ incubator at $37{ }^{\circ} \mathrm{C}$. Confluent cells were retrypsinized with a $0.1 \%$ trypsin-EDTA (Sigma, St. Louis, MO) for 5-7 min at $37{ }^{\circ} \mathrm{C}$. After centrifugation ( $125 \mathrm{~g}$ for $7 \mathrm{~min}$ ), cells were plated in fresh culture dishes and allowed to grow to confluence for 2-4 days. Eight- to nine -passage cells were used for oxidative stress treatment.

\subsubsection{Oxidative Stress Treatment}

To induce oxidative stress in vitro confluent HRP and ARPE-19 cells were incubated with $200 \mu \mathrm{M}$ of tert-butyl hydroperoxide (Sigma, St. Louis, MO) in serum free medium for $1 \mathrm{hr}$ and $2 \mathrm{hrs}$ respectively. Cells were washed twice with PBS before being harvested. Cells were lysed using mild detergent based lysis buffer to perform coimmunoprecipitation with prohibitin antibody. 


\subsubsection{Treatment of Animals}

Adult male Sprague-Dawley (SD) rats (250-300g) and mice (C57 black) obtained from Charles River Laboratories (Wilmington, MA) were made diabetic by intravenous injection with streptozotocin (STZ) (Sigma, St. Louis, MO) $(65 \mathrm{mg} / \mathrm{kg}$ dissolved in $0.1 \mathrm{M}$ sodium citrate $[\mathrm{pH} 4.5]$. Control rats and mice were delivered injections of vehicle alone. Rats and mice were considered to be diabetic at blood levels $>350$ $\mathrm{mg} / \mathrm{dL}$. Animals were sacrificed 2 and 4 weeks following onset of diabetes by an overdose of anesthesia. Comparative analysis was conducted with an identical animals strain (SD). Control SD rats and mice were sacrificed at 12 weeks of age and aged SD rats and mice were sacrificed at 52 and 54 weeks of age. Retinas of SD rats and mice were removed and snap frozen in liquid nitrogen. Retinas from different subgroups were collected and were prepared for biochemical analysis.

\subsubsection{Donor Eye Tissues}

Human diabetic retinopathy (DR), aged and control retinal tissue was obtained from Georgia eye bank. Human age-related macular degeneration (AMD) retinal (8mm macular and peripheral) and RPE (8mm macular and peripheral) and age matched control eye tissue was provided by the Lions eye bank at University of Utah, UT.

\subsubsection{Co-Immunoprecipitation}

HRP and ARPE-19 cells were washed once with 1X Modified Dulbecco's PBS and lyse the cells by adding ice cold IP lysis buffer [25 mM Tris, $150 \mathrm{mM} \mathrm{NaCl,} 1 \mathrm{mM}$ EDTA, 1\% NP-40, 5\% glycerol; $\mathrm{pH} 7.4$ and protease inhibitor cocktail] by incubating on ice for 5 min and periodic sonication $(3 \times 5 \mathrm{~min})$ followed by centrifugation at $13,000 \times \mathrm{g}$ for 10 minutes to pellet the cell debris. Proteins in the supernatant were pre cleared using control agarose resin, cross-linked by $4 \%$ bead agarose, to avoid the nonspecific binding. The anti-prohibitin antibody immobilization is performed using amino-linked protein- A beads by coupling buffer [ $1 \mathrm{mM}$ sodium phosphate, $150 \mathrm{mM} \mathrm{NaCl}(\mathrm{pH}$ 7.2)] followed by incubation with $3 \mu \mathrm{L}$ of $5 \mathrm{M}$ sodium cyanoborohydride solution on rocker at RT for $2 \mathrm{hrs}$ to make the slurry suspended. Columns were briefly washed with a wash solution [1M $\mathrm{NaCl}$ ] and protein lysate was incubated in the protein A-antibody column with gentle 
rocking for overnight at $4{ }^{\circ} \mathrm{C}$. Spun down the unbounded proteins as flow through and the columns were washed thrice with wash buffer to remove nonspecific binding proteins. Elute the interacting proteins by incubating with elution buffer for $5 \mathrm{~min}$ at RT. Finally the eluted proteins were equilibrated with $5 \mathrm{X}$ Laemmli sample buffer with the final concentration of $10 \% \beta$ - mercaptoethanol. Eluted proteins were resolved on SDS-PAGE and interacting protein bands were visualized by either coomassie (Pierce, IL) or silver staining (Bio-Rad, Hercules, CA).

\subsubsection{In-Gel Digestion and MALDI TOF Mass Spectrometry}

Selected protein bands from gels were excised into cubes (ca. $1 \times 1 \mathrm{~mm}$ ). The coomassie stained gel pieces were destained twice with $200 \mu \mathrm{L}$ of $50 \%$ acetonitrile $(\mathrm{MeCN}) / 25 \mathrm{mM}$ $\mathrm{NH}_{4} \mathrm{HCO}_{3}$ buffer ( $\mathrm{pH} \mathrm{8.0)}$ ) at room temperature for $20 \mathrm{~min}$, whereas the silver stained gels pieces were destained by soaking in $1: 1$ mixture of $30 \mathrm{mM}$ potassium ferricyanide and $100 \mathrm{mM}$ sodium thiosulfate for $5 \mathrm{~min}$ until the silver stain disappears and washed the gel pieces thrice with water. Incubate the gel pieces once with $200 \mu \mathrm{L}$ of $100 \% \mathrm{MeCN}$ until they become white and shrink, and vacuum-dried with a Speed Vac concentrator (Savant, Holbrook, NY). Reduce the proteins with $10 \mathrm{mM}$ DTT in $100 \mathrm{mM} \mathrm{NH}_{4} \mathrm{HCO}_{3}$ for $30 \mathrm{~min}$ at $56^{\circ} \mathrm{C}$ in an air thermostat and alkylate with $55 \mathrm{mM}$ iodoacetamide in $100 \mathrm{mM}$ $\mathrm{NH}_{4} \mathrm{HCO}_{3}$ for $20 \mathrm{~min}$ at $\mathrm{RT}$ in dark. The gel pieces were saturated with $13 \mathrm{ng} / \mu \mathrm{L}$ sequencing grade modified trypsin (Promega, Madison, WI) in $10 \mathrm{mM} \mathrm{NH4HCO3}$ containing $10 \%$ (vol/vol) $\mathrm{MeCN}$ and incubated the samples in air circulation thermostat at $37^{\circ} \mathrm{C}$ for overnight. Subsequently, the peptides were enriched twice with $50 \mu \mathrm{L}$ of a $50 \% \mathrm{MeCN} / 5 \%$ formic acid mixture for $20 \mathrm{~min}$ at $37{ }^{\circ} \mathrm{C}$ in a shaker. The solution containing peptide mixture is completely vacuum dried. The dried peptide is dissolved in 5-10 $\mu \mathrm{L}$ of $75 \% \mathrm{MeCN} / 1 \%$ TFA solution. The matrix $\alpha$-cyano-4-hydroxycinnamic acid ( $5 \mathrm{mg} / \mathrm{mL}$ CHCA, MW $189.04 \mathrm{Da}$ ) (Sigma, St. Louis, MO) is freshly dissolved in $50 \%$ acetonitrile/1\% triflouroacetic acid (TFA) and centrifuged at 13,000 g for $5 \mathrm{~min}$. The clear matrix solution is mixed with the tryptic digested peptide and spotted the $0.5 \mu \mathrm{L}$ of the matrix/peptide mixture on to the MALDI target (Ground steel, Bruker Daltonics, Germany) and allowed to form dried droplet of the sample. Commercially available 
target with pre-spotted known peptide samples were used to calibrate the accuracy of instrument. The mass spectra range of 800-3000 Da with the laser intensity of $70-75 \%$ and 100-300 shot numbers, was measured using Flex control MALDI-TOF mass spectrometry (Bruker Daltonics, Germany). Internal calibration for all the mass spectra were performed based on the autolysed trypsin (Promege) products (m/z 842.509 and 2211.105). Data analysis was performed using Flex analysis software (Bruker). Protein database is performed using Mascot search engine software (Matrix Science) along with the NCBI/SwissProt database(s) and followed the different parameters such as Taxonomy - Homo sapiens; allowed zero mismatch cleavage with fixed carbamidomethyl (C) modification of cysteine and variable modification of methionine oxidation. 100-300 ppm was considered as peptide mass tolerance. Peptide identification is considered based on the MASCOT Mowse scores, number of matched peptides and protein sequence coverage.

\subsubsection{Immunocytochemistry}

ARPE-19 cells were cultured on sterile glass cover slips with DMEM/F12 medium supplemented with $10 \% \mathrm{FBS}$ and $1 \%$ penicillin-streptomycin (Hyclone) in $5 \% \mathrm{CO}_{2}$ incubator at $37{ }^{\circ} \mathrm{C}$. Cells were treated with $200 \mu \mathrm{M}$ of hydrogen peroxide for $2 \mathrm{hrs}$ to induce oxidative stress. Cells were briefly washed with PBS and incubated with the final concentration $100 \mathrm{nM}$ MitoTracker Orange CMTMRos (Molecular Probes, Carlsbad, $\mathrm{CA}$ ) in serum free culture medium for $30 \mathrm{~min}$ at $37^{\circ} \mathrm{C}$. Cells were washed with PBS and fixed with $10 \%$ formaldehyde for $30 \mathrm{~min}$ at RT. After fixation, cells were treated in $0.2 \%$ Triton X-100 (Sigma) in PBS for 30 min to permeabilize the cell membrane and the cells were blocked with complete medium containing 10\% FBS and 0.05\% Tween-20 (Sigma) for $1 \mathrm{hr}$. Cells were probed with anti-prohibitin antibody (1:1000; Genemed Synthesis Inc, San Antonio, TX) for overnight at $4{ }^{\circ} \mathrm{C}$. Cells were washed with PBS and incubated with Alexa Fluor 488-conjugated anti-rabbit IgG secondary antibody (1:700; Molecular Probes) for $1 \mathrm{~h}$ at RT. To counter stain the nucleus, cells were mounted with VECTASHIELD mounting medium containing DAPI (4,6-diamidino-2-phenylindole). 
Images were acquired on fluorescent microscope (Zeiss AxioVert $200 \mathrm{M}$ Apo Tome) with $63 \times$ magnification. Images were analyzed and merged using ImageJ software $(\mathrm{NIH})$.

\subsubsection{SDS-PAGE and Western Blot Analysis}

Protein quantification was performed using BCA protein assay kit (Pierce) by plotting BSA standard curve graph. Protein samples were dissolved in 5X Laemmli sample buffer (240 mM Tris $\mathrm{pH} 6.8,8 \%$ SDS, 40\% glycerol, $0.4 \%$ bromophenol blue, $10 \% \beta$ mercaptoethanol) followed by denaturation at $90^{\circ} \mathrm{C}$ for $10 \mathrm{~min}$. Proteins were resolved using $8-16 \%$ gradient polyacrylamide precast gels (Bio-Rad), followed by electrotransfer on to the methanol activated PVDF membrane (Bio-Rad) using semidry transfer by applying $15 \mathrm{~V}$ for $30 \mathrm{~min}$. Non-specific proteins were blocked with $5 \%$ nonfat dry milk (Bio-Rad) prepared in TBS with $0.1 \%(\mathrm{v} / \mathrm{v})$ Tween-20 for $2 \mathrm{hr}$ at $4^{\circ} \mathrm{C}$. Membranes were probed with primary antibody prohibitin (Rabbit polyclonal, 1:1000; Genemed Synthesis Inc. TX) at $4{ }^{\circ} \mathrm{C}$ for overnight on a shaker. Subsequently, the membrane is incubated with anti-rabbit HRP conjugated secondary antibody (1:10000; Agrisera, Vännäs, Sweden) for $2 \mathrm{~h}$ at room temperature on shaker. Antibody probed membranes were developed with West Pico Chemiluminescent Substrate (Pierce) for 1-2 min. The immunoreactive protein bands (signal) were visualized by LAS 4000 mini luminescent image analyzer (GE, Piscataway, NJ). Membranes were reprobed with the $\beta$-actin (mouse monoclonal, 1:5000; Sigma, St. Louis, MO) followed by the incubation with anti-mouse HRP conjugated secondary antibody (1:7,000; Santa Cruz Biotechnology Inc, CA) for loading control. All the immunoblots were performed in triplicate. Bands were quantified based on pixel size/intensity/area using Quantity One software (Bio-Rad) and graphs were plotted based on relative intensity of bands using GraphPad Prism software.

\subsection{RESULTS}

\subsubsection{Prohibitin Expression Downregulated in the Retina of the Diabetic Model} Prohibitin regulates lipid metabolism by binding specific phospholipids, including cardiolipin and PIP3 (Sripathi et al., 2011c). Increased prohibitin levels negatively affect

insulin signaling through tyrosine phosphorylation as phosphatidylinositol-3 kinase (PI3K) downstream (Ande and Mishra, 2009). We tested our hypothesis that prohibitin 
signaling could be altered in diabetic pathway or aging model. We examined whether mitochondrial prohibitin was altered during hyperglycemic condition using streptozotocin (STZ)-treated murine or diabetic human model. Our Western blotting analysis showed that the prohibitin levels decreased significantly in the diabetic retina from the STZinduced mouse and rat (Figure 4.1-3). Next, considering reactive oxygen species (ROS) accumulation leads to the disruption of mitochondrial network during aging, we tested our hypothesis that prohibitin expression could be changed in aged retinas from mouse, rat (12 months), and human (71 years) compared to controls. In contrast to diabetic condition, we observed that the level of prohibitin is significantly increased in rats and humans, whereas minimum changes in elevated expression in the mouse retina (Figure $4.1-3)$.
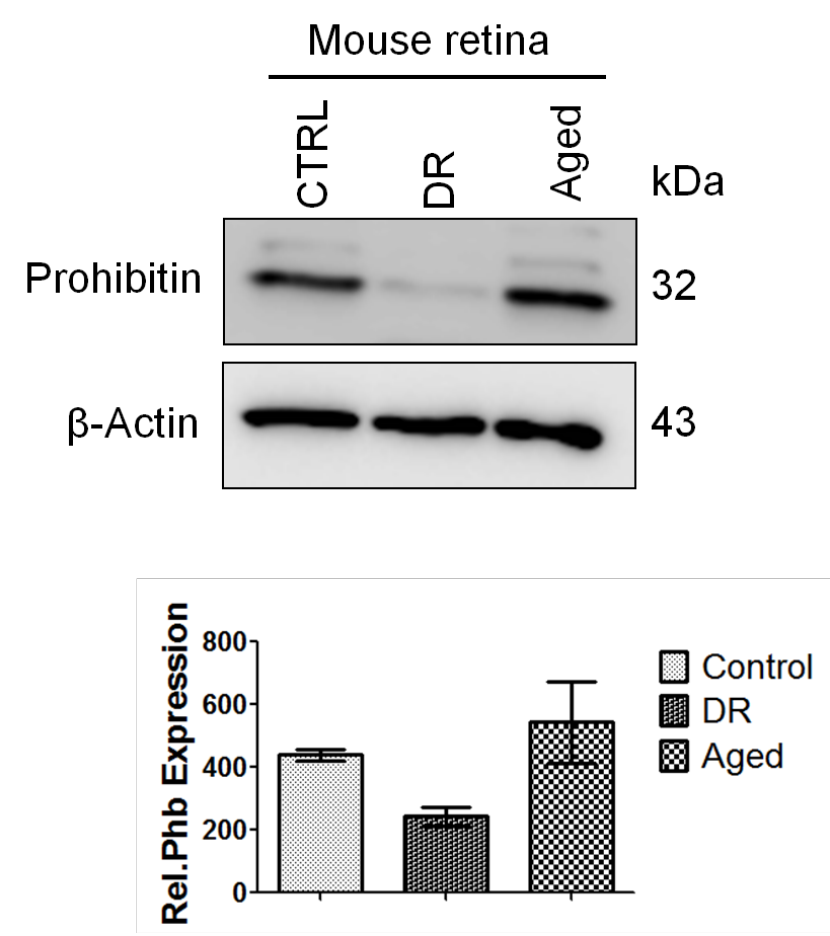

Figure 4.1 Expression difference of mouse retinal prohibitin (PHB) in control, diabetic retinopathy (DR) and aged retina was analyzed by western blotting. Retinal tissue from was homogenized in RIPA buffer followed by sonication. Proteins were separated by SDS-PAGE and PHB expression was visualized by western blotting. $\beta$-actin blot was used as a loading control. Bands were quantified based on pixel size/intensity/area using Quantity One software (Bio-Rad). Graphs were plotted based on relative prohibitin expression using GraphPad Prism software. 


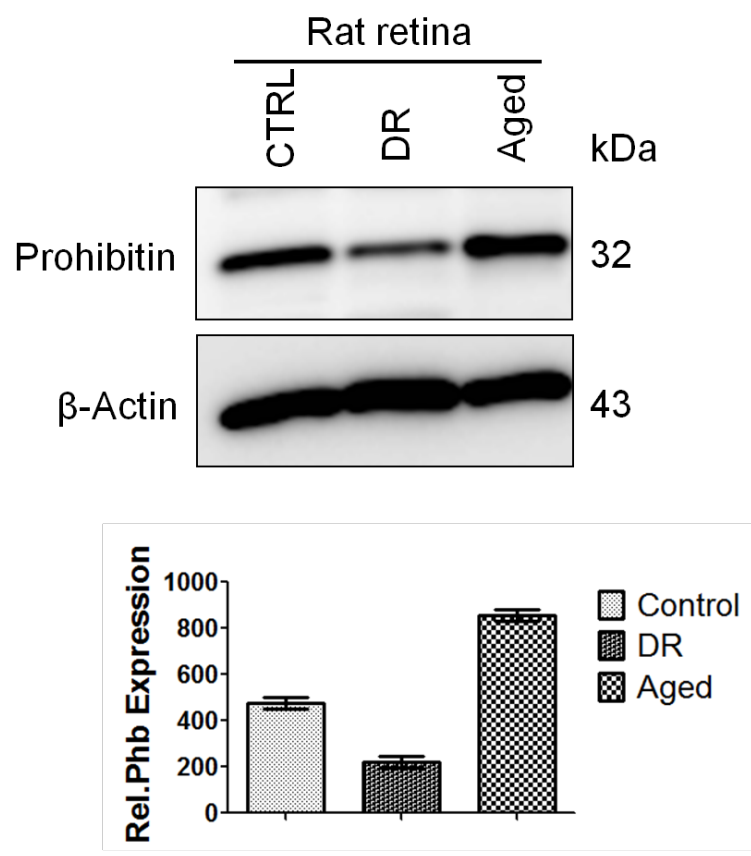

Figure 4.2 Expression difference of rat retinal prohibitin (PHB) in control, diabetic retinopathy (DR) and aged retina was analyzed by western blotting.

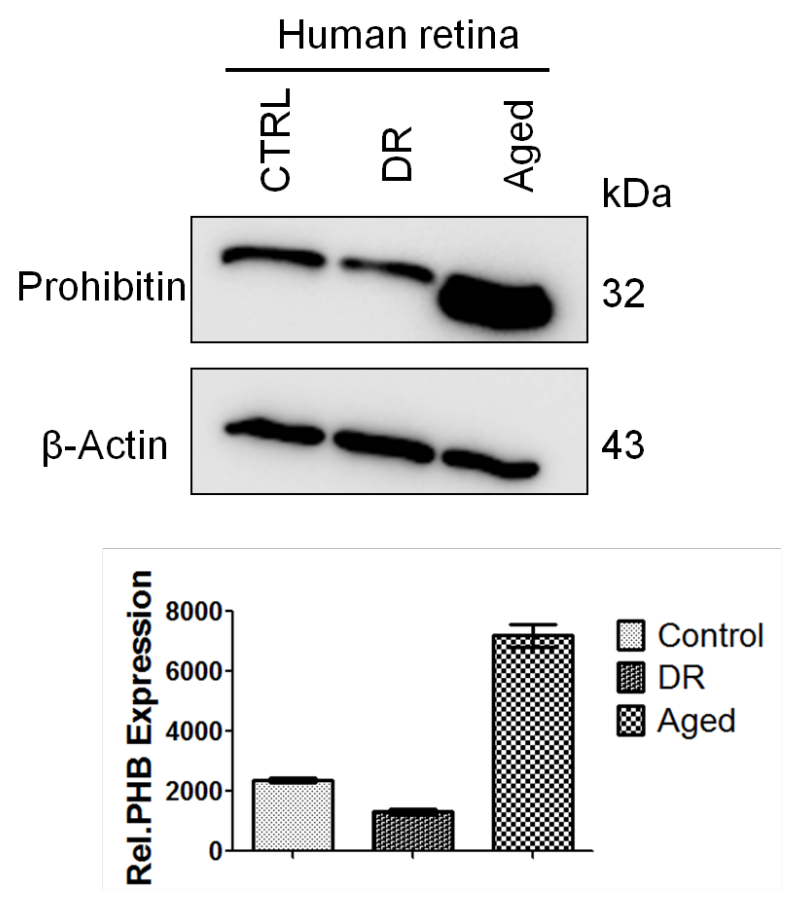

Figure 4.3 Expression difference of human retinal prohibitin (PHB) in control, diabetic retinopathy (DR) and aged was analyzed by western blotting. 


\subsubsection{Prohibitin Expression Increased in the Retina but Decreased in the RPE of}

AMD

The increased levels of reactive oxygen species under oxidative environment may initiate various pathophysiological events in the retina and RPE. Differences in region-specific protein content were reported in central and peripheral retina in the progression of AMD (Lee et al., 2010c). Since the susceptibility towards oxidative stress significantly varies from the retina and RPE cells, we aimed to analyze prohibitin expression in the macular and peripheral retinal and RPE region. Our Western blot analysis demonstrates that the prohibitin levels increased significantly in both macular $(8 \mathrm{~mm})$ and peripheral retinal region from the postmortem donor eyes of AMD (Figure 4.4). However, prohibitin levels decreased dramatically in both macular RPE region and peripheral RPE in AMD eyes compared to age matching controls, suggesting mitochondrial dysfunction and RPE cell death in AMD (Figure 4.5). $\beta$-tubulin expression was used as a loading control.
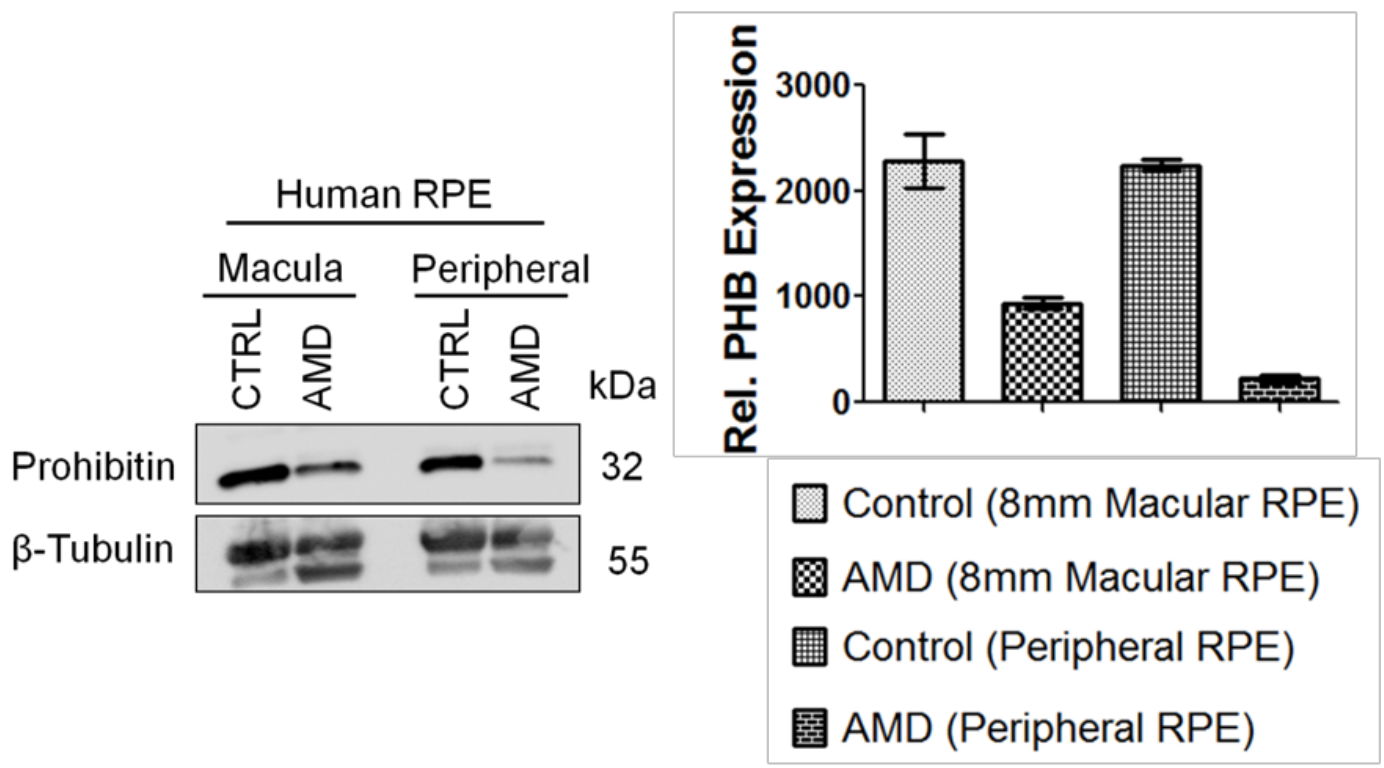

Figure 4.4 Expression difference of prohibitin (PHB) in human Age-related Macular Degeneration (AMD) retina ( $8 \mathrm{~mm}$ macular, peripheral retina) was analyzed by western blotting. Retinal tissue and RPE cells were homogenized in RIPA buffer followed by sonication. Proteins were separated by SDS-PAGE and PHB expression was visualized by western blotting. $\beta$-tubulin blot was used as a loading control. Bands were quantified based on pixel size/intensity/area using Quantity One software (Bio-Rad). Graphs were plotted based on relative prohibitin expression using GraphPad Prism software. 

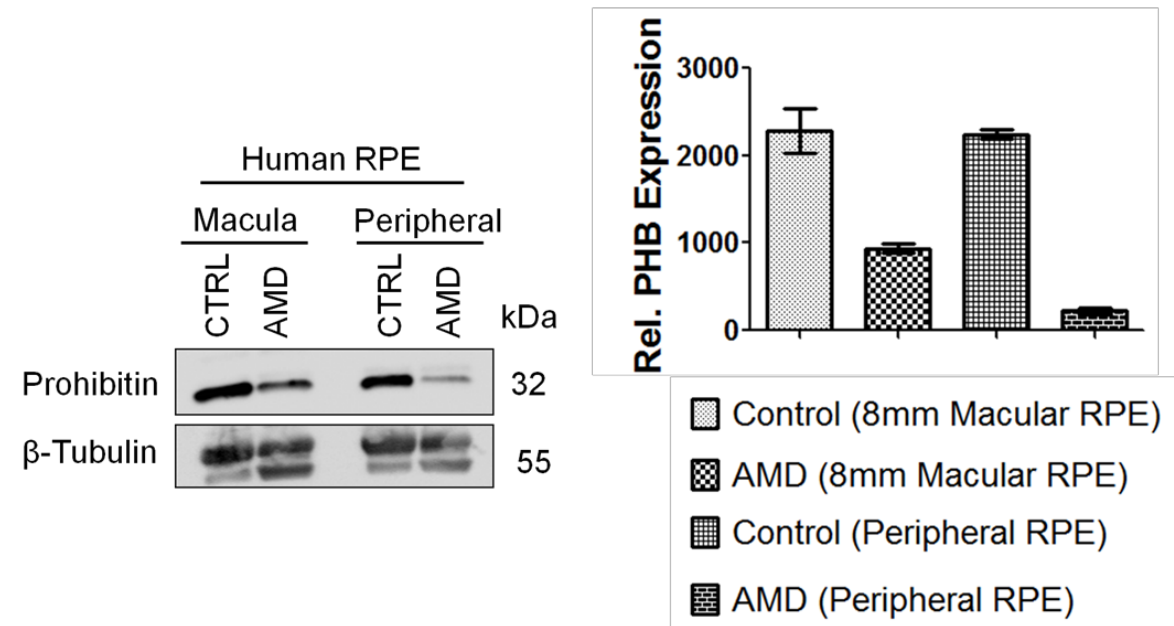

Figure 4.5 Expression difference of prohibitin (PHB) in human Age-related Macular Degeneration (AMD) retinas ( $8 \mathrm{~mm}$ macular, peripheral retina) were analyzed by western blotting. RPE cells were homogenized in RIPA buffer followed by sonication. Proteins were separated by SDS-PAGE and PHB expression was visualized by western blotting. $\beta$-tubulin blot was used as a loading control. Bands were quantified based on pixel size/intensity/area using Quantity One software (Bio-Rad). Graphs were plotted based on relative prohibitin expression using GraphPad Prism software.

\subsubsection{Prohibitin Depletion in the RPE}

To examine prohibitin depletion phenotype as shown in the RPE of AMD eyes, we determined a loss of function study using prohibitin-targeting small interfering RNA (siRNA). Prohibitin knockdown experiment demonstrates that a decreased level of prohibitin disrupts the regular lamellar cristae whereas random sequence control and $\mathrm{t}=0$ control does not affect the structure of mitochondria. The mitochondrial morphology, visualized by MitoTracker, showed that prohibitin silencing led to mitochondrial fragmentation instead of the tubular shape as shown in control cells (Figure 4.7). Then we examined prohibitin expression and mitochondrial morphological differences in RPE under oxidative stress. Our immunocytochemical analysis of retinal pigment epithelial cells (ARPE-19) shows that the disrupted mitochondrial morphology under oxidative stress (200 $\mu \mathrm{m} \mathrm{H}_{2} \mathrm{O}_{2}$ ) compared to the untreated control (Figure 4.7). However, we found no difference in the nuclear DNA morphological aberration between oxidative stress and control. MitoTracker Orange (mitochondria, red, 578 and $599 \mathrm{~mm}$ for absorption and 
emission), DAPI (nuclear DNA, blue, $369 \mathrm{~nm}$ absorption and $460 \mathrm{~nm}$ emission) and Alexa Fluor 488 (prohibitin, green, $495 \mathrm{~nm}$ absorption and $519 \mathrm{~nm}$ emission) were used to label subcellular organelles and prohibitin, respectively.

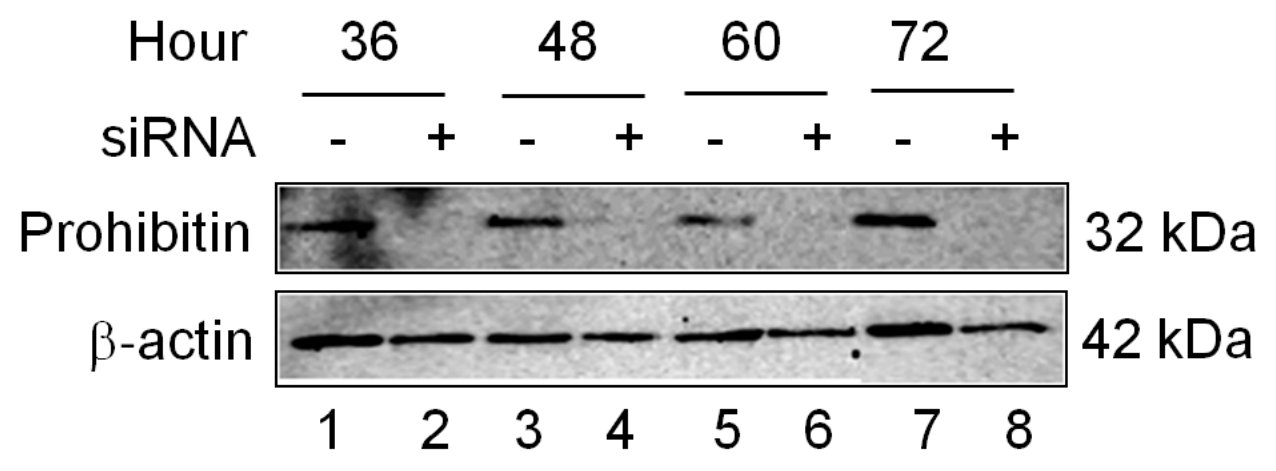

Figure 4.6 Depleted levels of prohibitin are shown by siRNA knockdown analysis. ARPE-19 cells were transfected by prohibitin specific siRNA in serum free medium by time dependant manner (36 to $72 \mathrm{~h}$ ). Prohibitin expression and depleted levels were analyzed by Western blotting analysis form cell extracts. Prohibitin levels were diminished during siRNA knockdown analysis. $\beta$-actin expression levels were considered as a loading control.

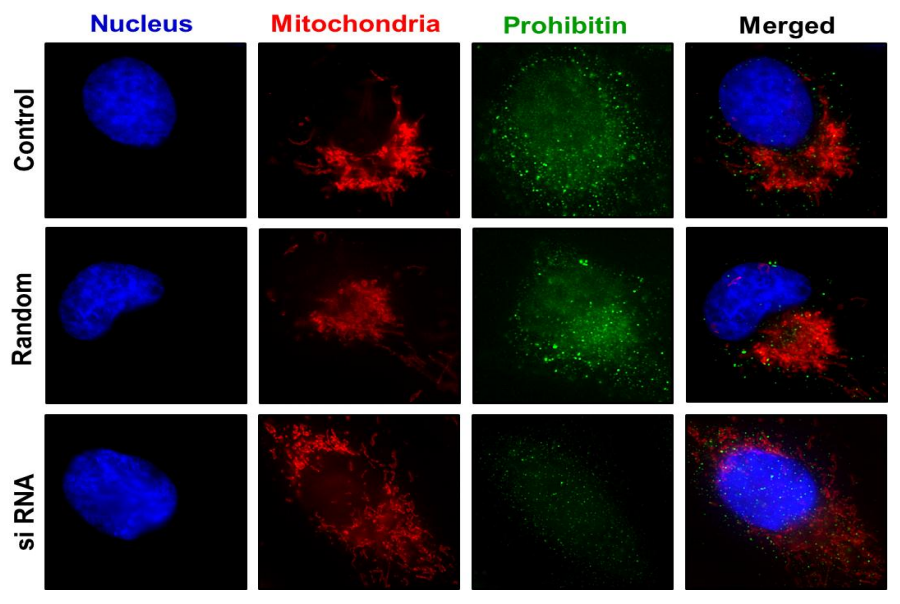

Figure 4.7 Mitochondrial morphological changes during prohibitin siRNA knockdown analysis. ARPE 19 cells were treated with prohibitin specific siRNA (175 ng for $48 \mathrm{~h}$ ) and random sequence control were analyzed by immunocytochemical analysis. Subcellular organelles and prohibitin levels were visualized by DAPI (blue, nucleus), MitoTracker Orange (red, mitochondria) and the prohibitin-specific primary antibody, the Alexa Fluor 488-conjugated secondary antibody (green, prohibitin).Disrupted mitochondrial morphological changes were observed under prohibitin depleted levels. The scale bar is $5 \mu \mathrm{m}$. 


\subsubsection{Prohibitin-Lipid Interaction}

We next asked whether prohibitin in various organelles or cells may have different cardiolipin affinity to test subcellular organelle-specific prohibitin-lipid interactions. Previously, the prohibitin-lipid binding assay demonstrated that prohibitin binds with cardiolipin, a major mitochondrial phospholipid, under oxidative stress (Sripathi et al., 2011a). The lipid interaction assay demonstrates that microsomal and cytosolic prohibitin showed stronger interaction compared to mitochondrial and nuclear prohibitin (Figure 4.8). In addition, prohibitin from bovine RPE or ARPE19 cells did not show any interaction with cardiolipin, however, prohibitin from the bovine retina showed cardiolipin binding. Microsomal prohibitin showed strong interaction with cholesterol and weaker interaction with phosphatidylserine. To determine cardiolipin and cholesterol changes under oxidative stress, relative lipid concentrations were analyzed by mass spectrometry. Cardiolipin decreased $20 \%$ under $200 \mu \mathrm{M} \mathrm{H}_{2} \mathrm{O}_{2}$ in a time and dose dependent manner (Figure 4.8) and cholesterol/cholesterol ester increased roughly 2.5 fold (data not shown). Addition of cholesterol $(125-250 \mu \mathrm{M})$ to APRE19 cells during cell culture down-regulated prohibitin and prohibitin2 expression (Figure 4.9). Addition of beta-cyclodextrin increased prohibitin expression (data not shown). Our data suggests that prohibitin from a different subcellular organelle or different cells may have a different affinity to cardiolipin. Further, our data may suggest that prohibitin expression has inverse correlation with cholesterol concentration. 


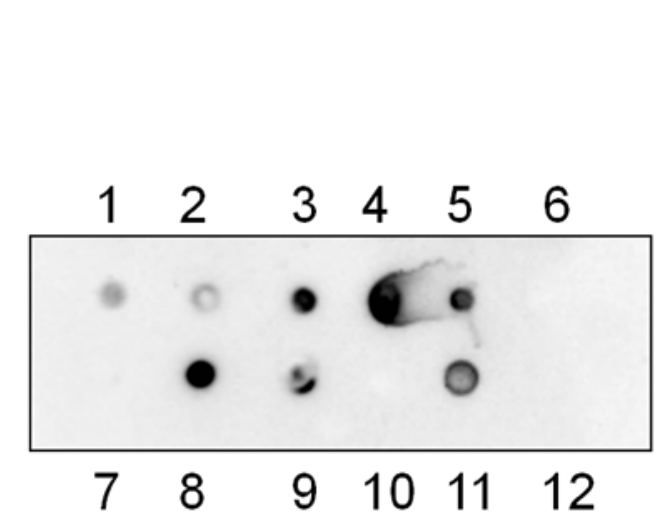

\section{Cardiolipin $+m+P H B$ \\ 2. Cardiolipin + nuPHB}

3. Cardiolipin + cytPHB

4. Cardiolipin+micPHB

5. Cardiolipin+Retina $\mathrm{PHB}$

6. Cardiolipin+ RPE PHB

7. Cardiolpin+ARPE19 PHB

8. Cholesterol+micPHB

9. $\mathrm{PS}+\mathrm{micPHB}$

\section{Cardiolipin \\ 11.ARPE19 lysate \\ 12.Negative control}

Figure 4.8 Subcellular prohibitin-lipid binding analysis. Blotting hybridization with PHB-antibody shows that subcellular PHBs have different binding affinity with cardiolipin, cholesterol and phosphatidylserine. Retina PHB and cardiolipin have strong binding affinity, while bovine RPE and human RPE (ARPE-19) PHB have weak binding affinity. Retinal microsomal PHB binds have high binding affinity with cardiolipin, cholesterol, and phosphotidylserine. Microsomal fraction applied onto PVDF membrane is considered as a negative control.

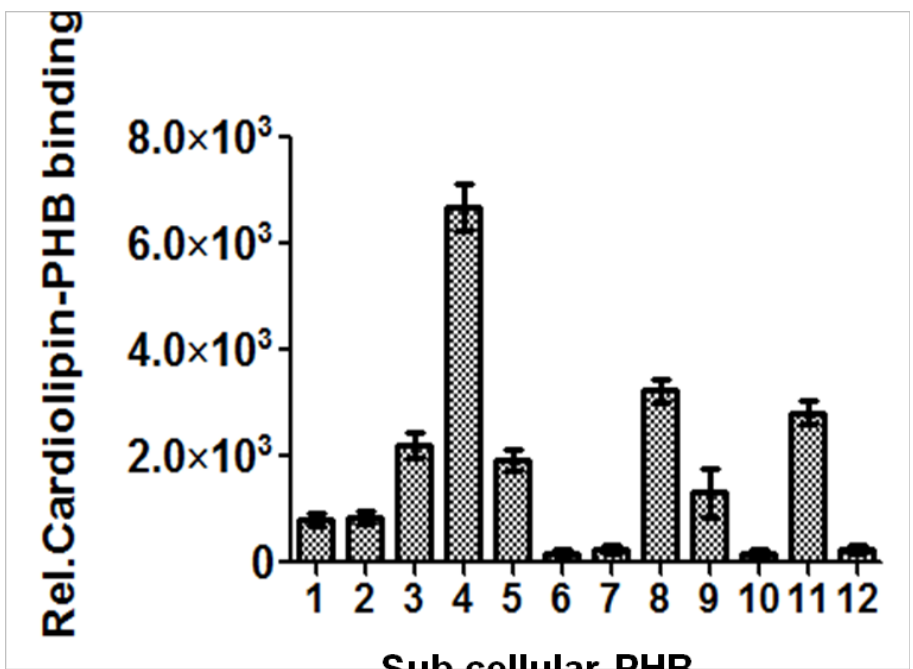

Sub cellular PHB

Figure 4.9 Quantitative analysis of Subcellular prohibitin-lipid binding: Spots were quantified based on pixel size/intensity/area using Quantity One software (Bio-Rad). Graphs were plotted based on relative prohibitin expression using GraphPad Prism software. 


\subsubsection{Prohibitin-Nucleotide Interaction}

To understand the origin of mitochondrial dysfunction by prohibitin depletion, we next asked the question of prohibitin-nucleotide interaction. Under oxidative stress, mitochondrial DNA (mtDNA) is more susceptible to damage than nuclear DNA (nuDNA) due to oxidative metabolism in mitochondria (Lee et al., 2010a). Thus, we examined whether prohibitin binds to mitochondrial or nuclear DNA to determine its molecular chaperone function. We tested the hypothesis that mitochondrial prohibitin may show different affinity toward mitochondrial DNA versus nuclear DNA. Using a native gel assay, we examined whether prohibitin in mitochondrial and nuclear extracts bind to mtDNA and nuDNA. It was found that mitochondrial prohibitin forms proteinmtDNA complex at $720 \mathrm{kDa}$ as shown in Figure 4.11 lane 2 and 3, whereas it forms 150 $\mathrm{kDa}$ complexes with nuclear DNA. Nuclear prohibitin showed the weaker interaction with mitochondrial and nuclear DNA, forming mixtures of 720 and $150 \mathrm{kDa}$ complexes (Figure 4.10, lane 5-8). Higher concentration of mtDNA and nuDNA with nuclear prohibitin breaks molecular interactions showing monomeric prohibitin at $32 \mathrm{kDa}$ (Figure 4.11, lane 6 and 8). To confirm prohibitin-mtDNA interaction, we used the sedimentation assay using mitochondrial prohibitin with or without mtDNA. Prohibitin from mitochondrial fraction formed high density complex with mtDNA (Figure 4.11). 


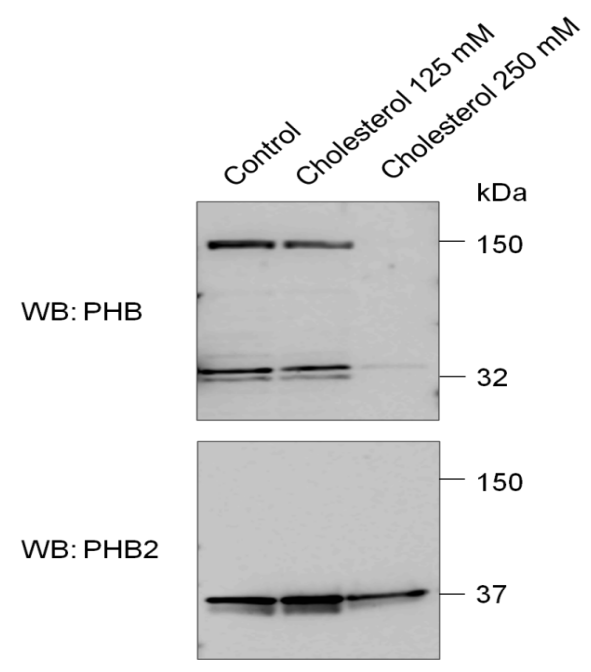

Figure 4.10 Cholesterol dependent prohibitin expression from RPE. ARPE-19 cells were treated with different concentrations of cholesterol for $16 \mathrm{hrs}$. Proteins were separated by SDS-PAGE and prohibitin expression is visualized by western blotting analysis. Increased cholesterol levels significantly down regulate the PHB1 expression whereas PHB2 levels show less sensitivity towards elevated cholesterol levels.

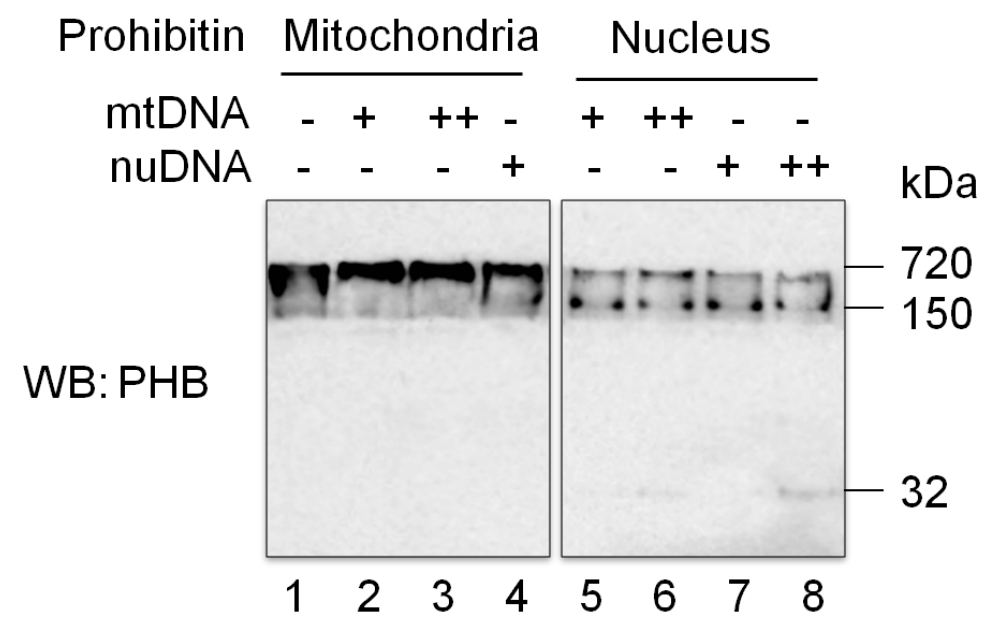

Figure 4.11 Prohibitin-DNA binding analysis. Sub cellular mitochondrial and nuclear PHB fractions from bovine retina were intercross mixed with gel-purified mitochondrial (mt) and nuclear (nu) DNA extracted from bovine retina. DNA-protein complexes were separated by native-PAGE and prohibitin expression is visualized by western blotting analysis. 


\section{Prohibitin-Binding Proteins}

To understand the downstream signaling of prohibitin in various subcellular organelles, prohibitin-binding proteins were determined using immunoprecipitation (IP) analysis. (Figure 4.12-13). ARPE-19 cells were treated with or without oxidative stress $(200 \mathrm{mM}$, $t$ - $\mathrm{BuOOH})$ and 49 putative prohibitin binding proteins in elution fractions were analyzed by MALDI-TOF mass spectrometry. IP with preimmune serum and a blank gel with trypsin digestion were used as negative controls and prohibitin-p53 binding was considered as a positive control (data not shown). Identified protein name, accession number, probability MOWSE score, sequence coverage, predicted mass, predicted pI, and identified peptide number were presented. Among these, a couple of cytoskeletal proteins, including kinesin, actin and myosin head motor domain, were found in both control and oxidative stress. Actins are highly conserved proteins that are involved in cell motility and structural integrity. It has a nucleotide binding domain which is crucial in the proper function of ion channels. Nucleoporin-like protein at $86 \mathrm{kDa}$ transports macromolecules between the nucleus and cytoplasm. Nucleoporin and lamins are speculated to be involved in the translocation of prohibitin between the nucleus and mitochondria. PI3K, p85 binding domain, suggests that prohibitin is involved in PIP3 pathway to regulate lipid and insulin signaling. Nuclear mitotic apparatus protein 1 isoform (NUMA) belongs to the same coiled coil family as prohibitin, myosins, lamins and intermediate filaments. NUMA is proposed to play a role in maintaining and establishing nuclear structure, possibly as a structural component of the nuclear matrix. Next, we used HRP (human retinal progenitor) cells to gain better understanding whether prohibitin in the retina may have similar function or binding partners. Actin and myosin binding of prohibitin may suggest mitochondrial DNA maintenance function of prohibitin in the retina. Pleckstrin $(\mathrm{PH})$ domain containing protein, $\mathrm{PH} 2$, Rab21 binding implies prohibitin-induced specific inositide and Ras signaling in the retina. 
Control

W1 W2 W3 E1 E2 E3 Eb

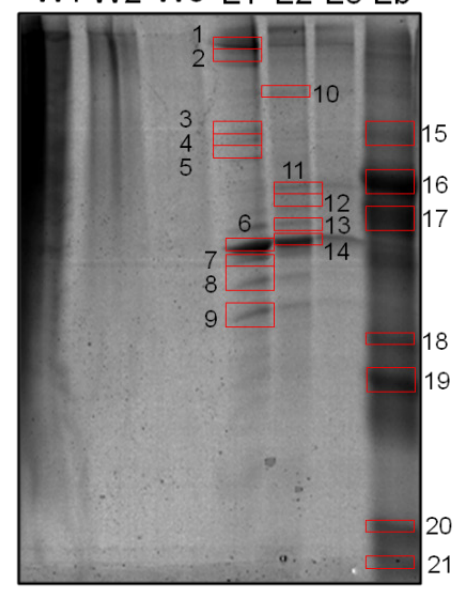

Oxidative stress

W1 W2 W3 E1 E2 E3 Eb kDa

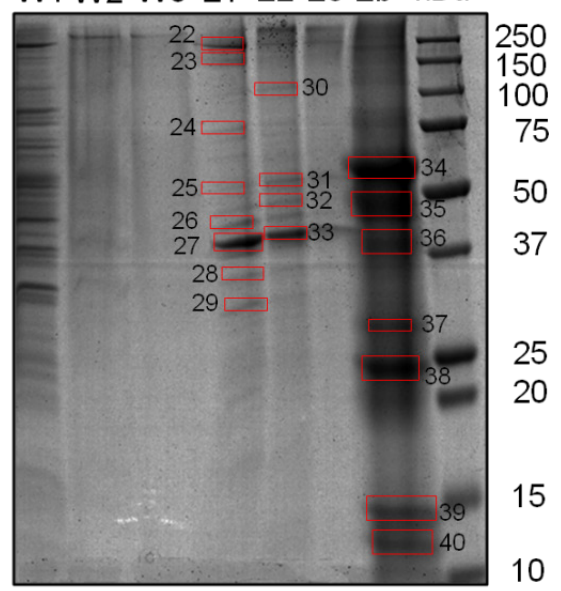

Figure 4.12 Immunoprecipitation of PHB interacting proteins. Coomassie stained gel of immunoprecipitated proteins from control ARPE-19 cells (lysate) with anti-PHB antibody. Cells were harvested, lysed followed by Co-IP and separated by SDS-PAGE. Proteins in the W1 to W3 represents wash fractions; E1 to E3 represents elution fractions; $\mathrm{Eb}$ represents the protein elution by immunoprecipitated boiling protein-A beads with sample buffer (Eb). Elution fractions showed that the potential binding partners of PHB, which were further processed for In-gel digestion and MALDI-TOF mass spectrometry. Coomassie stained gel of immunoprecipitated proteins from oxidative stress $(200 \mu \mathrm{M})$ treated ARPE-19 cells (lysate) with anti-PHB antibody. Cells were harvested, lysed followed by Co-IP and separated by SDS-PAGE. Proteins in the W1 to W3 represents wash fractions; E1 to E3 represents elution fractions; Eb represents the protein elution by immunoprecipitated boiling protein-A beads with sample buffer $(\mathrm{Eb})$. Protein standard (marker) represents the size between 10 to $120 \mathrm{kDa}$. . Elution fractions showed that the potential binding partners of PHB, which were further processed for In-gel digestion and MALDI-TOF mass spectrometry. 
Control

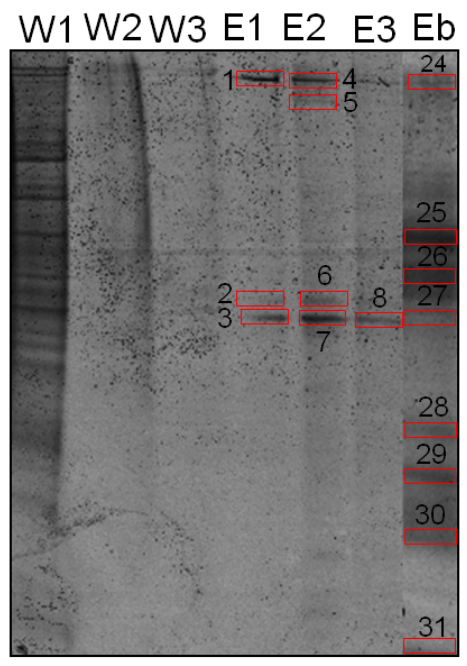

Oxidative stress

W1 W2 W3 E1 E2 E3 Eb kDa

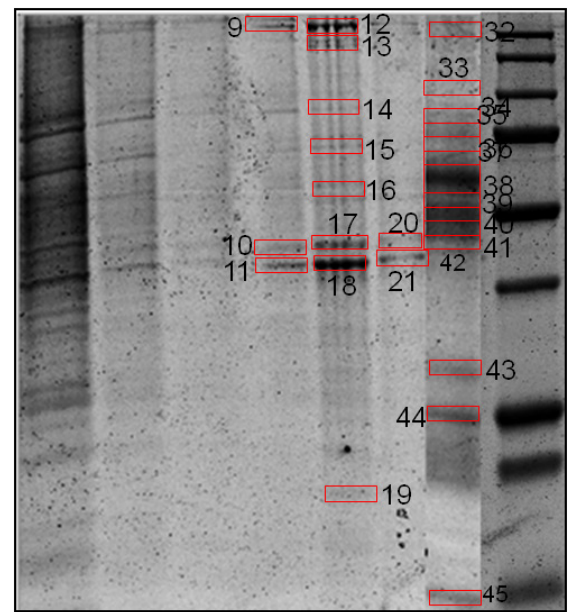

Figure 4.13 Co-Immunoprecipitation (Co-IP) of PHB interacting proteins. Coomassie stained gel of immunoprecipitated proteins from control human retinal progenitor (HRP) cells (lysate) with anti-PHB antibody. Cells were harvested, lysed followed by Co-IP and separated by SDS-PAGE. Proteins in the W1 to W3 represents wash fractions; E1 to E3 represents elution fractions; $\mathrm{Eb}$ represents the protein elution by immunoprecipitated boiling protein-A beads with sample buffer $(\mathrm{Eb})$. Elution fractions showed that the potential binding partners of PHB, which were further processed for In-gel digestion and MALDI-TOF mass spectrometry. Coomassie stained gel of immunoprecipitated proteins from oxidative stress $(100 \mu \mathrm{M})$ treated human retinal progenitor cells (lysate) with antiPHB antibody. Cells were harvested, lysed followed by Co-IP and separated by SDSPAGE. Proteins in the W1 to W3 represents wash fractions; E1 to E3 represents elution fractions; $\mathrm{Eb}$ represents the protein elution by immunoprecipitated boiling protein-A beads with sample buffer $(\mathrm{Eb})$. Protein standard (marker) represents the size between 10 to $120 \mathrm{kDa}$. Elution fractions showed that the potential binding partners of $\mathrm{PHB}$, which were further processed for In-gel digestion and MALDI-TOF mass spectrometry. 
Table 4.1 Potential binding partners of prohibitin from human retinal pigment epithelial (ARPE-19) and human retinal progenitor (HRP) cells.

\begin{tabular}{|c|c|c|c|c|c|c|c|}
\hline Band & Accession & Protein identified & score & $\%$ coverage & Mass & PI & Peptide \\
\hline A1 & 83404899 & Kinesin Family member 19 protein & 47325 & 8.2 & 93161 & 6.2 & 7 \\
\hline A1 & 194388398 & Myosin head (motor domain) & 253758 & 9.0 & 110912 & 8.5 & 7 \\
\hline A13 & $\underline{26330300}$ & Cadherin_repeat $\left(\mathrm{Ca}^{2+}\right.$ binding site $)$ & 633431 & 10.0 & 88790 & 4.7 & 6 \\
\hline A16 & 292352 & Collagen, partial & 189998 & 11.0 & 72107 & 7.3 & 5 \\
\hline A18 & $\underline{74187742}$ & Nucleoporin-like protein & $1.95 \mathrm{e}+6$ & 12.0 & 86380 & 6.5 & 6 \\
\hline A22 & $\underline{2217933}$ & PKU-beta(Serine/Threonine kinases) & 2211 & 7.6 & 88883 & 8.9 & 4 \\
\hline A22 & $\underline{8392959}$ & Beta-1,4-galactosyltransferase 2 & 3975 & 15.4 & 41910 & 9.4 & 4 \\
\hline A 22 & $\underline{113195686}$ & Lamin-B2 & 3513 & 10.9 & 67319 & 5.4 & 4 \\
\hline $\mathrm{A} 23$ & 194388398 & Myosin head (motor domain) & $9.80 \mathrm{e}+7$ & 15.1 & 110912 & 8.5 & 12 \\
\hline A25 & 158259341 & PI3-Kinase, $p 85$ binding domain protein & 645600 & 11.6 & 124285 & 6.9 & 8 \\
\hline A28 & 40352738 & Ion transport protein & 306309 & 18.5 & 61801 & 5.5 & 5 \\
\hline A32 & $\underline{4220898}$ & Transcriptional co-activator CRSP130 & 441010 & 8.4 & 106209 & 8.5 & 6 \\
\hline A33 & $\underline{41945518}$ & Tiam1 PH domain lipid binding protein & 105719 & 8.6 & 99654 & 8.7 & 7 \\
\hline A34 & 38569540 & 5'-3' exoribonuclease 2 isoform 3 & 140868 & 10.6 & 103802 & 8.2 & 7 \\
\hline A34 & $\underline{148705232}$ & Leucine rich repeats,pyrin death domain & 179814 & 9.4 & 112138 & 8.0 & 8 \\
\hline A35 & $\underline{624871}$ & a1(XIX) collagen chain precursor & $2.94 \mathrm{e}+7$ & 12.9 & 115096 & 8.4 & 8 \\
\hline A41 & $\underline{74187742}$ & Nucleoporin-like protein & 379387 & 10.2 & 86380 & 6.5 & 5 \\
\hline A44 & $\underline{62897409}$ & Beta actin variant & $2.47 \mathrm{e}+8$ & 35.5 & 41723 & 5.3 & 10 \\
\hline A 45 & $\underline{3603443}$ & Fibrousheathin I & 192098 & 11.7 & 94617 & 6.0 & 5 \\
\hline A45 & $\underline{5834582}$ & E3 ubiquitin-protein ligase TRIM33 & 66846 & 8.7 & 115982 & 7.1 & 6 \\
\hline
\end{tabular}




\begin{tabular}{|c|c|c|c|c|c|c|c|}
\hline A47 & 119582405 & Cadherin_repeat $\left(\mathrm{Ca}^{2+}\right.$ binding site $)$ & $4.44 \mathrm{e}+8$ & 18.6 & 88669 & 5.0 & 10 \\
\hline A49 & $\underline{13278786}$ & Nuclear mitotic apparatus protein 1 isoform CRA & $1.85 \mathrm{e}+7$ & 14.2 & 109280 & 8.1 & 11 \\
\hline Band & Accession & Protein identified & score & $\%$ coverage & Mass & PI & Peptide \\
\hline $\mathrm{H} 1$ & 194388398 & Myosin head (motor domain) & 161675 & 8.6 & 110912 & 8.5 & 7 \\
\hline $\mathrm{H} 4$ & $\underline{158256650}$ & Meckelin & $1.14 \mathrm{e}+9$ & 14.3 & 116422 & 6.2 & 11 \\
\hline H5 & $\underline{119603470}$ & Esterase 31, isoform CRA_e & 43420 & 7.7 & 59890 & 5.4 & 4 \\
\hline H6 & $\underline{7019942}$ & 5'-3' Exonuclease & $6.28 \mathrm{e}+6$ & 17.1 & 63785 & 9.0 & 6 \\
\hline H11 & $\underline{11908000}$ & BCL-6 corepressor short isoform & $1.78 \mathrm{e}+7$ & 17.8 & 107405 & 8.8 & 9 \\
\hline H11 & $\underline{119584312}$ & Inositol 1,4,5-triphosphate receptor, type 1 & $1.47 \mathrm{e}+6$ & 8.8 & 117553 & 6.2 & 6 \\
\hline $\mathrm{H} 13$ & $\underline{119612108}$ & Transmembrane protein 67 , isoform CRA_b & 752714 & 10.2 & 109958 & 6.2 & 6 \\
\hline H14 & $\underline{5882259}$ & Genethonin 3 & $9.41 \mathrm{e}+6$ & 15.3 & 89342 & 5.2 & 8 \\
\hline H19 & $\underline{14250401}$ & Actin, beta, partial & $4.89 \mathrm{e}+6$ & 32.3 & 41005 & 5.6 & 9 \\
\hline $\mathrm{H} 21 \mathrm{~S}$ & 74213524 & ACTB protein, partial & $1.22 \mathrm{e}+9$ & 33.6 & 41751 & 5.3 & 10 \\
\hline $\mathrm{H} 23 \mathrm{~S}$ & $\underline{2656123}$ & P-53 binding protein & 2881 & 7.4 & 93501 & 9.6 & 4 \\
\hline $\mathrm{H} 26$ & $\underline{2102696}$ & Karyopherin beta 3 & $6.53 \mathrm{e}+6$ & 13.2 & 123599 & 4.8 & 10 \\
\hline $\mathrm{H} 29$ & $\underline{115529728}$ & Guanine nucleotide exchange factor OSTIII & $5.98 \mathrm{e}+6$ & 8.8 & 123524 & 5.7 & 8 \\
\hline H32 & $\underline{34189309}$ & Nuclear Pore Protein 107 & $2.40 \mathrm{e}+11$ & 19.2 & 79971 & 5.2 & 8 \\
\hline H34 & $\underline{272982598}$ & Anti-HIV-1 gp120 immunoglobulin heavy chain & $4.02 \mathrm{e}+8$ & 22.4 & 51810 & 8.1 & 8 \\
\hline H36 & $\underline{5305448}$ & $\mathrm{PH}$ domain containing signaling mediator isoform & 175808 & 16.8 & 70047 & 5.7 & 6 \\
\hline $\mathrm{H} 38$ & $\underline{39644830}$ & Pleckstrin 2 protein, partial & 152085 & 24.2 & 39711 & 9.5 & 5 \\
\hline
\end{tabular}




\begin{tabular}{lrllllll} 
Band & Accession & Protein identified & score & \%coverage & Mass & PI & Peptide \\
\hline H39 & $\underline{7661922}$ & Ras related protein Rab-21 & 38925 & 33.8 & 24348 & 8.1 & 5 \\
H41 & $\underline{148692949}$ & Leucine rich repeat containing 21 & 169639 & 9.6 & 111679 & 6.8 & 5 \\
H44 & $\underline{226958677}$ & Guanine nucleotide exchange factor DSB isoform 3 & 872951 & 7.6 & 123694 & 5.7 & 8 \\
H45 & $\underline{148682292}$ & Retinis pigmentosa 1 homolog (human) & 30379 & 5.1 & 124037 & 9.5 & 6
\end{tabular}




\subsubsection{Lipid Binding Pocket in Prohibitin}

Controlled translocalization of prohibitin to specific subcellular organelle under stress condition is a critical event for apoptosis, proliferation, lipid metabolism, and aging. We speculate that prohibitin translocalization and trafficking might be influenced by specific lipid binding sequence and temporal lipid concentration. We hypothesized that prohibitin may have a putative lipid binding domains that include conserved basic amino acids. To test our hypothesis, we examined whether prohibitin has any homologous lipid binding domain or conserved basic amino acids using PFAM database (http://www.sanger.ac.uk/software/pfam), Ensembl human genome browser (http://www.ensembl.org/homo_sapiens), and support vector machine-based functional prediction (http://jing.cz3.nus.edu.sg/cgi-bin/svmprot.cgi). Lipid binding modules, including $\mathrm{C} 1$, C2, pleckstrin homology (PH), Phox homology (PX), Fab1-Yop-Vac1Eea1 (FVVE), Epsin amino-terminal homology (ENTH), Four-point-one-Ezrin-RadixinMoesin (FERM) domains, ANTH, BAR, PDZ, tubby, START, and Src homology 3 (SH3) domains, were examined. Previously we demonstrated that prohibitin has a strong affinity with phosphatidylinositol 3,4,5-triphosphate (PIP3) and cardiolipin under various stress conditions. Prohibitin also has low affinity toward PI (4)P, PI (4,5)P2, 3sulfogalactosylceramide, phosphatidic acid and phosphatidylserine. PIP3 interacts with PX domain containing proteins that include $\mathrm{p} 40^{\text {phox }}, \mathrm{p} 47^{\text {phox }}$, phospholipase D1 (PLD1), SNX6, and cytokine-independent serine/threonine kinase (CISK or SGK3). Multiple sequence alignment demonstrated that two of the most well conserved basic amino acids in prohibitin are R35, R43, R72 that are homologous to K75, R90, and R135 of SGK3, which represent phosphoinositide binding pocket (Figure 4. 8). R41 and R72 in prohibitin are also homologous to R43 and R90 in the PX domain of p47 phox (data not shown). Other conserved basic residues are K11, K83, R97, R105, R143, R157, K207, and K208 with SNX6 and SGK3, both known as phosphoinositide binding proteins. We compared the PX domain of prohibitin with the known $\mathrm{p} 47^{\text {phox }}$ structure. The conserved basic amino acid sequence is homologous to the cationic residues in the putative PIP3 binding pocket (R41, R72) of $\mathrm{p} 47^{\text {phox }}$ (data not shown). Phosphate groups in PIP3 may interact with 
three arginine residues, R41/43 and R72 of prohibitin. A conserved F42 (F44 in p47phox) seems essential for the inositide ring interaction to make $U$ shape PIP3 binding pocket. Two conserved proline residues, P64 and P98, suggest a $\beta$ turn structure, mimicking the second anion-binding site of $\mathrm{p} 47^{\mathrm{phox}}(\mathrm{P} 73, \mathrm{P} 76)$. Many more conserved basic residues that include R143, R157, K207, and K208, imply a putative second anion-binding site (e.g. cardiolipin) at $\mathrm{C}$ terminus.

\subsection{Discussion}

The current study is aimed to determine whether prohibitin is downregulated in the RPE leading to mitochondrial dysfunction in AMD. Decreased prohibitin may modulate lipid metabolism, transcriptional activation and RPE apoptosis to accelerate AMD pathway. We tested our working hypothesis of inverse correlation of prohibitin expression and AMD using in vivo model, prohibitin knockdown and molecular interaction assays. Our data demonstrates that prohibitin is depleted in the RPE during AMD pathogenesis. To determine the downstream mechanism of prohibitin signaling at the molecular level, we examined various prohibitin-binding assays, including mitochondrial/nuclear DNA, phospholipid, and immunoprecipitation. As the susceptibility of the RPE and retina to

oxidative stress is different, altered expression of prohibitin in the RPE and the retina are anticipated in the diabetic and aging model. Previously, our data showed that prohibitin is differentially expressed in the retina and RPE as an oxidative stress biomarker that significantly changed its concentration in light induced stress, aging and diabetic conditions (Lee et al., 2011). Further, we demonstrated that 1) stress-dependent translocalization of prohibitin between the nucleus and mitochondria as a retrograde signal, 2) PIP3 and cardiolipin binding changes under stress, 3) phosphorylation in the nucleus and interaction with the tumor suppressor p53, 4) accelerated apoptosis by prohibitin depletion. The changes in the expression and localization of prohibitin induced by reactive oxygen species are crucial events for mitochondrial integrity. Prohibitin is a lipid metabolism switch that binds to PIP3 and cardiolipin in a stress-dependent manner (Sripathi et al., 2011c). We speculated that prohibitin may contain lipid binding domain, including conserved basic amino acids. The rationale for examining the prohibitin-lipid 
interaction is that prohibitin showed stress-dependent lipid binding properties in vitro. Changes of prohibitin-lipid and protein interaction in RPE cells under oxidative stress characterized here will help to identify key elements of apoptotic networks that follow lipid metabolism and serve as a framework of biochemical pathways for future studies of AMD. Prohibitin-PIP3 interaction leads to attenuation of insulin signaling (Ande and Mishra, 2009). PIP3 has a central role in transmitting insulin signaling and may also provide a platform for protein-protein interaction. PIP3 acts as a signaling molecule in a variety of cellular processes including cell proliferation, cell motility, metabolism, and immune response. Prohibitin contains conserved basic amino acid residues as the PX domain with $25-50 \%$ homology. The PX domain is a phosphoinositide-binding domain with many functions including protein sorting, vesicular trafficking and phospholipid metabolism. Our multiple sequence alignment shows that prohibitin may have a phosphoinisitide binding site that may influence PIP3 and cardiolipin binding. Conserved basic residues are R43, R72, K83, R97, and R105 that are aligned with the p47 $7^{\text {phox }}$, SNX6, and SGK3 PX domain. PX domain residues are not highly conserved as shown as 25-50\% compared to other PX domain proteins, however, essential basic amino acids with hydrophobic (F, I, L, A) and structural (P, G) amino acids seems enough to make a phospholipid binding pocket. A putative secondary pocket also suggests that allosteric or post-translational modification-dependent, including $\mathrm{T} / \mathrm{Y}$ phosphorylation and $\mathrm{C}$ palmitoylation, regulatory mechanism on lipid binding. We speculate that the origin of prohibitin function on metabolism and aging is from altered lipid bindings, including cardiolipin and PIP3, under stress condition. Prohibitin binds to PIP3/PI(4,5)P2 with 5 fold ratio. In normal conditions, PI $(4,5) \mathrm{P} 2$ has higher concentration than PIP3, so strong PIP3 binding will facilitate PI3K reaction. However, prohibitin modulates this interaction toward cardiolipin under oxidative stress, suggesting switch-off function of phosphoinositide reaction. Cardiolipin plays an important role in assembly of respiratory chain complexes, m-AAA protease complex, and the $\alpha$-ketoglutarate dehydrogenase complex. m-AAA protease removes non-assembled polypeptides from inner mitochondrial membrane. Phosphatidylinositol is a key membrane constituent and a participant in essential metabolic processes on PI3K pathway. PIP3 stimulates signaling 
pathways involved in cell growth, survival, motility and proliferation. Phosphoinositidebinding proteins are phospholipases, protein kinases, membrane trafficking regulators, cytoskeletal scaffold, and ion channels. PIP3 binding involves electrostatic interactions with the negative charges of the phosphate groups on the inositol ring with characteristic clusters of basic amino acid residues in proteins. Prohibitin is a part of mitochondrial nucleotide-protein complex to protect endothelial cells against reactive oxygen speciesinduced senescence. Fibroblasts lacking prohibitin show aberrant mitochondrial cristae and exhibit a decreased resistance toward apoptosis. Apoptotic cells and photoreceptor discs are eliminated in circadian dependent manner by the phagocytotic mechanism by RPE. PI(4,5) $\mathrm{P}_{2}$ interventions, both degradation and synthesis, compromise phagocytic pathway. During phagocytosis, PIP3 and PI3K are regulated for clustering receptors and actin polymerization. Considering weak binding of PHB PI $(4,5) \mathrm{P}_{2}$ and strong binding with PIP3, prohibitin may act as a cell fate determinant by altering lipid interaction under oxidative stress. Prohibitin has an anti-apoptotic function in mitochondria as the default function showing high affinity toward PIP3 under normal condition as a positive regulator of PI3K pathway. Prohibitin may become a transcriptional regulator in the nucleus under oxidative stress with weaker interaction with PIP3. The dual lipid binding switch might be essential to regulate RPE cells from uncontrolled proliferation under oxidative and altered lipid environment on diabetes and aging. Depletion of prohibitin may affect lipid metabolism in aging- and oxidative stress-dependent manner. Prohibitinmediated signaling, including epithelial migration, reversal of obesity, drug sensitivity, and longevity, is known (Kolonin et al., 2004a; Rajalingam et al., 2005). Prohibitin was proposed as an anti-proliferative protein or a tumor suppressor forming a high molecular complex with prohibitin2 in mitochondria. Localization of prohibitin has been controversial as being mitochondrial, nuclear, or cell surface possibly due to cell type and lipid environment. The current study identified the potential binding partners of prohibitin and their putative functional roles in the retina and RPE. Differential expression of prohibitin was observed in the postmortem retinas of diabetic retinopathy (DR), aged, also in the retinas of mouse and rats in vivo. Region-specific expression of prohibitin with respect to retina (macular and peripheral) and RPE (central and 
peripheral) were observed in the postmortem tissues of AMD. Based on our biochemical and proteomic analysis, we suggest that prohibitin is a specific lipid binding modulator in diabetes-induced retinopathy and age-related retinal degenerative diseases. Prohibitin showed strong affinity with PIP3 compared to PI(4,5)P2. This interaction may facilitate the forward reaction of PI3K pathway in normal and stress conditions. Prohibitin interacts with cardiolipin as a retrograde response to activate mitochondrial proliferation. Lipid binding switch mechanism of prohibitin may suggest the origin of prohibitin effect on energy metabolism and age-related diseases. 


\section{CONCLUSION}

In this study, we demonstrate that mitochondrial chaperone and anti-apoptotic protein prohibitin is translocalized from mitochondria to nucleus in response to oxidative stress. Mitochondrial-nuclear (MT-NU) communication by prohibitin shuttling involves lipid interaction changes such as PHB-phosphatidylinositol phosphates (PIP3) in normal condition compared to PHB- cardiolipin binding and nuclear prohibitin phosphorylation during oxidative stress. Prohibitin interaction with p53 reveals the role of nuclear PHB in transcriptional regulation. Our knockdown approach using prohibitin specific small interfering RNA (siRNA) resulted in the upregulation of pro-apoptotic proteins (AIF, caspases-9, BAK) and downregulation of anti-apoptotic protein (Bcl-xL). The phenotypic sub cellular organelle changes provide valid evidence that prohibitin is involved in the anti-apoptotic signaling to protect the RPE from oxidative damage.

Our data reveals that, concentration of NO generation is elevated during intense light exposure, oxidative damage and re-oxygenation towards RPE cells. We provide the evidence that inducible nitric oxide synthase (iNOS) is actively involved in the production of $\mathrm{NO}$ and also increase in protein nitration by the formation of 3 nitrotyrosine in the RPE under oxidative stress. We also determined that upregulation of PP2Ac (catalytic subunit) phosphorylation negatively correlates with the vimentin phosphorylation under oxidative stress. NO production in the cells enables the down regulation of PP2Ac phosphorylation to further achieve vimentin filament stabilization during stress induction. The timely generated NO may indirectly influence the cytoskeletal dynamics and apoptotic pathways via phosphorylation or dephosphorylation signaling.

Further, we have identified the potential binding partners of prohibitin in the retina and RPE cells under oxidative stress. Increased levels of prohibitin in the central (macular) and peripheral retina, and decreased levels of prohibitin in the central (macular) and peripheral RPE were identified from age-related macular degeneration (AMD) donor eyes. We also found that prohibitin in the retinas of diabetic retinopathy is increased 
from rats, mouse and humans. On the other hand, increase in expression of prohibitin was observed in the aged retinas of rats, mouse and human as well. 


\section{FUTURE DIRECTIONS}

We found that prohibitin is up regulated in the retina but down regulated in the RPE of age-related macular degeneration (AMD) and diabetic retinopathy (DR). The tissue specific prohibitin expression and regulation is needed to be clearly understood in transgenic animal models. Retinal neo-vascularization is the common pathological feature in diabetic retinopathy (DR), AMD and retinopathy of prematurity (ROP), so understanding the role of prohibitin during hypoxia induced retinal angiogenesis may reveal its crucial function in retinal degenerative diseases. Identification of prohibitin interacting protein network will unveil the various signaling pathways that are involved in prohibitin expression and regulation in disease condition. Sequence-specific DNAprohibitin binding is crucial in understanding the nuclear functions of prohibitin in the retina and RPE. We observed that nuclear prohibitin is phosphorylated, however, other post translational modifications such as acetylation, palmitoylation, and glycosylation need to be confirmed. We measured the concentration of nitric oxide generated from RPE cells in vitro, however, the ideal levels of NO required for RPE protection from apoptosis need to be established. As the RPE cells release NO under stress response, determining the beneficial or deleterious effects of such NO on neural retina is highly necessary. NO signaling studies need to be performed in age-related macular degeneration, diabetic retinopathy and aged models in vivo. In our study, we mainly focused on biochemical and proteomic approaches to understand the involvement of various proteins during retina and RPE apoptosis. Identification of complete protein, lipid binding network, and detailed phosphorylation signaling for target proteins is required to understand the mechanism of retina and RPE cell death. 


\section{REFERENCES}

Adrian, W., Everson, R.W., and Schmidt, I. (1977). Protection against photic damage in retinitis pigmentosa. Advances in experimental medicine and biology 77, 233-247.

Alder, V.A., and Cringle, S.J. (1985). The effect of the retinal circulation on vitreal oxygen tension. Current eye research 4, 121-129.

Ande, S.R., and Mishra, S. (2009). Prohibitin interacts with phosphatidylinositol 3,4,5triphosphate (PIP3) and modulates insulin signaling. Biochemical and biophysical research communications 390, 1023-1028.

Ande, S.R., and Mishra, S. (2010). Palmitoylation of prohibitin at cysteine 69 facilitates its membrane translocation and interaction with Eps 15 homology domain protein 2 (EHD2). Biochemistry and cell biology $=$ Biochimie et biologie cellulaire 88, 553-558.

Ando, S., Tanabe, K., Gonda, Y., Sato, C., and Inagaki, M. (1989). Domain-Specific and Sequence-Specific Phosphorylation of Vimentin Induces Disassembly of the Filament Structure. Biochemistry-Us 28, 2974-2979.

Arnouk, H., Lee, H., Zhang, R., Chung, H., Hunt, R.C., and Jahng, W.J. (2011a). Early biosignature of oxidative stress in the retinal pigment epithelium. Journal of proteomics $74,254-261$.

Arnouk, H., Lee, H., Zhang, R.N., Chung, H., Hunt, R.C., and Jahng, W.J. (2011b). Early biosignature of oxidative stress in the retinal pigment epithelium. Journal of proteomics $74,254-261$.

Artal-Sanz, M., and Tavernarakis, N. (2009a). Prohibitin couples diapause signalling to mitochondrial metabolism during ageing in C-elegans. Nature 461, 793-U747.

Artal-Sanz, M., and Tavernarakis, N. (2009b). Prohibitin couples diapause signalling to mitochondrial metabolism during ageing in C. elegans. Nature 461, 793-797.

Artal-Sanz, M., and Tavernarakis, N. (2010). Opposing function of mitochondrial prohibitin in aging. Aging 2, 1004-1011. 
Artal-Sanz, M., Tsang, W.Y., Willems, E.M., Grivell, L.A., Lemire, B.D., van der Spek, H., and Nijtmans, L.G. (2003). The mitochondrial prohibitin complex is essential for embryonic viability and germline function in Caenorhabditis elegans. The Journal of biological chemistry 278, 32091-32099.

Bailey, T.A., Kanuga, N., Romero, I.A., Greenwood, J., Luthert, P.J., and Cheetham, M.E. (2004). Oxidative stress affects the junctional integrity of retinal pigment epithelial cells. Investigative ophthalmology \& visual science 45, 675-684.

Beatty, S., Koh, H., Phil, M., Henson, D., and Boulton, M. (2000). The role of oxidative stress in the pathogenesis of age-related macular degeneration. Surv Ophthalmol 45, $115-$ 134.

Bourges, I., Ramus, C., Mousson de Camaret, B., Beugnot, R., Remacle, C., Cardol, P., Hofhaus, G., and Issartel, J.P. (2004). Structural organization of mitochondrial human complex I: role of the ND4 and ND5 mitochondria-encoded subunits and interaction with prohibitin. The Biochemical journal 383, 491-499.

Brown, B.M., Carlson, B.L., Zhu, X.M., Lolley, R.N., and Craft, C.M. (2002). Lightdriven translocation of the protein phosphatase $2 \mathrm{~A}$ complex regulates light/dark dephosphorylation of phosducin and rhodopsin. Biochemistry-Us 41, 13526-13538.

Calzi, S.L., Purich, D.L., Chang, K.H., Afzal, A., Nakagawa, T., Busik, J.V., Agarwal, A., Segal, M.S., and Grant, M.B. (2008). Carbon monoxide and nitric oxide mediate cytoskeletal reorganization in microvascular cells via vasodilator-stimulated phosphoprotein phosphorylation - Evidence for blunted responsiveness in diabetes. Diabetes 57, 2488-2494.

Cannino, G., Di Liegro, C.M., and Rinaldi, A.M. (2007). Nuclear-mitochondrial interaction. Mitochondrion 7, 359-366.

Chakravarthy, U., Stitt, A.W., Mcnally, J., Bailie, J.R., Hoey, E.M., and Duprex, P. (1995). Nitric-Oxide Synthase Activity and Expression in Retinal Capillary EndothelialCells and Pericytes. Current eye research 14, 285-294. 
Chang, G.Q., Hao, Y., and Wong, F. (1993). Apoptosis: final common pathway of photoreceptor death in rd, rds, and rhodopsin mutant mice. Neuron 11, 595-605.

Chen, S.J., Wang, Y.L., Lo, W.T., Wu, C.C., Hsieh, C.W., Huang, C.F., Lan, Y.H., Wang, C.C., Chang, D.M., and Sytwu, H.K. (2010). Erythropoietin enhances endogenous haem oxygenase-1 and represses immune responses to ameliorate experimental autoimmune encephalomyelitis. Clinical and experimental immunology 162, 210-223.

Chen, W., Arroyo, J.D., Timmons, J.C., Possemato, R., and Hahn, W.C. (2005). Cancerassociated PP2A Aalpha subunits induce functional haploinsufficiency and tumorigenicity. Cancer Res 65, 8183-8192.

Cho, U.S., and Xu, W.Q. (2007). Crystal structure of a protein phosphatase 2A heterotrimeric holoenzyme. Nature 445, 53-57.

Chung, H., Lee, H., Lamoke, F., Hrushesky, W.J., Wood, P.A., and Jahng, W.J. (2009a). Neuroprotective role of erythropoietin by antiapoptosis in the retina. J Neurosci Res 87 , $2365-2374$.

Chung, H., Lee, H., Lamoke, F., Hrushesky, W.J.M., Wood, P.A., and Jahng, W.J. (2009b). Neuroprotective Role of Erythropoietin by Antiapoptosis in the Retina. J Neurosci Res 87, 2365-2374.

Coates, P.J., Jamieson, D.J., Smart, K., Prescott, A.R., and Hall, P.A. (1997). The prohibitin family of mitochondrial proteins regulate replicative lifespan. Current biology : CB 7, 607-610.

Cox, B., and Emili, A. (2006a). Tissue subcellular fractionation and protein extraction for use in mass-spectrometry-based proteomics. Nature protocols 1, 1872-1878.

Cox, B., and Emili, A. (2006b). Tissue subcellular fractionation and protein extraction for use in mass-spectrometry-based proteomics. Nature protocols 1, 1872-1878.

Davis, A.A., Bernstein, P.S., Bok, D., Turner, J., Nachtigal, M., and Hunt, R.C. (1995). A Human Retinal-Pigment Epithelial-Cell Line That Retains Epithelial Characteristics after Prolonged Culture. Investigative ophthalmology \& visual science 36, 955-964. 
Delsite, R., Kachhap, S., Anbazhagan, R., Gabrielson, E., and Singh, K.K. (2002). Nuclear genes involved in mitochondria-to-nucleus communication in breast cancer cells. Molecular cancer 1,6 .

Di, C., Xu, W.Y., Su, Z., and Yuan, J.S. (2010). Comparative genome analysis of PHB gene family reveals deep evolutionary origins and diverse gene function. Bmc Bioinformatics 11 .

Di Stasi, A.M., Mallozzi, C., Macchia, G., Petrucci, T.C., and Minetti, M. (1999). Peroxynitrite induces tryosine nitration and modulates tyrosine phosphorylation of synaptic proteins. Journal of neurochemistry 73, 727-735.

Dong, A., Xie, B., Shen, J., Yoshida, T., Yokoi, K., Hackett, S.F., and Campochiaro, P.A. (2009). Oxidative Stress Promotes Ocular Neovascularization. J Cell Physiol 219, 544552.

Dong, P., Flores, J., Pelton, K., and Solomon, K.R. (2010). Prohibitin is a cholesterolsensitive regulator of cell cycle transit. Journal of cellular biochemistry 111, 1367-1374.

Dunn, K.C., Aotaki-Keen, A.E., Putkey, F.R., and Hjelmeland, L.M. (1996). ARPE-19, a human retinal pigment epithelial cell line with differentiated properties. Exp Eye Res 62, 155-169.

Estrada, C., and DeFelipe, J. (1998). Nitric oxide-producing neurons in the neocortex: morphological and functional relationship with intraparenchymal microvasculature. Cereb Cortex 8, 193-203.

Fusaro, G., Dasgupta, P., Rastogi, S., Joshi, B., and Chellappan, S. (2003a). Prohibitin induces the transcriptional activity of p53 and is exported from the nucleus upon apoptotic signaling. The Journal of biological chemistry 278, 47853-47861.

Fusaro, G., Dasgupta, P., Rastogi, S., Joshi, B., and Chellappan, S. (2003b). Prohibitin induces the transcriptional activity of p53 and is exported from the nucleus upon apoptotic signaling. Journal of Biological Chemistry 278, 47853-47861. 
Genc, S., Kuralay, F., Genc, K., Akhisaroglu, M., Fadiloglu, S., Yorukoglu, K., Fadiloglu, M., and Gure, A. (2001). Erythropoietin exerts neuroprotection in 1-methyl-4phenyl-1,2,3,6-tetrahydropyridine-treated C57/BL mice via increasing nitric oxide production. Neuroscience letters 298, 139-141.

Goureau, O., Hicks, D., Courtois, Y., and De Kozak, Y. (1994). Induction and regulation of nitric oxide synthase in retinal Muller glial cells. Journal of neurochemistry 63, 310317.

Gregory-Bass, R.C., Olatinwo, M., Xu, W., Matthews, R., Stiles, J.K., Thomas, K., Liu, D., Tsang, B., and Thompson, W.E. (2008). Prohibitin silencing reverses stabilization of mitochondrial integrity and chemoresistance in ovarian cancer cells by increasing their sensitivity to apoptosis. International Journal of Cancer 122, 1923-1930.

Grimm, C., Wenzel, A., Groszer, M., Mayser, H., Seeliger, M., Samardzija, M., Bauer, C., Gassmann, M., and Reme, C.E. (2002). HIF-1-induced erythropoietin in the hypoxic retina protects against light-induced retinal degeneration. Nature medicine 8, 718-724.

Grimm, C., Wenzel, A., Hafezi, F., Yu, S., Redmond, T.M., and Reme, C.E. (2000). Protection of Rpe65-deficient mice identifies rhodopsin as a mediator of light-induced retinal degeneration. Nat Genet 25, 63-66.

Holscher, C. (1997). Nitric oxide, the enigmatic neuronal messenger: its role in synaptic plasticity. Trends in neurosciences 20, 298-303.

Ikonen, E., Fiedler, K., Parton, R.G., and Simons, K. (1995). Prohibitin, an Antiproliferative Protein, Is Localized to Mitochondria. FEBS letters 358, 273-277.

Jahng, W.J. (2012). New Biomarkers in the Retina and RPE Under Oxidative Stress.

Kalev, P., and Sablina, A.A. (2011). Protein Phosphatase 2A as a Potential Target for Anticancer Therapy. Anti-Cancer Agent Me 11, 38-46.

Karnovsky, M.J. (1985). Citation Classic - a Formaldehyde-Glutaraldehyde Fixative of High Osmolality for Use in Electron-Microscopy. Cc/Life Sci, 20-20. 
Knowles, R.G., and Moncada, S. (1994). Nitric-Oxide Synthases in Mammals. Biochemical Journal 298, 249-258.

Ko, K.S., Tomasi, M.L., Iglesias-Ara, A., French, B.A., French, S.W., Romani, K., Lozano, J.J., Oh, P., He, L., Stiles, B.L., et al. (2010). Liver-Specific Deletion of Prohibitin 1 Results in Spontaneous Liver Injury, Fibrosis, and Hepatocellular Carcinoma in Mice. Hepatology 52, 2096-2108.

Koch, K.W., Lambrecht, H.G., Haberecht, M., Redburn, D., and Schmidt, H.H. (1994). Functional coupling of a $\mathrm{Ca} 2+/$ calmodulin-dependent nitric oxide synthase and a soluble guanylyl cyclase in vertebrate photoreceptor cells. The EMBO journal 13, 3312-3320.

Kolonin, M.G., Saha, P.K., Chan, L., Pasqualini, R., and Arap, W. (2004a). Reversal of obesity by targeted ablation of adipose tissue. Nature medicine 10, 625-632.

Kolonin, M.G., Saha, P.K., Chan, L., Pasqualini, R., and Arap, W. (2004b). Reversal of obesity by targeted ablation of adipose tissue. Nature medicine 10, 625-632.

Lee, H., Arnouk, H., Sripathi, S., Chen, P., Zhang, R.A., Bartoli, M., Hunt, R.C., Hrushesky, W.J.M., Chung, H., Lee, S.H., et al. (2010a). Prohibitin as an oxidative stress biomarker in the eye. Int J Biol Macromol 47, 685-690.

Lee, H., Chung, H., Arnouk, H., Lamoke, F., Hunt, R.C., Hrushesky, W.J., Wood, P.A., Lee, S.H., and Jahng, W.J. (2010b). Cleavage of the retinal pigment epithelium-specific protein RPE65 under oxidative stress. Int J Biol Macromol 47, 104-108.

Lee, H., Chung, H., Arnouk, H., Lamoke, F., Hunt, R.C., Hrushesky, W.J.M., Wood, P.A., Lee, S.H., and Jahng, W.J. (2010c). Cleavage of the retinal pigment epitheliumspecific protein RPE65 under oxidative stress. Int J Biol Macromol 47, 104-108.

Lee, H., Chung, H., Lee, S.H., and Jahng, W.J. (2011). Light-induced phosphorylation of crystallins in the retinal pigment epithelium. Int J Biol Macromol 48, 194-201.

Liversidge, J., Grabowski, P., Ralston, S., Benjamin, N., and Forrester, J.V. (1994). Rat retinal pigment epithelial cells express an inducible form of nitric oxide synthase and 
produce nitric oxide in response to inflammatory cytokines and activated $\mathrm{T}$ cells. Immunology 83, 404-409.

Mann, B.E., and Motterlini, R. (2007). CO and NO in medicine. Chem Commun, 41974208.

Marletta, M.A. (1993). Nitric-Oxide Synthase Structure and Mechanism. Journal of Biological Chemistry 268, 12231-12234.

Marletta, M.A., Yoon, P.S., Iyengar, R., Leaf, C.D., and Wishnok, J.S. (1988). Macrophage Oxidation of L-Arginine to Nitrite and Nitrate - Nitric-Oxide Is an Intermediate. Biochemistry-Us 27, 8706-8711.

McClung, J.K., Danner, D.B., Stewart, D.A., Smith, J.R., Schneider, E.L., Lumpkin, C.K., Dell'Orco, R.T., and Nuell, M.J. (1989). Isolation of a cDNA that hybrid selects antiproliferative mRNA from rat liver. Biochemical and biophysical research communications $164,1316-1322$.

McClung, J.K., Jupe, E.R., Liu, X.T., and Dell'Orco, R.T. (1995a). Prohibitin: potential role in senescence, development, and tumor suppression. Experimental gerontology 30, 99-124.

Mcclung, J.K., Jupe, E.R., Liu, X.T., and Dellorco, R.T. (1995b). Prohibitin - Potential Role in Senescence, Development, and Tumor Suppression. Experimental gerontology 30, 99-124.

Medearis, S., Han, I.C., Huang, J.K., Yang, P., and Jaffe, G.J. (2011). The role of Bcl-xL in mouse RPE cell survival. Investigative ophthalmology \& visual science 52, 65456551.

Mishra, S., Murphy, L.C., Nyomba, B.L., and Murphy, L.J. (2005). Prohibitin: a potential target for new therapeutics. Trends in molecular medicine 11, 192-197.

Mishra, S., Vessal, M., Moulik, S., and Murphy, L.J. (2006). Prohibitin attenuates insulin-stimulated glucose and fatty acid oxidation in adipose tissue by inhibition of pyruvate carboxylase. Diabetes 55, A314-A314. 
Miyachi, E., Murakami, M., and Nakaki, T. (1990). Arginine blocks gap junctions between retinal horizontal cells. Neuroreport 1, 107-110.

Miyagi, M., Sakaguchi, H., Darrow, R.M., Yan, L., West, K.A., Aulak, K.S., Stuehr, D.J., Hollyfield, J.G., Organisciak, D.T., and Crabb, J.W. (2002). Evidence that light modulates protein nitration in rat retina. Molecular \& Cellular Proteomics 1, 293-303.

Mocellin, S., Bronte, V., and Nitti, D. (2007). Nitric oxide, a double edged sword in cancer biology: Searching for therapeutic opportunities. Medicinal research reviews 27, 317-352.

Monteiro, H.P., Arai, R.J., and Travassos, L.R. (2008). Protein tyrosine phosphorylation and protein tyrosine nitration in redox signaling. Antioxidants \& redox signaling $10,843-$ 889.

Morrow, I.C., Rea, S., Martin, S., Prior, I.A., Prohaska, R., Hancock, J.F., James, D.E., and Parton, R.G. (2002). Flotillin-1/reggie-2 traffics to surface raft domains via a novel golgi-independent pathway. Identification of a novel membrane targeting domain and a role for palmitoylation. The Journal of biological chemistry 277, 48834-48841.

Nathan, C. (1992). Nitric-Oxide as a Secretory Product of Mammalian-Cells. Faseb J 6, 3051-3064.

Nijtmans, L.G., Artal, S.M., Grivell, L.A., and Coates, P.J. (2002). The mitochondrial PHB complex: roles in mitochondrial respiratory complex assembly, ageing and degenerative disease. Cellular and molecular life sciences : CMLS 59, 143-155.

Nijtmans, L.G., de Jong, L., Artal Sanz, M., Coates, P.J., Berden, J.A., Back, J.W., Muijsers, A.O., van der Spek, H., and Grivell, L.A. (2000a). Prohibitins act as a membrane-bound chaperone for the stabilization of mitochondrial proteins. The EMBO journal 19, 2444-2451.

Nijtmans, L.G.J., de Jong, L., Sanz, M.A., Coates, P.J., Berden, J.A., Back, J.W., Muijsers, A.O., van der Spek, H., and Grivell, L.A. (2000b). Prohibitins act as a membrane-bound chaperone for the stabilization of mitochondrial proteins. Embo Journal 19, 2444-2451. 
Noell, W.K., Walker, V.S., Kang, B.S., and Berman, S. (1966). Retinal damage by light in rats. Investigative ophthalmology 5, 450-473.

Nuell, M.J., Stewart, D.A., Walker, L., Friedman, V., Wood, C.M., Owens, G.A., Smith, J.R., Schneider, E.L., Dellorco, R., Lumpkin, C.K., et al. (1991). Prohibitin, an Evolutionarily Conserved Intracellular Protein That Blocks DNA-Synthesis in Normal Fibroblasts and Hela-Cells. Molecular and cellular biology 11, 1372-1381.

Osborne, N.N., Barnett, N.L., and Herrera, A.J. (1993). Nadph Diaphorase Localization and Nitric-Oxide Synthetase-Activity in the Retina and Anterior Uvea of the Rabbit Eye. Brain research 610, 194-198.

Osman, C., Haag, M., Potting, C., Rodenfels, J., Dip, P.V., Wieland, F.T., Brugger, B., Westermann, B., and Langer, T. (2009). The genetic interactome of prohibitins: coordinated control of cardiolipin and phosphatidylethanolamine by conserved regulators in mitochondria. The Journal of cell biology 184, 583-596.

Owaribe, K., Sugino, H., and Masuda, H. (1986). Characterization of intermediate filaments and their structural organization during epithelium formation in pigmented epithelial cells of the retina in vitro. Cell and tissue research 244, 87-93.

Palamalai, V., Darrow, R., Organisciak, D.T., and Miyagi, M. (2006). Light-induced changes in protein nitration in photoreceptor rod outer segments. Molecular vision 12, 1543-1551.

Patel, N., Chatterjee, S.K., Vrbanac, V., Chung, I., Mu, C.J., Olsen, R.R., Waghorne, C., and Zetter, B.R. (2010). Rescue of paclitaxel sensitivity by repression of Prohibitin1 in drug-resistant cancer cells. Proceedings of the National Academy of Sciences of the United States of America 107, 2503-2508.

Perez, M.T., Larsson, B., Alm, P., Andersson, K.E., and Ehinger, B. (1995). Localisation of neuronal nitric oxide synthase-immunoreactivity in rat and rabbit retinas. Experimental brain research Experimentelle Hirnforschung Experimentation cerebrale 104, 207-217. 
Porteracailliau, C., Sung, C.H., Nathans, J., and Adler, R. (1994). Apoptotic Photoreceptor Cell-Death in Mouse Models of Retinitis-Pigmentosa. Proceedings of the National Academy of Sciences of the United States of America 91, 974-978.

Rajalingam, K., Wunder, C., Brinkmann, V., Churin, Y., Hekman, M., Sievers, C., Rapp, U.R., and Rudel, T. (2005). Prohibitin is required for Ras-induced Raf-MEK-ERK activation and epithelial cell migration. Nat Cell Biol 7, 837-843.

Rivera-Milla, E., Stuermer, C.A., and Malaga-Trillo, E. (2006). Ancient origin of reggie (flotillin), reggie-like, and other lipid-raft proteins: convergent evolution of the SPFH domain. Cellular and molecular life sciences : CMLS 63, 343-357.

Rose, M.J., and Mascharak, P.K. (2008). Fiat Lux: selective delivery of high flux of nitric oxide (NO) to biological targets using photoactive metal nitrosyls. Curr Opin Chem Biol $12,238-244$.

Ryan, M.T., and Hoogenraad, N.J. (2007). Mitochondrial-nuclear communications. Annual review of biochemistry 76, 701-722.

Sanchez-Quiles, V., Santamaria, E., Segura, V., Sesma, L., Prieto, J., and Corrales, F.J. (2010). Prohibitin deficiency blocks proliferation and induces apoptosis in human hepatoma cells: molecular mechanisms and functional implications. Proteomics 10, 16091620.

Sanz, M.A., Tsang, W., Willems, E., Grivell, L., Lemire, B., van der Spek, H., and Nijtmans, L. (2004). The mitochondrial prohibitin complex is essential for embryonic viability, germline function and mitochondrial morphology in Caenorhabditis elegans. Bba-Bioenergetics 1657, 73-74.

Sharma, A., and Qadri, A. (2004a). Vi polysaccharide of Salmonella typhi targets the prohibitin family of molecules in intestinal epithelial cells and suppresses early inflammatory responses. Proceedings of the National Academy of Sciences of the United States of America 101, 17492-17497.

Sharma, A., and Qadri, A. (2004b). Vi polysaccharide of Salmonella typhi targets the prohibitin family of molecules in intestinal epithelial cells and suppresses early 108 
inflammatory responses. Proceedings of the National Academy of Sciences of the United States of America 101, 17492-17497.

Shi, S.L., Li, Q.F., Liu, Q.R., Xu, D.H., Tang, J., Liang, Y., Zhao, Z.L., and Yang, L.M. (2009). Nuclear Matrix Protein, Prohibitin, Was Down-Regulated and Translocated From Nucleus to Cytoplasm During the Differentiation of Osteosarcoma MG-63 Cells Induced by Ginsenoside Rg1. Cinnamic acid, and Tanshinone IIA (RCT). Journal of cellular biochemistry 108, 926-934.

Shigenaga, M.K., Hagen, T.M., and Ames, B.N. (1994a). Oxidative damage and mitochondrial decay in aging. Proceedings of the National Academy of Sciences of the United States of America 91, 10771-10778.

Shigenaga, M.K., Hagen, T.M., and Ames, B.N. (1994b). Oxidative Damage and Mitochondrial Decay in Aging. Proceedings of the National Academy of Sciences of the United States of America 91, 10771-10778.

Sortino, S. (2010). Light-controlled nitric oxide delivering molecular assemblies. Chemical Society reviews 39, 2903-2913.

Sripathi, S., He, W., Atkinson, C., Smith, J., Liu, Z., Elledge, B., and Jahng, W. (2011a). Mitochondrial-nuclear communication by prohibitin shuttling under oxidative stress. Biochemistry-Us 50, 8342.

Sripathi, S.R., He, W., Atkinson, C.L., Smith, J.J., Liu, Z., Elledge, B.M., and Jahng, W.J. (2011b). Mitochondrial-nuclear communication by prohibitin shuttling under oxidative stress. Biochemistry-Us 50, 8342-8351.

Sripathi, S.R., He, W., Um, J.-Y., Moser, T., Dehnbostel, S., Kindt, K., Goldman, J., Frost, M.C., and Jahng, W.J. (2012). Nitric oxide leads to cytoskeletal reorganization in the retinal pigment epithelium under oxidative stress.

Sripathi, S.R., He, W.L., Atkinson, C.L., Smith, J.J., Liu, Z.C., Elledge, B.M., and Jahng, W.J. (2011c). Mitochondrial-Nuclear Communication by Prohibitin Shuttling under Oxidative Stress. Biochemistry-Us 50, 8342-8351. 
Steglich, G., Neupert, W., and Langer, T. (1999). Prohibitins regulate membrane protein degradation by the m-AAA protease in mitochondria. Molecular and cellular biology 19, 3435-3442.

Sugimoto, K., Fujii, S., Takemasa, T., and Yamashita, K. (2000). Detection of intracellular nitric oxide using a combination of aldehyde fixatives with 4,5diaminofluorescein diacetate. Histochemistry and cell biology 113, 341-347.

Tanimukai, H., Kudo, T., Tanaka, T., Grundke-Iqbal, I., Iqbal, K., and Takeda, M. (2009). Novel therapeutic strategies for neurodegenerative disease. Psychogeriatrics : the official journal of the Japanese Psychogeriatric Society 9, 103-109.

Taylor, H.R., West, S., Munoz, B., Rosenthal, F.S., Bressler, S.B., and Bressler, N.M. (1992). The long-term effects of visible light on the eye. Arch Ophthalmol 110, 99-104.

Terashima, M., Kim, K.M., Adachi, T., Nielsen, P.J., Reth, M., Kohler, G., and Lamers, M.C. (1994). The Igm Antigen Receptor of B-Lymphocytes Is Associated with Prohibitin and a Prohibitin-Related Protein. Embo Journal 13, 3782-3792.

Theiss, A.L., Idell, R.D., Srinivasan, S., Klapproth, J.M., Jones, D.P., Merlin, D., and Sitaraman, S.V. (2007a). Prohibitin protects against oxidative stress in intestinal epithelial cells. Faseb J 21, 197-206.

Theiss, A.L., Obertone, T.S., Merlin, D., and Sitaraman, S.V. (2007b). Interleukin-6 transcriptionally regulates prohibitin expression in intestinal epithelial cells. The Journal of biological chemistry 282, 12804-12812.

Thomas, D.D., Espey, M.G., Ridnour, L.A., Hofseth, L.J., Mancardi, D., Harris, C.C., and Wink, D.A. (2004). Hypoxic inducible factor 1alpha, extracellular signal-regulated kinase, and p53 are regulated by distinct threshold concentrations of nitric oxide. Proceedings of the National Academy of Sciences of the United States of America 101, 8894-8899.

Thomas, D.D., Ridnour, L.A., Isenberg, J.S., Flores-Santana, W., Switzer, C.H., Donzelli, S., Hussain, P., Vecoli, C., Paolocci, N., Ambs, S., et al. (2008). The chemical biology of nitric oxide: Implications in cellular signaling. Free Radical Bio Med 45, 18-31. 
van Gestel, R.A., Rijken, P.J., Surinova, S., O'Flaherty, M., Heck, A.J., Killian, J.A., de Kroon, A.I., and Slijper, M. (2010). The influence of the acyl chain composition of cardiolipin on the stability of mitochondrial complexes; an unexpected effect of cardiolipin in alpha-ketoglutarate dehydrogenase and prohibitin complexes. Journal of proteomics $73,806-814$.

Wang, S., Fusaro, G., Padmanabhan, J., and Chellappan, S.P. (2002a). Prohibitin colocalizes with $\mathrm{Rb}$ in the nucleus and recruits $\mathrm{N}-\mathrm{CoR}$ and HDAC1 for transcriptional repression. Oncogene $21,8388-8396$.

Wang, S., Fusaro, G., Padmanabhan, J., and Chellappan, S.P. (2002b). Prohibitin colocalizes with $\mathrm{Rb}$ in the nucleus and recruits $\mathrm{N}-\mathrm{CoR}$ and HDAC1 for transcriptional repression. Oncogene 21, 8388-8396.

Wang, S., Nath, N., Adlam, M., and Chellappan, S. (1999a). Prohibitin, a potential tumor suppressor, interacts with RB and regulates E2F function. Oncogene 18, 3501-3510.

Wang, S., Nath, N., Fusaro, G., and Chellappan, S. (1999b). Rb and prohibitin target distinct regions of E2F1 for repression and respond to different upstream signals. Molecular and cellular biology 19, 7447-7460.

Wu, F., and Wilson, J.X. (2009). Peroxynitrite-dependent activation of protein phosphatase type 2A mediates microvascular endothelial barrier dysfunction. Cardiovascular research 81, 38-45.

Xu, Y.H., Xing, Y.N., Chen, Y., Chao, Y., Lin, Z., Fan, E., Yu, J.W., Strack, S., Jeffrey, P.D., and Shi, Y.G. (2006). Structure of the protein phosphatase 2A holoenzyme. Cell $127,1239-1251$.

Xue, L., Gollapalli, D.R., Maiti, P., Jahng, W.J., and Rando, R.R. (2004). A palmitoylation switch mechanism in the regulation of the visual cycle. Cell 117, 761-771. Yamamoto, R., Bredt, D.S., Snyder, S.H., and Stone, R.A. (1993). The localization of nitric oxide synthase in the rat eye and related cranial ganglia. Neuroscience 54, 189-200. 
Young, R.W. (1988). Solar radiation and age-related macular degeneration. Surv Ophthalmol 32, 252-269.

Zangwill, L.M., Bowd, C., Kraker, J., Sample, P.A., and Weinreb, R.N. (2000). The association between change in optic disc topography and progression of visual field damage. Investigative ophthalmology \& visual science 41, S288-S288.

Zhang, R., Hrushesky, W.J., Wood, P.A., Lee, S.H., Hunt, R.C., and Jahng, W.J. (2010a). Melatonin reprogrammes proteomic profile in light-exposed retina in vivo. Int $\mathrm{J}$ Biol Macromol 47, 255-260.

Zhang, R.N., Hrushesky, W.J.M., Wood, P.A., Lee, S.H., Hunt, R.C., and Jahng, W.J. (2010b). Melatonin reprogrammes proteomic profile in light-exposed retina in vivo. Int J Biol Macromol 47, 255-260.

Zubovych, I., Doundoulakis, T., Harran, P.G., and Roth, M.G. (2006). A missense mutation in Caenorhabditis elegans prohibitin 2 confers an atypical multidrug resistance. Proceedings of the National Academy of Sciences of the United States of America 103, 15523-15528. 


\section{APPENDIX}

Chapter 2 of this dissertation was published in the Journal "Biochemistry" in 2011. Copyright (C) 2011 American Chemical Society. As the first author, I am allowed to "include the article in full or in part in my thesis or dissertation". Below are the excerpts from the American Chemical Society copyright declaration for authors.

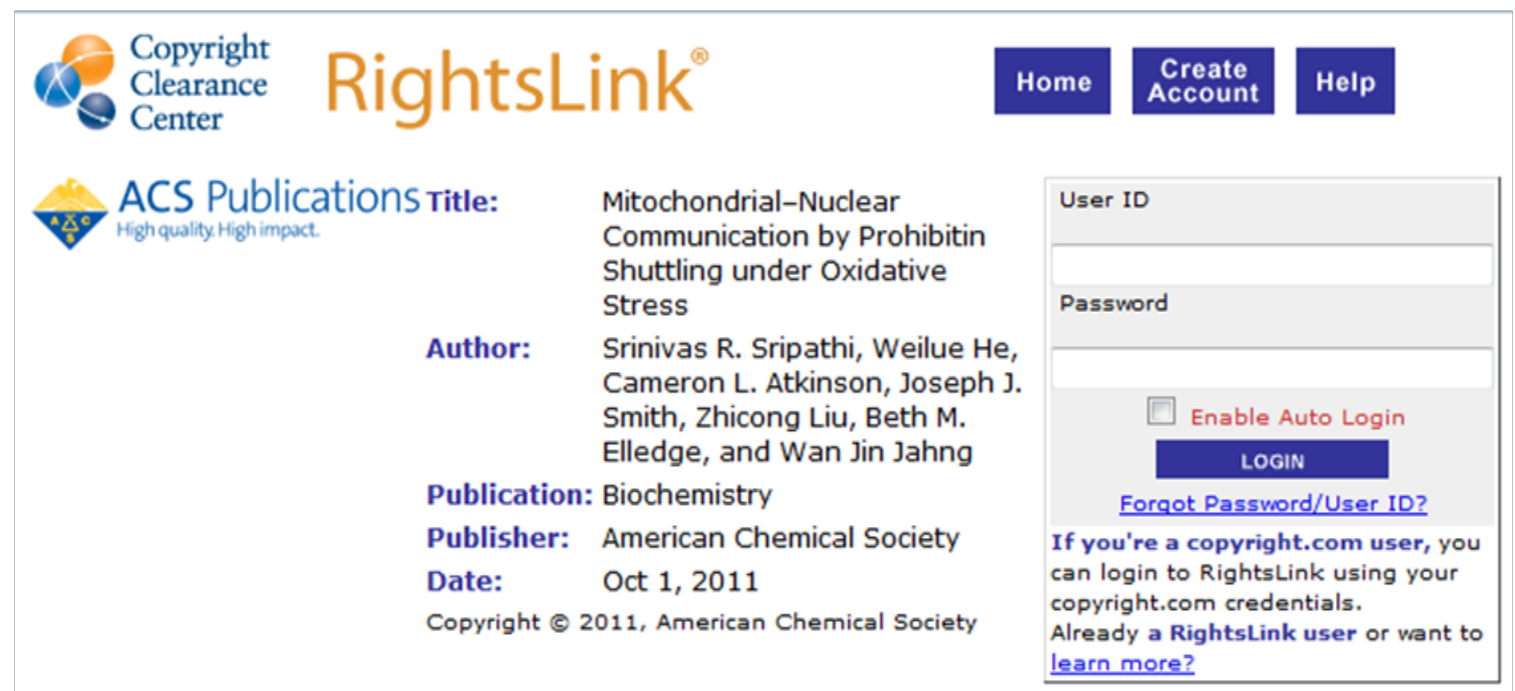

\section{PERMISSION/LICENSE IS GRANTED FOR YOUR ORDER AT NO CHARGE}

This type of permission/license, instead of the standard Terms \& Conditions, is sent to you because no fee is being charged for your order. Please note the following:

- Permission is granted for your request in both print and electronic formats, and translations.

- If figures and/or tables were requested, they may be adapted or used in part.

- Please print this page for your records and send a copy of it to your publisher/graduate school.

- Appropriate credit for the requested material should be given as follows: "Reprinted (adapted) with permission from (COMPLETE REFERENCE CITATION). Copyright (YEAR) American Chemical Society." Insert appropriate information in place of the capitalized words.

- One-time permission is granted only for the use specified in your request. No additional uses are granted (such as derivative works or other editions). For any other uses, please submit a new request.

http://pubs.acs.org/doi/abs/10.1021/bi2008933 


\section{Chapter 3}

Advances in Bioscience and Biotechnology, 2013

\section{Declaration}

Below are the excerpts from the Scientific Research Publishing Inc copyright declaration for authors.

Paper ID: 7300420

Title:

Nitric oxide leads to cytoskeletal reorganization in the retinal pigment epithelium under oxidative stress

Chapter 3 of this dissertation was published in the Journal Advances in Bioscience and Biotechnology. Copyright (C) Scientific Research Publishing Inc., the first author, is allowed to "include the article in full or in part in thesis or dissertation" which is not for commercial use.

Best wishes

Yours Sincerely

Joyce Yin

On behalf of

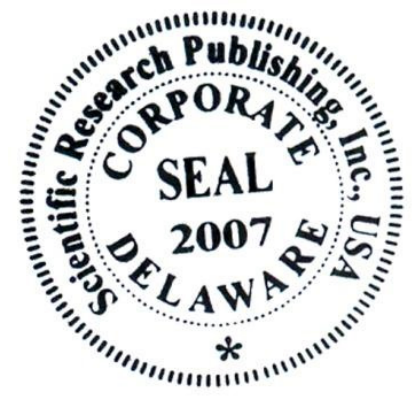

Advances in Bioscience and

Biotechnology

http://www.scirp.org/journal/abb/

http://www.scirp.org/journal/PaperInformation.aspx?paperID=25832 